\title{
Adolescents' Interpretations of Parental Psychological Control: The Role of Beliefs and Disapproval on Problematic Outcomes
}

\author{
Katelyn F. Romm \\ West Virginia University, kfromm@mix.wvu.edu
}

Follow this and additional works at: https://researchrepository.wvu.edu/etd

Part of the Developmental Psychology Commons

\footnotetext{
Recommended Citation

Romm, Katelyn F., "Adolescents' Interpretations of Parental Psychological Control: The Role of Beliefs and Disapproval on Problematic Outcomes" (2020). Graduate Theses, Dissertations, and Problem Reports. 7629.

https://researchrepository.wvu.edu/etd/7629

This Dissertation is protected by copyright and/or related rights. It has been brought to you by the The Research Repository @ WVU with permission from the rights-holder(s). You are free to use this Dissertation in any way that is permitted by the copyright and related rights legislation that applies to your use. For other uses you must obtain permission from the rights-holder(s) directly, unless additional rights are indicated by a Creative Commons license in the record and/ or on the work itself. This Dissertation has been accepted for inclusion in WVU Graduate Theses, Dissertations, and Problem Reports collection by an authorized administrator of The Research Repository @ WVU. For more information, please contact researchrepository@mail.wvu.edu.
} 
Adolescents' Interpretations of Parental Psychological Control: The Role of Beliefs and Disapproval on Problematic Outcomes

\author{
Katelyn F. Romm, M.S. \\ Dissertation submitted to \\ the Eberly College of Arts and Sciences \\ at West Virginia University \\ in partial fulfillment of the requirements \\ for the degree of \\ Doctor of Philosophy \\ in \\ Psychology
}
Aaron Metzger, Ph.D., Chair
Amy Gentzler, Ph.D.
Cheryl McNeil, Ph.D.
Christine Rittenour, Ph.D.
Department of Psychology
Morgantown, West Virginia
2020

Keywords: adolescence, parenting, psychological control, beliefs, disapproval, health-risk behavior

Copyright 2020 Katelyn F. Romm 


\begin{abstract}
Adolescents' Interpretations of Parental Psychological Control: The Role of Beliefs and Disapproval on Problematic Outcomes
\end{abstract}

Katelyn F. Romm

Parental psychological control has consistently been found to be associated with problematic outcomes among adolescents, including substance use (Galambos, Barker, \& Almeida, 2003), risky cyber behaviors (Li, Li, \& Newman, 2013), problematic eating behaviors (Soenens et al., 2008), and depressive symptoms (Romm \& Metzger, 2018). However, few studies have examined how adolescents reason about and react to psychological control. Recent research has suggested that adolescents vary in their beliefs about parental motivations for using psychological control, as well as their level of disapproval of psychological control (Camras et al., 2012; Kakihara \& Tilton-Weaver, 2009). These cognitive factors (i.e., beliefs about parental motivations and disapproval) may influence adolescents' likelihood of experiencing problematic outcomes in response to psychological control. Thus, the current study examined whether adolescents' beliefs about parental motivations for using psychological control, as well as their level of disapproval of psychological control moderate the association between psychological control and problematic outcomes. The current study also examined the three-way interaction between psychological control, adolescents' beliefs about parental motivations for using psychological control, and adolescents' level of disapproval of psychological control on predicting problematic outcomes.

To address these goals, 410 adolescents $\left(M_{\mathrm{age}}=15.00, S D=1.64 ; 57.6 \%\right.$ female $)$ were recruited from two middle schools and two high schools in two mid-Atlantic states. Participants completed self-report questionnaires in their classrooms assessing parental psychological control, adolescents' beliefs about their parents' motivations for using psychological control, adolescents' disapproval of psychological control, as well as adolescents' engagement in substance use, risky cyber behaviors, problematic eating behaviors, and depressive symptoms.

The associations among psychological control and adolescents' problematic outcomes varied by adolescents' beliefs about and disapproval of psychological control. Specifically, maternal psychological control was associated with greater substance use for adolescents with fewer positive beliefs and with greater over-eating behaviors for adolescents with greater negative beliefs about their mothers' use of psychological control. Adolescents with greater disapproval of maternal psychological control were at greater risk for experiencing depressive symptoms in response to maternal psychological control. Paternal psychological control was associated with greater over-eating behaviors and depressive symptoms for adolescents with greater levels of negative beliefs about their fathers' motivations for using psychological control. Three-way interactions between psychological control, adolescents' beliefs, and adolescents' disapproval also emerged. Specifically, maternal psychological control was associated with greater under-eating for adolescents with high levels of negative beliefs and high levels of disapproval only. Additionally, paternal psychological control was associated with greater substance use and under-eating behaviors for adolescents with low levels of positive beliefs and high levels of disapproval only. 
The current study builds on the psychological control literature by examining how adolescents' interpretations and feelings about psychological control influence their likelihood for being negatively influenced by this parenting behavior. Findings suggest that adolescents are differentially impacted by psychological control based on their beliefs about why their parents engage in this parenting behavior, as well as their disapproval of psychological control. This research offers insight into the importance of adolescents' sociocognitive factors in influencing their response to negative parenting. 


\section{ACKNOWLEDGMENTS}

I would like to thank the Eberly College of Arts and Sciences and the Department of Psychology for their financial support for this project. I would like to thank Dr. Aaron Metzger, my dissertation chair and advisor, for his guidance throughout my graduate career. I am also grateful for the support, feedback, and time from my committee members Drs. Amy Gentzler, Cheryl McNeil, and Christine Rittenour. I am also incredibly grateful for the support I have received from my colleagues and friends, Lauren Alvis, Abigail Nehrkorn-Bailey, and Tyia Wilson. I am also appreciative of the assistance received from undergraduate research assistants, including Danielle Kisner, Julie Gilmore, and Hannah Brown. Finally, I would like to thank my family and friends for their continued support. 


\section{TABLE OF CONTENTS}

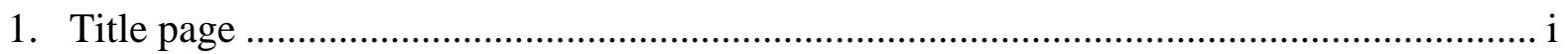

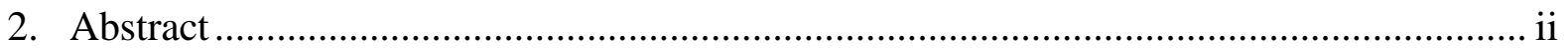

3. Acknowledgements ................................................................................................... iv

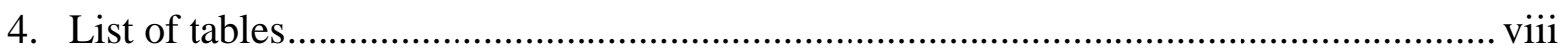

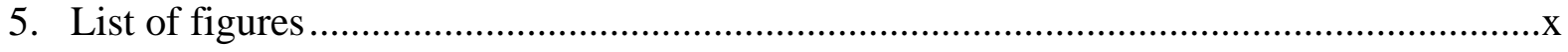

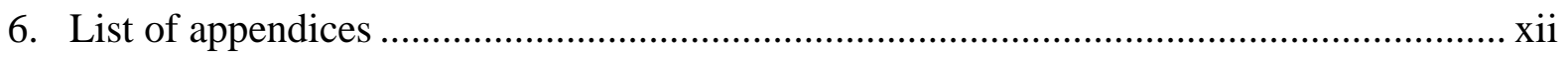

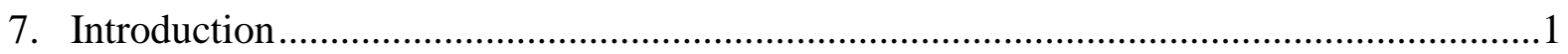

7.1 Parental Psychological Control.....................................................................

7.2 Adolescents' Reasoning about Parental Psychological Control ........................8

7.3 Age and Gender Differences in Adolescents' Beliefs about Psychological

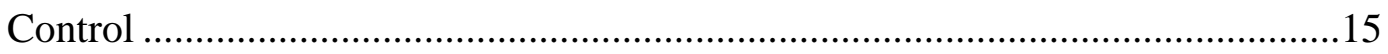

7.4 Links between Adolescent Beliefs about Psychological Control and Problem

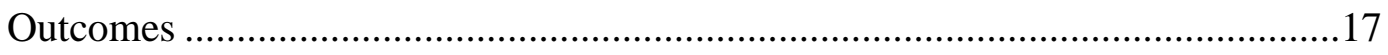

7.5 Adolescents' Approval of Parental Psychological Control ..............................19

7.6 Measurement of Parental Psychological Control.........................................23

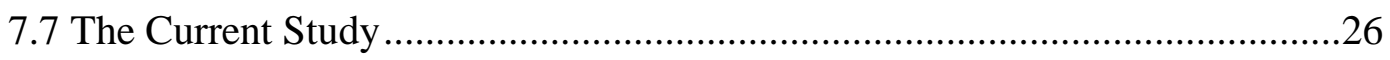

7.7.1 Research Questions and Hypotheses ....................................27

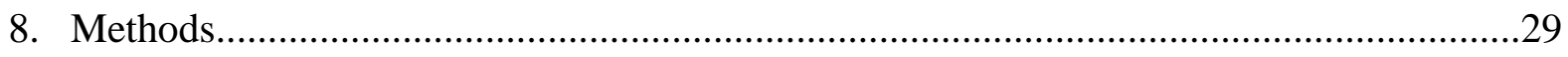

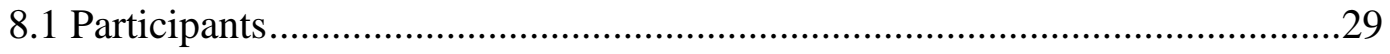

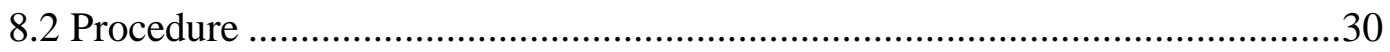

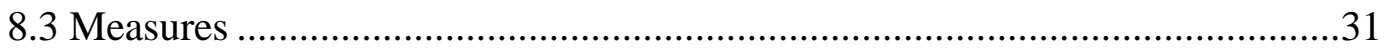

8.3.1 Demographics ……………………......................................... 
8.3.2 Parental Psychological Control.............................................

8.3.3 Beliefs about Parental Motivations .........................................31

8.3.4 Disapproval of Parental Psychological Control ......................32

8.3.5 Parental Behavioral Control.....................................................33

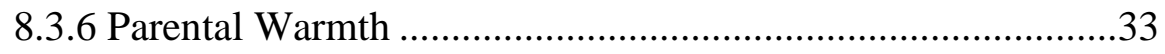

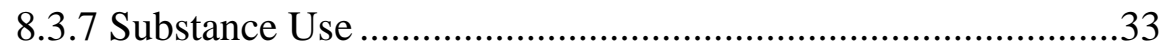

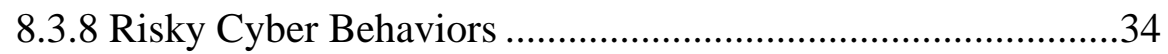

8.3.9 Problematic Eating Behaviors..............................................34

8.3.10 Center for Epidemiological Studies - Depression Inventory

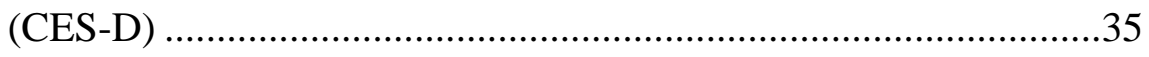

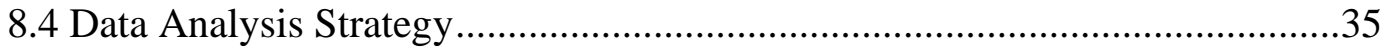

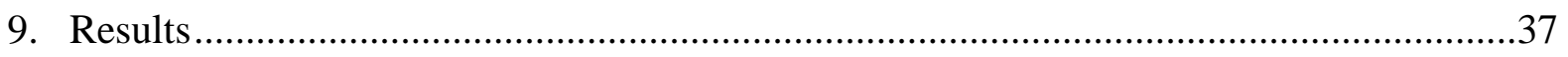

9.1 Data Cleaning and Preliminary Analyses .............................................. 37

9.2 Differences in Adolescents' Beliefs about Parental Motivations for Using

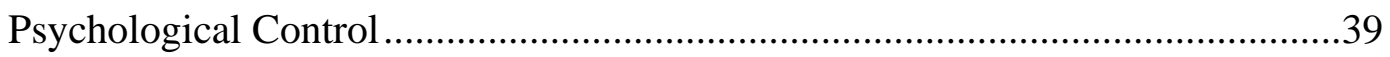

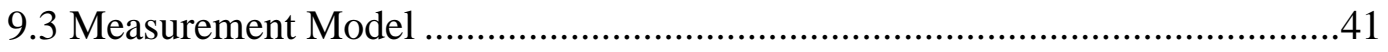

9.4 Measurement Invariance by Adolescent Disapproval of Psychological Control

9.5 Associations between Psychological Control and Problematic Outcomes......42

9.6 Psychological Control X Adolescent Belief Interactions ............................43

9.7 Psychological Control X Adolescent Disapproval Interactions.....................46

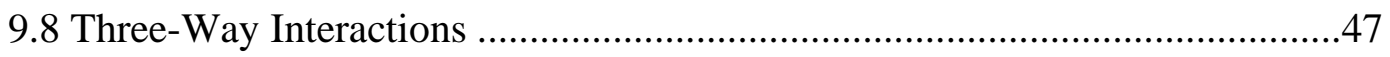

9.9 Summary of Main Findings from Predictive Models .................................49 
10. Discussion

10.1 Differences Among Adolescents' Beliefs about Parental Motivations for Using Psychological Control ...................................................................50

10.2 Implications of Beliefs about Psychological Control ................................54

10.3 Disapproval of Psychological Control as a Moderator ...............................59

10.4 Limitations and Future Directions ..........................................................62

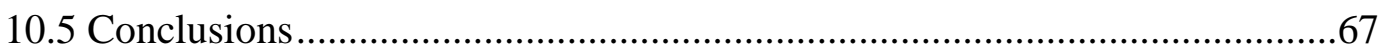

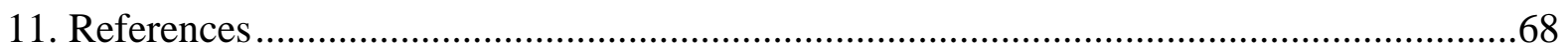

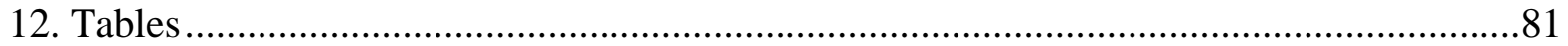

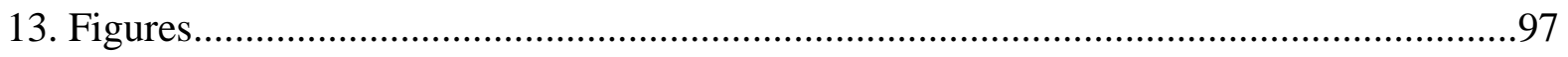

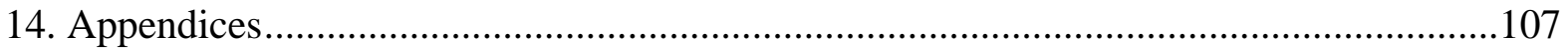




\section{LIST OF TABLES}

1. Table 1: Categories of Adolescents' Beliefs about Parental Motivations for Using

Psychological Control

2. Table 2: Sample Demographics

3. Table 3: Tests of Independence with Survey Version and Demographic Characteristics .84

4. Table 4: Descriptive Statistics for Key Study Variables ...............................................85

5. Table 5: Correlations among Key Study Variables ................................................ 86

6. Table 6: Differences in Key Study Variables by Maternal Education.............................87

7. Table 7: Differences in Key Study Variables by Paternal Education ..............................88

8. Table 8: Differences in Key Study Variables by Parent Relationship Status ..................89

9. Table 9: Differences in Adolescents' Beliefs about Parental Motivations for Using

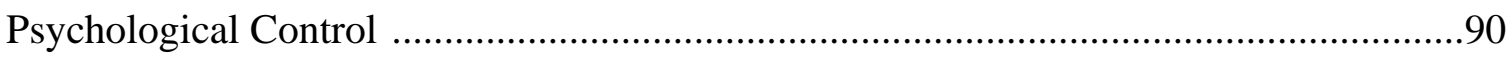

10. Table 10: Latent Means, Standard Deviations, and Standardized Factor Loadings of

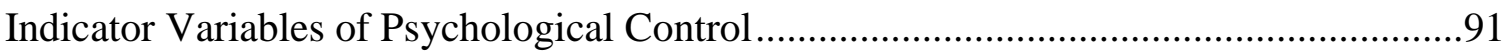

11. Table 11: Measurement Invariance Tests for Maternal and Paternal Psychological Control across Adolescents with Low Versus High Disapproval ............................................92

12. Table 12: Unstandardized Estimates and Standard Errors of Structural Model Testing Associations among Psychological Control and Problematic Outcomes

13. Table 13: Unstandardized Estimates and Standard Errors for Psychological Control (PC) X Negative Beliefs and PC X Positive Beliefs Interactions Predicting Problematic Outcomes

14. Table 14: Unstandardized Estimates and Standard Errors for Psychological Control (PC) X Disapproval Interactions Predicting Problematic Outcomes 
15. Table 15: Model Comparisons Testing Three-Way Interactions: Psychological Control X

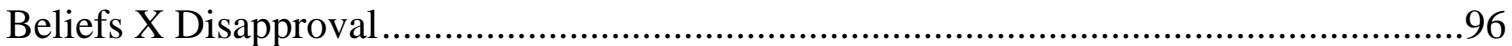




\section{LIST OF FIGURES}

1. Figure 1: Conceptual model examining interactions between maternal/paternal psychological control and positive/negative beliefs about parental motivations for using psychological control as predictors of problematic outcomes ..........................................97

2. Figure 2: Proposed conceptual model for Hypothesis 3 .................................................98

3. Figure 3: Proposed conceptual model for Hypothesis 4 ................................................99

4. Figure 4: Measurement model for psychological control ..............................................100

5. Figure 5: Maternal psychological control by adolescents' positive beliefs about maternal psychological control interaction effects on substance use (left) and over-eating (right)

6. Figure 6: Paternal psychological control by adolescents' positive beliefs about paternal psychological control interaction effects on substance use (left) and under-eating (right)

7. Figure 7: Paternal psychological control by adolescents' negative beliefs about paternal psychological control interaction effects on over-eating (left) and depressive symptoms (right)

8. Figure 8: Maternal psychological control by adolescents' disapproval of maternal psychological control interaction effects on depressive symptoms

9. Figure 9: Maternal psychological control by adolescents' negative beliefs about maternal psychological control interaction effects on under-eating for adolescents with high levels of disapproval. 
10. Figure 10: Paternal psychological control by adolescents' positive beliefs about paternal psychological control interaction effects on substance use (left) and under-eating behaviors (right) for adolescents with high levels of disapproval ....................................106 


\section{LIST OF APPENDICES}

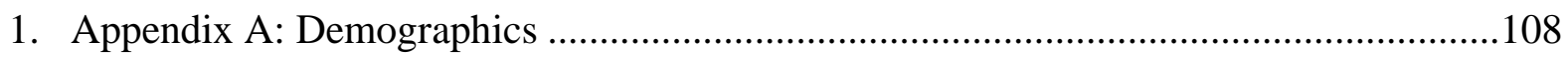

2. Appendix B: Psychological Control Scale - Youth Self-Report (Barber, 1996) ............111

3. Appendix C: Adolescents' Beliefs about Parental Motivations for Using Psychological

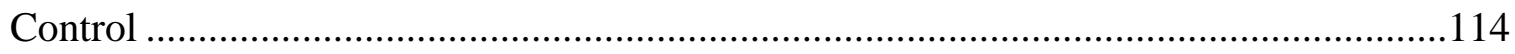

4. Appendix D: Adolescents' Disapproval of Parental Psychological Control ..................116

5. Appendix E: Behavioral Control - Children's Reports of Parental Behavior: An

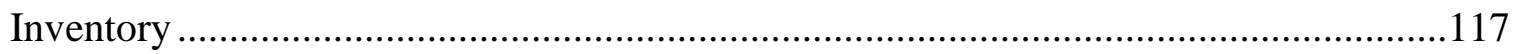

6. Appendix F: Parental Warmth - Child Rearing Practices Questionnaire .....................118

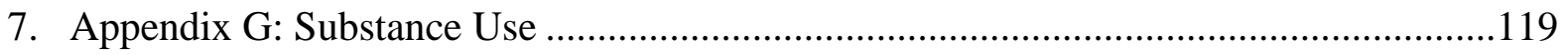

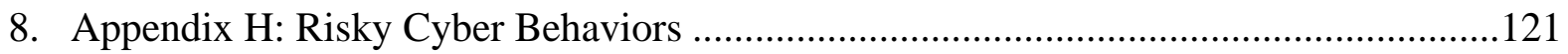

9. Appendix I: Dutch Eating Behavior Questionnaire - Problematic Eating Behaviors .....122

10. Appendix J: Center for Epidemiological Studies - Depression Inventory .....................125

11. Appendix K: State, School Level, and School Differences in Key Study Variables.......127 
Adolescents' Interpretations of Parental Psychological Control: The Role of Beliefs and Disapproval on Problematic Outcomes

Adolescents experience numerous developmental changes, including a push for greater levels of autonomy and independence from parents (Collins \& Steinberg, 2006; Steinberg, 2001). Researchers have consistently examined the various parenting behaviors that either support or impede these developmental tasks (Collins \& Steinberg, 2006; Steinberg, 2001). As adolescents strive for increases in autonomy and independence from parents, adjustments in the parent-child relationship often occur (Collins \& Steinberg, 2006; Koepke \& Denissen, 2012). These adjustments typically include a renegotiation of previous boundaries of the relationship, including a gradual decline in control balanced with parental warmth (Barber \& Xia, 2013; Baumrind, 1971). One aspect of parenting thought to directly hinder such a balance is parental psychological control (Barber, 1996; Finkenauer, Engels, \& Baumeister, 2005). Parental psychological control refers to an emotionally manipulative parenting behavior that involves parental attempts to control adolescents' thoughts, feelings, and behaviors so that they align with parents' own thoughts, feelings, and behaviors (Barber, 1996).

Although psychological control has consistently been examined as a predictor of adolescents' problematic outcomes, including substance use (Galambos, Barker, \& Almeida, 2003), risky cyber behaviors (Li, Li, \& Newman, 2013), over-eating behaviors (Snoek, Engels, Janssens, \& van Strien, 2007), under-eating behaviors (Soenens et al., 2008), and depressive symptoms (Hunter, Barber, \& Stolz, 2015; Romm \& Metzger, 2018; Soenens, Vansteenkiste, \& Luyten, 2010), less emphasis has been placed on how adolescents reason about and react to psychological control. This is somewhat surprising given the theoretical and empirical accounts cautioning against unidirectional, parent-driven models (Bell, 1979; Grusec \& Goodnow, 1994; 
Kuczynski, 2003). It is likely that adolescents may vary in their beliefs about why their parents use psychological control based on certain individual characteristics, such as age (McElhaney, Allen, Stephenson, \& Hare, 2009; Smetana, Campione-Barr, \& Daddis, 2004; Zimmer-Gembeck \& Collins, 2003) or gender (Fuligni, 1998; Ruble \& Martin, 1998). It remains important to examine adolescents' beliefs about parental motivations for using psychological control and level of disapproval of psychological control, as these factors may influence their likelihood of experiencing problematic outcomes as a result of psychologically controlling parenting (Camras, Sun, Li, \& Wright, 2012; Kakihara \& Tilton-Weaver, 2009). For instance, it is possible that adolescents who believe that parents engage in psychological control for negative reasons, such as aiming to control the adolescent, may be at greater risk for experiencing problematic outcomes in response to such control (Barber, Xia, Olsen, McNeely, \& Bose, 2012). In contrast, adolescents who have more positive views of psychological control (e.g., believing that their parent uses psychological control to keep them safe) may be less likely to experience problematic outcomes in response to psychological control. Additionally, adolescents' level of disapproval of psychological control may influence the association between parents' use of such control and adolescents' problematic outcomes. That is, psychological control may be more strongly associated with problematic outcomes for adolescents with greater disapproval of such parenting (Camras et al., 2012).

Researchers have been urged to examine how adolescents perceive and reason about parenting practices, as such research is relatively rare (Bell, 1979; Harris, 1995; Kuczysnki, 2003). It has been suggested that adolescents' perception of parenting behaviors may be a stronger predictor of adolescents' developmental outcomes than the actual parenting behaviors exhibited by parents (Abar, Jackson, Colby, \& Barnett, 2014). One potentially important 
component of adolescents' conceptualization of parenting practices is their beliefs or assumptions about parents' underlying intentions for using specific parenting behaviors (Camras et al., 2012). If adolescents interpret parents' motivations for using psychological control negatively, it may be more harmful than if adolescents interpret parents' use of psychological control more positively (Camras et al., 2012; Chao, 1994). For instance, some adolescents may view their parents' psychological controlling behavior as overly controlling or disrespectful (Barber et al., 2012). When adolescents feel intruded upon or disrespected by parents, they have been found to engage in various problematic outcomes in order to reassert their autonomy (Hawk, Hale, Raaijmakers, \& Meeus, 2012; Kerr, Stattin, Biesecker, \& Ferrer-Wreder, 2003). Thus, adolescents who believe that parents engage in psychologically controlling parenting for negative reasons, such as controlling or disrespecting the adolescent, may be more likely to turn to problem behaviors to cope with their threatened sense of autonomy (Kerr et al., 2003). However, adolescents who believe that parents engage in psychologically controlling parenting for more positive reasons (i.e., keeping the adolescent safe, because parents view it as a normative parenting behavior), may be less likely to experience problematic outcomes. For example, although adolescents may recognize that psychological control is a negative parenting behavior, they may believe that their parents may not have negative intentions, but are misguided in their use of such control (Camras et al., 2012). That is, adolescents may believe that parents are intending to keep adolescents safe because they are concerned for the adolescent, though adolescents also recognize that these parents are unknowingly using parenting behaviors that are not consistent with this goal.

Adolescents likely vary in their views of parental motivations for using psychological control. For instance, due to increases in autonomy with age, older adolescents may be more 
likely to view parents' psychological controlling behaviors more negatively than younger adolescents. In contrast, younger adolescents may be more likely to view parental psychological control more positively than older adolescents (McElhaney et al., 2009; Smetana et al., 2004; Zimmer-Gembeck \& Collins, 2003). Additionally, compared to males, female adolescents may be more likely to believe that parents engage in psychological control for positive reasons, as parents often report greater concerns about the safety of female compared to male adolescents (Fuligni, 1998; Ruble \& Martin, 1998).

In addition to adolescents' beliefs about parental motivations for using psychological control, adolescents' level of disapproval of psychological control may also influence the likelihood of experiencing problematic outcomes when faced with psychologically controlling parenting (Camras et al., 2012). Adolescents are thought to be more likely to experience problematic outcomes if they are more disapproving of parents' use of psychological control (Camras et al., 2012). Some adolescents may be more disapproving and believe that their parents' use of such control is more harmful or negative than others. Other teens may be less disapproving and more accepting of their parents' use of psychological control. Therefore, even though adolescents may perceive a similar level of psychological control, this control may not be harmful for all adolescents to the same degree, as adolescents' level of disapproval of such parenting may vary. Although adolescents with negative beliefs about parental motivations for using psychological control may be more disapproving of such control than adolescents with positive or neutral beliefs, adolescents' level of disapproval may not be entirely redundant with their beliefs about parental motivations. For instance, certain adolescents may believe that parents engage in psychological control for negative reasons (e.g., to control the adolescent's personal world). However, some adolescents may be less disapproving of these parental actions 
than others. That is, adolescents may report negative beliefs about parental motivations for using psychological control, but may be less disapproving of this control.

Adolescents' disapproval of psychological control may also intersect with their beliefs about psychological control in predicting whether they experience problematic outcomes. For instance, if adolescents believe that their parents are using psychological control to manage the adolescent's personal world, they may experience greater problematic outcomes. However, this association may depend on adolescents' level of disapproval of such parenting (Camras et al., 2012; Chao, 1994). That is, psychological control may be especially harmful for adolescents who have negative beliefs about parental motivations for using psychological control, but may be even more harmful if adolescents are also more disapproving of such parenting. Research has suggested that adolescents may be less disapproving of parental psychological control even when they report negative beliefs about parental motivations for using such control (Camras et al., 2012). Similarly, adolescents may be more disapproving of psychological control, but believe that parents are using it to benefit the adolescent, suggesting that these adolescents believe that parents may be well-intentioned, but misguided in their use of this control (Camras et al., 2012). Adolescents who believe that their parents are using psychological control for negative reasons (e.g., controlling the adolescent's personal world) may experience greater problematic outcomes as a result of psychological control than adolescents who believe that parents are using psychological control for positive reasons (e.g., to keep the adolescent safe). However, this association may depend on adolescents' disapproval of such parenting. For instance, although adolescents who believe that parents are using psychological control for positive reasons may be less likely to experience problematic outcomes in response to psychological control, this may only be true for adolescents who are also less disapproving of such control. That is, adolescents' 
beliefs that parents are using psychological control for positive reasons may serve as a buffer of the association between psychological control and problematic outcomes for adolescents with lower levels of disapproval only. Thus, it is likely that adolescents' beliefs about parents' motivations for using psychological control, as well as adolescents' disapproval of parental psychological control may each independently moderate the association between psychological control and adolescents' problematic outcomes. Furthermore, there may be a three-way interaction between parental psychological control, adolescents' beliefs about parental motivations, and adolescents' level of disapproval on adolescents' problematic outcomes.

Taken together, researchers have suggested that adolescents' beliefs about parents' motivations for using psychological control, as well as their own level of disapproval of such control may have important implications for the degree to which adolescents experience problematic outcomes as a result of psychologically controlling parenting (Camras et al., 2012; Chao, 1994; Kuczysnki, 2003). Investigating both adolescents' beliefs about parental motivations and level of disapproval of psychological control may provide insight into the potential cognitive and emotional factors that place certain adolescents at greater risk for experiencing problematic outcomes when faced with psychologically controlling parenting. Therefore, the proposed study will examine whether adolescents' beliefs about parental motivations for using psychological control, as well as their level of disapproval of psychological control moderate the association between parental psychological control and adolescents' problematic outcomes, including substance use, risky cyber behaviors, over-eating behaviors, under-eating behaviors, and depressive symptoms. Additionally, the proposed study will examine the three-way interaction between psychological control, adolescents' beliefs about 
parental motivations for using psychological control, and adolescents' level of disapproval of psychological control on predicting problematic outcomes.

\section{Parental Psychological Control}

Parental psychological control refers to an emotionally manipulative and intrusive parenting behavior that involves the use of various tactics, such as love withdrawal, guilt induction, and conditional approval in order to pressure the adolescent to think, feel, and behave in ways that are consistent with the parent's own thoughts, feelings, and behaviors (Barber, 1996; Schaefer, 1965). The role of parental psychological control on the developmental outcomes of children and adolescents has been consistently examined by researchers over the past two decades (Barber \& Harmon, 2002; Barber et al., 2012). Because psychologically controlling parents lack the empathic capacities necessary to properly respond to the physical, emotional, and psychological needs of youth, this parenting behavior has been found to be associated with a vast array of problematic outcomes. For instance, psychological control is associated with both internalizing and externalizing problems among youth ranging from early childhood through emerging adulthood (Barber, Maughan, \& Olsen, 2005; Luyckx, Soenens, Vansteenkiste, Goossens, \& Berzonsky, 2007; Padilla-Walker \& Nelson, 2012; Stone et al., 2013). However, this intrusive parenting behavior is thought to be especially harmful during adolescence, as it directly interferes with adolescents' autonomy development, contributing to greater dependence on parents, greater social isolation, less emotional control, and greater levels

of stress and negative emotions (Barber \& Xia, 2013; Soenens et al., 2010). In order to cope with these feelings, many adolescents engage in problem behaviors, including substance use, risky cyber behaviors, over-eating behaviors, and under-eating behaviors (Pesola et al., 2015; Skinner, Haines, Austin, \& Field, 2012; Soenens et al., 2008; Tokunage \& Rains, 2010). These 
adolescents have also been found to experience greater internalizing problems, including depressive symptoms as a result of psychologically controlling parenting (Hunter et al., 2015; Soenens et al., 2010).

\section{Adolescents' Reasoning about Parental Psychological Control}

Although researchers have consistently found evidence for the role of psychological control on adolescents' problematic outcomes, more recent research suggests that the association between psychological control and problematic outcomes depends on the individual characteristics of the adolescent. For instance, adolescents' personality has been found to moderate the association between psychological control and externalizing problems, such that adolescents low in agreeableness experienced greater externalizing problems in response to psychologically controlling parenting (Mabbe, Soenens, Vansteenkiste, \& Van Leeuwe, 2016). Similarly, adolescents with poor sadness and anger regulation were more likely to experience internalizing symptoms and externalizing problems, respectively, compared to adolescents with adaptive emotion-regulation strategies (Cui, Morris, Criss, Houltberg, \& Silk, 2014). Finally, adolescents with greater depressive symptoms have also been found to exhibit greater substance use, risky cyber behaviors, and problematic eating behaviors in response to psychologically controlling parenting (Romm \& Metzger, 2018). Together, these findings suggest that individual characteristics may amplify or buffer the effects of parental psychological control on adolescent problem outcomes.

However, researchers have not yet examined the role of cognitive factors on the association between parental psychological control and adolescents' problematic outcomes. Adolescents' beliefs about feeling controlled by parents may be essential to fully understand the influence of psychological control on developmental outcomes among youth (Barber et al., 
2012). This is especially important for adolescents given their unique developmental advancements in cognition and self-other awareness, as well as age-related shifts in perceptions of parental control (Smetana, 2000; Smetana \& Daddis, 2002). The association between parental psychological control and adolescents' problematic outcomes may vary depending upon their beliefs about psychological control (i.e., beliefs about parental motivations or why parents engage in psychologically controlling parenting) and their level of disapproval of psychological control (i.e., the degree to which adolescents accept psychologically controlling parenting; Barber et al., 2012; Camras et al., 2012; Kakihara \& Tilton-Weaver, 2009). Adolescents who believe that parents use psychological control for negative reasons may be at an increased risk for experiencing problematic outcomes compared to adolescents who believe that parents use psychological control for positive or neutral reasons. Additionally, adolescents may be more negatively impacted by psychological control when they have greater disapproval of such parenting compared to adolescents with less disapproval.

Researchers have theorized potential ways that adolescents may view parents as having potentially positive or negative motivations for using psychological control (see Table 1). Barber proposed two negative ways that adolescents may perceive psychological control, including viewing the behavior as intrusion into the personal domain and as disrespect (Barber et al., 2012). Much research attention has been placed on the manipulative aspect of psychological control. This manipulative aspect of psychological control includes coercing the adolescent into feeling pressured to control or change his or her thoughts, feelings, and behaviors to meet parental demands or expectations, as well as making parental affection or regard contingent on specific child behavior (Barber et al., 2012). Parents may engage in this aspect of psychological control in order to make their affection dependent on youth conformity to parental demands 
(Barber et al., 2012). Drawing on social domain theory, research has stressed the importance of a psychological space known as the personal domain, which is outside of parental control or authority (Barber, Olsen, \& Shagle, 1994; Nucci, Hasebe, \& Lins-Dyer, 2005; Smetana, Crean, \& Campione-Barr, 2005). According to social domain theory, the preservation of the adolescent's personal domain is critical to psychological development, especially regarding the boundaries between the self and others that are fundamental to the development of identity (Nucci, 1996; Smetana \& Daddis, 2002). Parents who excessively manage issues or behaviors within the personal domain are viewed as intrusive, resulting in the adolescent resisting or rejecting such regulation (Nucci, 1996). In line with this idea, certain adolescents may believe that parents use psychological controlling behaviors to exert control over adolescents' personal world. Additionally, Barber et al. (2012) argued that adolescents may reason about parents' motivations for using psychological control as being disrespectful. That is, adolescents may perceive parental intrusiveness as disrespecting the integrity and individuality of the adolescent. Barber et al. (2012) define disrespect as interfering with the adolescent's individuality by engaging in behaviors that intrude, exploit, or manipulate this individuality. This belief is thought to be potentially harmful, as experiencing positive emotional connections with parents and significant others is theorized to be essential to healthy development during adolescence (Barber et al., 2012). The researchers arrived at the term of disrespect after interviewing adolescents from five different cultures about their parents' use of psychological control. Because psychological control involves parental manipulation, coercion, and intrusiveness into the psychological development of youth, adolescents may believe that parents use psychological control as a means of disrespecting the adolescent. 
In addition to violations of the personal domain or disrespect, researchers have also argued that adolescents may have negative views of psychological control related to competence, relatedness, and intrusiveness (Kakihara \& Tilton-Weaver, 2009). According to selfdetermination theory, people have three basic, psychological needs that need to be met for optimal functioning: competence, relatedness, and autonomy (Grolnick \& Pomerantz, 2009; Ryan, Deci, Grolnick, \& La Guardia, 2006; Ryan \& Decci, 2000). Parental psychological control may restrict each of these needs and, in turn, undermine adolescents' social and emotional development (Ryan \& Decci, 2000). For instance, adolescents may believe parents use psychological control to make decisions for the adolescent or tell the adolescent how to think to compensate for the adolescent's lack of competence (Kakihara \& Tilton-Weaver, 2009). That is, adolescents may believe their parents do not view the adolescent as having the necessary abilities to make their own decisions about their behaviors or activities and thus, may believe that parents compensate for their lack of ability by making these decisions for adolescents. Additionally, adolescents may believe that parents use psychological control because they do not matter to their parents (i.e., relatedness; Kakihara \& Tilton-Weaver, 2009). These adolescents may feel as though they are not important to their parents or that their parents do not notice their feelings. Adolescents may also view parents' psychological controlling behavior as intrusive and as a means to control the adolescent or invade their privacy (i.e., intrusiveness), which overlaps conceptually with viewing psychological control as an attempt to control their personal world (Barber et al., 2012). Taken together, researchers have identified four distinct negative parental motivations for using psychological control rooted in Social Domain and Self-Determination theories: 1) to control the adolescent's personal world, 2) to disrespect the adolescent, 3) to 
compensate for the adolescent's lack of competence, and 4) because the adolescent does not matter to the parents.

Although the above review anticipates that adolescents may have negative views of their parents' use of psychological control, recent research also suggests that some adolescents may actually view parents as having more positive motivations for engaging in psychological controlling behavior (Camras et al., 2012; Chao, 1994). For instance, some adolescents may believe that parents' use of psychological control is motivated by parental concern for the adolescent and a desire to keep the adolescent safe. It has been suggested that some adolescents believe that parents use psychological control to promote positive behavior and keep the adolescent out of trouble (Camras et al., 2012; Kakihara \& Tilton-Weaver, 2009). Additionally, adolescents may view such parenting as normative, believing parents engagement in psychological control represents typical or common behavior that is experienced by most youth. Previous researchers have found that adolescents perceive other types of negative parenting behaviors, such as physical discipline as normative (Lansford et al., 2005). Youth who believe that their parents engage in parenting behaviors that are similar to those in which other parents engage are more likely to perceive such behaviors as positive and caring (Lansford et al., 2005). Thus, adolescents may have more positive beliefs because they 1) believe parents use psychological control to keep the adolescent safe and 2) view psychological control as a normative parenting behavior (see Table 1).

Together, previous research on adolescents' beliefs about parental motivations for using psychological control suggests that adolescents may have heterogenous views about why their parents engage in psychologically controlling behaviors. Some adolescents may believe that parents are using psychological control for negative reasons, whereas other adolescents may 
believe that parents are using psychological control for positive reasons (Barber et al., 2012;

Camras et al., 2012; Chao, 1994; Kakihara \& Tilton-Weaver, 2009). Although adolescents may have a variety of beliefs about parental motivations for using psychological control, including both positive and negative beliefs, it is important to note that these beliefs are not necessarily mutually exclusive. That is, adolescents may have both negative and positive beliefs about why their parents engage in psychological control. For instance, an adolescent may believe that their parents use psychological control to try to intrude into their personal world and to keep them safe and out of trouble.

Although previous researchers have examined how adolescents reason about their parents' motivations for using parental psychological control, this research has only examined whether adolescents believe that parents use psychological control as a reaction to youth competence, lack of relatedness, and attempts at intrusiveness (Kakihara \& Tilton-Weaver, 2009). However, more recent research suggests that adolescents may also view parents' use of psychological control as a form of disrespect and that some adolescents may also have more positive views of parents' use of psychological control (Barber et al., 2012; Camras et al., 2012). Thus, it remains important to explore a wider range of ways that adolescents may reason about parental psychological control to understand whether certain types of reasoning place adolescents at a greater risk for experiencing problematic outcomes in response to psychological control. Additionally, previous research examining adolescents' beliefs about psychological control utilized hypothetical vignettes. Kakihara and Tilton-Weaver (2009) presented adolescents with a scenario asking them to imagine telling their parents that they want to go somewhere with friends, but their parents suspect that there might be alcohol around. Participants were divided into two groups and read vignettes in which the protagonist adolescent was exposed to either 
moderate or high levels of psychological control. Adolescents were then asked a series of followup questions that assessed adolescents' interpretation or explanation for the parents' psychological control in the vignettes. Specifically, adolescents rated how much they viewed psychological control as a reaction to youth competence (i.e., parents use of psychological control to compensate for the adolescent's lack of competence), lack of relatedness (i.e., parents use of psychological control because the youth does not matter to parents), and attempts at intrusiveness (i.e., parents use of psychological control to control adolescents' behaviors or invade their privacy). However, this study did not examine whether adolescents varied in their prioritization of these motivations. Moreover, the researchers acknowledge that assessing the motives of parents in vignettes does not guarantee that adolescents would similarly interpret their own parents' use of psychological control (Kakihara \& Tilton-Weaver, 2009).

Other research has examined adolescents' beliefs about their own parents' motivations for using other types of parental control, such as authoritarian parenting that focuses on demands for obedience (Camras et al., 2012). A sample of early adolescents reported on ten items assessing their own parents' engagement in authoritarian parenting practices. Statements were adapted from Buri’s (1991) parental authority questionnaire and described parents' high expectations for obedience without explanation, as well as the use of physical force. Sample items included "My parents do not allow me to question any decision that they make" and "My parents let me know what behavior they expect of me, and if I do not meet those expectations, they punish me." For each authoritarian parenting practice, youth responded to nine statements on which they rated possible reasons for parents' use of this behavior. The nine statements were broken down into three categories: for the child's benefit (e.g., for the child's own good), for parents' own benefit (e.g., to make things easier for the parents), and for conventional reasons 
(e.g., because most parents do this). Interestingly, adolescents tended to judge coercive authority assertion to be practiced for the benefit of the child more than the benefit of the parents, suggesting that many adolescents believe that their parents are well-meaning but misguided. Taken together, previous research suggests that adolescents may have several different views about why parents engage in psychological control, but adolescents appear to be placing greater emphasis on certain parental motivations. A methodology, which requires participants to rank parents' motivations would provide a better understanding as to whether participants are more or less likely to experience problematic outcomes as a result of psychological control depending on which beliefs about parental motivations they prioritize.

\section{Age and Gender Differences in Adolescents' Beliefs about Psychological Control}

Although adolescents may reason about parental motivations for using psychological control in several different ways, it remains unknown whether there are individual differences in adolescents' prioritization of parental motivations for using psychological control. For instance, it is likely that demographic characteristics, such as adolescent age and gender may explain differences in adolescents' beliefs about parental motivations for using psychological control. With age, adolescents begin to claim more autonomy over their behaviors, as the parent-child relationship transforms from a hierarchical to an egalitarian structure (McElhaney et al., 2009; Smetana et al., 2004; Zimmer-Gembeck \& Collins, 2003). Thus, older adolescents may be more likely to view psychological control as negative and an attempt by parents to control the adolescent's personal world. Older adolescents may also be more likely to believe that parents use psychological control because the adolescent is less competent (Pomerantz \& Eaton, 2000). Older adolescents may desire lower levels of parental control, as they may want to make decisions for themselves due to their increased desire for autonomy. However, parents who 
interfere with this autonomous decision making through the use of psychological control may send messages to older adolescents that the adolescent is not competent enough to make decisions for him or herself (Pomerantz \& Eaton, 2000). Younger adolescents, however, may be more likely to view parents' use of psychological control more positively or neutrally, such as believing parents are motivated by a desire to keep the adolescent safe since parents typically exhibit greater rules over younger adolescents as a means of ensuring safety and structure (Keijsers \& Poulin, 2013; Koepke \& Denissen, 2012). Younger adolescents may also be more likely to indicate that their parents engage in psychological control because they believe that it is a normative parenting behavior, as younger adolescents view controlling parenting as a more typical parenting behavior (Keijsers \& Poulin, 2013; Koepke \& Denissen, 2012). Because younger adolescents spend less time with peers away from the home, they may have less exposure to more positive parenting practices exhibited by the parents of their peers (Rubin, Bukowski, \& Parker, 2006). Thus, they may have fewer points of comparison when judging the behaviors exhibited by their own parents. Older adolescents, however, may spend greater time with their peers away from their parents and potentially with the parents of their peers.

There may also be gender differences in adolescents' beliefs about psychological control. Adolescent boys are given and expect more autonomy than girls (Fuligni, 1998; Ruble \& Martin, 1998). Thus, boys may be more likely to reason negatively about parents' motivations for using psychological control and believe that parents are using psychological control for negative reasons such as to control their personal world or to make up for their lack of competence. In contrast, adolescent girls may view parents' use of psychological control as being motivated by concerns for safety, as parents often express greater concerns and worry about physical harm over adolescent daughters compared to adolescent sons (Fuligni, 1998; Ruble \& Martin, 1998). 
Parents' report engaging in greater controlling behaviors over their daughters compared to sons to protect them from physical harm (Jaccard, Dodge, \& Dittus, 2002). Therefore, adolescent girls may be more likely to believe that their parents need to exhibit controlling parenting practices in order to protect them from harm and to keep them safe. Girls may adopt similar beliefs as their parents (i.e., believing that they are at a greater risk for harm than adolescent boys) and believe that parents are exhibiting psychological control for positive or neutral reasons (i.e., to keep the adolescent safe).

\section{Links between Adolescent Beliefs about Psychological Control and Problem Outcomes}

Adolescents' potential heterogeneous beliefs about parents' motivations for using psychological control may influence whether psychological control leads to problematic outcomes. Although psychological control is consistently problematic among adolescents, the associations between psychological control and specific problematic outcomes have been inconsistent across studies. For instance, parental psychological control has been found to be predictive of substance use (Galambos et al., 2003; Soenens, Vansteenkiste, Duriez, \& Goossens, 2006), risky cyber behaviors (Li et al., 2013), over-eating behaviors (Rodenburg, Kremers, Oenema \& van de Mheen, 2014; Topham et al., 2011), and under-eating behaviors (McEwen \& Flouri, 2009) in some studies. However, associations between psychological control and these specific problematic outcomes have not been found in other studies (Giles \& Price, 2008; Silk, Morris, Kanaya, \& Steinberg, 2003; Soenens et al., 2008; Van der Vorst, Engels, Meeus, \& Dekovic, 2006). One reason for this inconsistency may be individual differences that place certain adolescents at risk for experiencing greater problematic outcomes in the face of parental psychological control. Adolescents' beliefs about parental motivations for using psychological control may be an important individual difference that could amplify the risk of experiencing 
problematic outcomes in response to psychological control. A better understanding of the ways in which cognitive mechanisms affect the association between psychological control and adolescents' problematic outcomes may provide insight into the particular risk factors that make psychological control especially harmful for certain adolescents. It has been theorized that adolescents who believe that their parents use psychological control for negative reasons may be more likely to experience problematic outcomes in response to psychologically controlling parenting. Adolescents are thought to be more likely to act out and engage in problem behaviors when they believe that their parents are engaging in controlling behaviors for negative reasons (Camras et al., 2012; Kakihara \& Tilton-Weaver, 2009). Previous research indicates that adolescents' beliefs about other types of parental control, such as coercive authority assertion, moderate the association between parenting and problematic outcomes during adolescence (Camras et al., 2012). Positive associations between coercive authority assertion and adolescents' depression were stronger when adolescents believed parents' use of coercion was not intended to benefit the adolescent. Additionally, the negative association between coercive authority assertion and adolescents' school effort was weaker when adolescents perceived the parental behavior as positive or normative (Camras et al., 2012). Together, this research suggests that adolescents who believe that parents use coercive authority assertion for negative reasons are more likely to experience problematic outcomes in response to this negative parenting compared to adolescents who believe that parents are using this type of parenting for positive or neutral reasons.

Alternatively, adolescents who have positive or neutral beliefs about their parents' motivations for using psychological control may experience fewer problematic outcomes than adolescents who have negative beliefs about parental motivations for using psychological 
control. These youth may believe that their parents' use of psychological control is motivated by a desire to promote positive behavior and keep the adolescent out of trouble (Camras et al., 2012; Kakihara \& Tilton-Weaver, 2009; Walton \& Flouri, 2010). Positive perceptions of parenting have also been found to buffer against the development of problematic outcomes among adolescents experiencing high levels of family conflict (Etkin, Koss, Cummings, \& Davies, 2014). Thus, it is likely that adolescents who perceive their parents as exhibiting psychological control out of concern for the adolescent's safety may experience fewer problematic outcomes when faced with psychological control. Similarly, adolescents who perceive their parents' use of psychological control as normative may also experience fewer problematic outcomes as a result of psychological control. Previous researchers have found that adolescents who perceive negative parenting behaviors, such as physical discipline, as normative were less likely to experience problematic outcomes (i.e., aggression and anxiety) in response to negative parenting compared to adolescents who did not view such parenting as normative (Lansford et al., 2005). Youth who believe that their parents are engaging in parenting behaviors that are similar to those in which other parents engage are often more likely to perceive such behaviors as positive and caring (Lansford et al., 2005). Thus, it is likely that the association between psychological control and problematic outcomes may be weaker for adolescents who believe that parents use psychological control because they perceive it as normative.

\section{Adolescents' Approval of Parental Psychological Control}

In addition to adolescents' beliefs about parents' motivations, adolescents' level of disapproval of psychological control may also play an important role on either buffering or amplifying the problematic effects of parental psychological control. It is also important to note that adolescents' approval or disapproval of parental psychological control may not be redundant 
with their reasoning about parental motivations for using psychological control. That is, adolescents who believe that parents use psychological control for negative reasons may vary on their level of disapproval of psychological control. Specifically, certain adolescents may believe that parents use psychological control for negative reasons (e.g., to control the adolescent's personal world or because the adolescent does not matter to the parent), and may be disapproving of their parent's engagement in psychological control. However, other adolescents may believe that their parents engage in psychologically controlling parenting for negative reasons, but may be less disapproving of parental psychological control. Thus, adolescents may have similar beliefs about their parent's motivations for using psychological control, but may vary in their level of disapproval of such parenting. Alternatively, adolescents may believe that parents are using psychological control for the adolescent's own benefit or because they believe that it is a normative parenting behavior, but may still disapprove of such parenting. Adolescents may believe that their parents have positive intentions, but are misguided in their parenting strategies (Camras et al., 2012), and thus may still disapprove of psychological control. For instance, an adolescent may believe that their parents are worried about the adolescent and concerned for their safety. However, these adolescents may not believe that parents' use of psychological control is the appropriate way to express their concern or to keep the adolescent safe. Adolescents' level of disapproval of psychological control may moderate the association between parental psychological control and adolescents' engagement in problematic outcomes, such that adolescents with lower levels of disapproval of such parenting may be less likely to experience problematic outcomes as a result of psychologically controlling parenting. This hypothesis is consistent with previous research, which has found that adolescents with greater disapproval of other types of parental control, including coercive authority assertion, were more 
likely to experience depressive symptoms than adolescents with lower levels of disapproval of such parenting (Camras et al., 2012).

One example illustrating why adolescents may be less likely to disapprove of psychologically controlling parenting even when they believe that their parents are using it for negative reasons, is their level of desired autonomy. Adolescents vary in how much autonomy they desire with some adolescents desiring more autonomy than others (Smetana, 2002). Although adolescents who desire lower levels of autonomy may interpret psychological control as an intrusion into their personal domain, these adolescents may be less likely to disapprove of such control because it is not interfering with their desired autonomy (Smetana, 2002). Thus, adolescents may be less likely to disapprove of psychological control even when they believe that parents are using it to control their personal world, when they have lower levels of desired autonomy. An additional example highlighting why certain adolescents may be less likely to disapprove of psychological control is adolescents' level of self-esteem. Specifically, adolescents with lower self-esteem may be less likely to disapprove of psychological control when they believe that parents engage in such control to compensate for the adolescent's lack of competence compared to adolescents with higher self-esteem. Research suggests that adolescents prefer feedback from others (e.g., parents) that is consistent with their own self view, rather than self-enhancing feedback (Rosen, Principe, \& Langlois, 2013). Thus, adolescents with lower selfesteem or a more negative self-view may be motivated to perceive parents' motivations for using psychological control in a negative light (e.g., to compensate for the adolescent's lack of competence) in order to maintain their own self-view (Swann, 1983; 1987). However, it is likely that these adolescents may be less disapproving of psychological control, even when interpreted 
in a negative light, as individuals have been found to prefer self-verification, even when this verification is negative (Rosen et al., 2013).

Adolescents' level of disapproval of psychologically controlling parenting may also influence the association between adolescents' beliefs about parental motivations for using psychological control and problematic outcomes. Although it has been suggested that adolescents may experience fewer problematic outcomes if they believe that their parents are using psychological control for positive or neutral reasons, that moderated effect may, itself, be moderated by adolescents' level of disapproval of psychological control (Camras et al., 2012; Chao, 1994). Adolescents were assumed to have lower levels of disapproval of psychological control if they believe their parents are using it to keep them safe or because they view it as normal (Chao, 1994). However, even when adolescents view psychological control as normal or motivated by a desire to keep them safe, adolescents may still have high levels of disapproval of parental psychological control. That is, adolescents may believe that their parents are wellmeaning but misguided in their use of psychological control (Camras et al., 2012). Similarly, adolescents were assumed to have high levels of disapproval of parental psychological control if they believe that parents use it for negative reasons (Barber et al., 2012; Camras et al., 2012; Kakihara \& Tilton-Weaver, 2009). However, certain adolescents may have low levels of disapproval of psychological control even if the adolescent believes it is being used for these potentially negative reasons. Taken together, level of disapproval may moderate the association between adolescents' reasoning about parents' motivations for using psychological control and the problematic outcomes experienced by the adolescent. For instance, adolescents who believe that their parents use parental psychological control for negative reasons may be more likely to experience problematic outcomes than adolescents who believe their parents use psychological 
control for positive or neutral reasons. However, this moderated association may be true only for adolescents with high levels of disapproval of psychologically controlling parenting. Similarly, adolescents who believe that their parents use psychological control for positive or neutral reasons may be less likely to experience problematic outcomes when they have lower levels of disapproval of psychological control. Therefore, the proposed study will examine whether adolescents' beliefs about parental motivations for using psychological control moderate the association between psychological control and adolescents' problematic outcomes. The proposed study will also examine whether adolescents' level of disapproval of psychological control moderates the association between psychological control and problematic outcomes. Finally, the proposed study will examine the three-way interaction between psychological control, adolescents' beliefs about parental motivations for using psychological control, and adolescents' level of disapproval of psychological control.

\section{Measurement of Parental Psychological Control}

Parental psychological control was initially measured using Schaefer's (1965) ten items from the Children's Report of Parental Behavior Inventory (CRPBI). This measure assessed Psychological Autonomy versus Psychological Control and contained items capturing love withdrawal, guilt induction, and excessive pressure for change. Building upon this work, Barber (1996) developed a 16-item scale (Parental Psychological Control Scale - Youth Self-Report (PCS-YSR)) assessing children's and adolescents' perceived psychological control. Although Barber (1996) also began preliminary work on creating an observational measure of psychological control, researchers have not yet utilized an observational measure of psychological control when assessing the association between psychological control and youth outcomes. Researchers have relied solely on survey measures of psychological control in which 
adolescents are asked to rate the extent to which parents exhibit various aspects of psychological control or parents are asked to rate the extent of their own engagement in psychological control (Barber et al., 2012). More recently, Barber developed a new eight item psychological control scale to assess psychological control as disrespect of individuality (Barber et al., 2012). This new scale consisted of eight additional items asking adolescents to report on whether their parent(s) engage(s) in behaviors that involve disrespecting the integrity and individuality of the adolescent. However, factor analyses indicated that the model fit was better when the eight items assessing psychological control as disrespect were kept separately from the PCS-YSR. Findings suggested that the new scale assessing psychological control as disrespect, labeled the Psychological Control - Disrespect Scale (PCDS), accounted for more of the variance in youth depression and antisocial behaviors than the PCS-YSR. Barber noted that it is necessary for future researchers to replicate the findings on additional samples, as the sample used in this initial study was not representative of all youth (Barber et al., 2012). However, to date, researchers have not yet replicated these findings and thus, conclusions cannot be made about the advantages of the PCDS over the PCS-YSR in its prediction of problematic outcomes among youth.

Although the PCS-YSR has been subject to the most measurement work among various samples of youth, more recent research suggests that psychological control may consist of distinct components that are differentially associated with problematic outcomes among preadolescent-aged children (Cheah, Yu, Hart, Sun, \& Olsen, 2015; Nelson, Yang, Coyne, Olsen, \& Hart, 2013; Romm, Metzger, \& Alvis, under review). For instance, Cheah et al. (2015) examined the factor structure of an 18-item psychological control measure developed for their particular study and found evidence for three components, including personal attack (i.e., parent 
attacking the worth of the child), love withdrawal (i.e., parent threatening to withdraw love from the child), and guilt induction (i.e., parent pointing out that the child's behavior had a negative impact on a family member) among a sample of Chinese youth. Similarly, Nelson et al. (2013) examined the factor structure of the 37-item Parental Psychological Control measure created by Hart and Robinson (1995), and found evidence for six distinct components, including personal attack, invalidating feelings (i.e., parent telling the child how to feel or think), love withdrawal, guilt induction, constraining verbal expressions (i.e., parent speaking for the child), and erratic emotional behavior (i.e., parents switching rapidly between displays of caring behavior and attacking expressions) among a sample of Russian youth. More recent research has built upon these findings by examining the factor structure of the 16 items that make up the commonly used PCS-YSR among a sample of adolescents (Romm, Metzger, \& Alvis, 2019). Analyses yielded three distinct components of psychological control, including love withdrawal, invalidating feelings, and personal attack. Furthermore, these three components of psychological control were differentially predictive of adolescents' problematic outcomes. Specifically, love withdrawal was associated with greater substance use and risky cyber behaviors, invalidating feelings was associated with greater under-eating behaviors and depressive symptoms, and personal attack was associated with greater over-eating behaviors. In order to build on the recent work suggesting that psychological control consists of distinct components that may be uniquely predictive of problematic outcomes, the current study used a measurement strategy that robustly measures psychological control by incorporating previous measurement work that has assessed various components of psychological control among youth from various cultures and age groups. The current study assessed parental psychological control using the full 16-item PCS-YSR in order to assess distinct components of psychological control consistent with previous research 
(Romm et al., 2019). Additionally, the current study incorporated additional items consistent with the components found in the PCS-YSR, including love withdrawal, invalidating feelings, and personal attack, from additional measures that assess distinct components of psychological control in order to robustly and completely assess all of the constructs that comprise parental psychological control (Cheah et al., 2015; Nelson et al., 2013).

\section{The Current Study}

Investigating adolescents' beliefs about parents' motivations for using psychological control, as well as adolescents' level of disapproval of psychological control can provide insight into the sociocognitive factors that place certain adolescents who experience parental psychological control at greater risk for problematic outcomes. Understanding how adolescents reason about psychological control may aid practitioners in identifying which specific cognitions to target when working with adolescents experiencing problematic outcomes as a result of psychologically controlling parenting. Greater insight into adolescents' reasoning about psychological control may also allow practitioners to identify adolescents who are at greater risk for experiencing problem behaviors as a result of parental psychological control. The first aim of the current study was to examine whether adolescents' beliefs about parental motivations for using psychological control vary as a function of individual characteristics including youth age and gender. The second aim of the current study was to examine whether adolescents' beliefs about parental motivations for using psychological control moderate the associations between psychological control and adolescents' problematic outcomes.

Additionally, researchers have suggested that adolescents' level of disapproval of psychological control may have important implications for the association between parental psychological control and adolescents' problematic outcomes (Camras et al., 2012). Thus, the 
third aim of the current study was to examine whether adolescents' level of disapproval of parental psychological control moderates the association between psychological control and adolescents' problematic outcomes. Although previous research suggests that the way in which adolescents reason about psychological control may moderate the association between parental psychological control and adolescents' problematic outcomes, this moderated association may also be affected by adolescents' level of disapproval of psychologically controlling parenting. Thus, the fourth aim of the current study was to examine the three-way interaction between psychological control, adolescents' beliefs about parental motivations for using psychological control, and adolescents' level of disapproval of such control on adolescents' problematic outcomes. Because adolescents' perception of psychological control, internalizing symptoms, and engagement in problem behaviors has been found to vary based upon demographic factors (Pettit, Laird, Dodge, Bates, \& Criss, 2001; van der Ende \& Verhulst, 2005), as well as parenting behaviors (Steinberg, 2001), all models controlled for adolescent age and gender, as well as parental behavioral control and warmth.

\section{Research Questions and Hypotheses}

\section{Research Question 1}

Are differences in adolescents' beliefs about parental motivations for using psychological control associated with adolescent age and gender?

Hypothesis 1a. It was hypothesized that the beliefs about parental psychological control prioritized by adolescents would vary by adolescent age. Older adolescents were expected to prioritize the following negative beliefs: 1) to control the adolescent's personal world, and 2) to compensate for the adolescent's lack of competence. Younger adolescents, however, were 
expected to prioritize the following positive beliefs: 1) to keep the adolescent safe and 2) because parents view psychological control as a normative parenting behavior.

Hypothesis 1b. Adolescents' beliefs about parental motivations for using psychological control were also thought to vary by adolescent gender. Adolescent boys were expected to prioritize the following negative beliefs: 1) to control the adolescent's thoughts, feelings, or behaviors, 2) to control the adolescent's personal world, and 3) to make up for the adolescent's lack of competence, whereas adolescent girls were expected to prioritize the following positive beliefs: 1) to keep the adolescent safe.

\section{Research Question 2}

Do adolescents' beliefs about parental motivations for using psychological control moderate the association between parents' use of psychological control and adolescents' problematic outcomes?

Hypothesis 2. The positive association between parental psychological control and adolescents' problematic outcomes was expected to be stronger for adolescents who believe that their parents use psychological control for negative reasons (i.e., to control their personal world, as a form of disrespect, to compensate for the adolescent's lack of competence, or because they do not matter to the parent) compared to adolescents who believe that parents use psychological control for positive reasons (i.e., to keep the adolescent safe or because the parent views psychological control as a normative parenting behavior).

\section{Research Question 3}

Does adolescents' level of disapproval of parental psychological control moderate the association between psychological control and adolescents' problematic outcomes? 
Hypothesis 3. It was hypothesized that parental psychological control would be associated positively with adolescents' problematic outcomes for adolescents with greater disapproval of psychological control, but not for adolescents with less disapproval of psychological control.

\section{Research Question 4}

Do parental psychological control, adolescents' beliefs about parental motivations for using psychological control, and adolescents' level of disapproval interact to predict adolescents' problematic outcomes?

Hypothesis 4. It was hypothesized that the positive association between psychological control and adolescents' problematic outcomes would be stronger for adolescents with negative beliefs about parental motivations for using psychological control when they also have greater disapproval of psychological control. However, the association between psychological control and adolescents' problematic outcomes was not expected to be stronger for adolescents with negative beliefs when they have less disapproval of psychological control. Similarly, the positive association between psychological control and adolescents' problematic outcomes was expected to be weaker for adolescents with positive or neutral beliefs about parental motivations for using psychological control for adolescents who are less disapproving of psychological control only (see Figure 3).

\section{Method}

\section{Participants}

The sample for the current study consisted of 406 adolescents (ages 11-19 years, $M=$ $15.00, S D=1.64)$ recruited from two middle schools and two high schools in two mid-Atlantic states. Adolescents who were enrolled in Social Studies and English courses at their respective 
schools were eligible to participate. A total of 67 participants were recruited from middle schools (ages $11-15$ years, $M=12.73, S D=1.43$ ) and 339 participants were recruited from high schools (ages $13-19$ years, $M=15.45, S D=1.26)$. Over half of participants identified as female $(57.6 \%)$ and one participant reported identifying as neither male nor female. The majority of participants identified as White or Caucasian (85.7\%), 5.2\% identified as African American or Black, 2\% identified as Asian American or Pacific Islander, 1.5\% identified as Hispanic or Latino, 1.5\% identified as Native American, and $4.2 \%$ of participants reported identifying as a race/ethnicity that was not listed. See Table 2 for complete sample demographic information. The majority of adolescents indicated that they completed surveys with their biological mother $(95.3 \%)$ and biological father $(86.5 \%)$ in mind. Additionally, $62 \%$ of adolescents reported that their mother had at least a four-year college degree, whereas $43 \%$ of adolescents reported that their father had at least a four-year college degree. Over half of participants indicated that their family had no trouble paying bills (56.2\%) and that their parents were currently married (65\%). Additionally, the majority of participants reported receiving either mostly As or some As and some Bs in $\operatorname{school}(84.2 \%)$

\section{Procedure}

Participant recruitment and data collection were completed in several phases at each school. During the first school visit, adolescents were provided with parental permission forms, which were completed by their primary caregivers. The second school visit occurred approximately two weeks after adolescents were provided with parent permission forms. All adolescents who obtained parent permission were recruited to participate in the study at the second school visit. Adolescents then provided informed assent followed by the survey on a laptop computer or an electronic tablet during class time at their respective school. Upon 
completion of the survey, adolescents were asked to provide their contact information so that they could be entered into a drawing to win one of ten $\$ 100$ Amazon gift cards.

\section{Measures}

Demographics. Participants reported their age, grade, gender, ethnicity/race, financial strain, parents' education level, parents' relationship status, relation to their mother figure and father figure, and grades in school (Appendix A).

Parental psychological control. Parental psychological control was assessed using the 16-item Parental Psychological Control Scale - Youth Self-Report (PCS-YSR; Barber 1996), as well as an additional five items created by Olsen et al. (2002) and five items from the Psychological Control Measure created by Hart and Robinson (1995) that assess specific components of psychological control, including love withdrawal, invalidating feelings, and personal attack. To reduce participant burden, a planned missing design was used for parental psychological control items (Graham, 2012). Each participant completed either 17 or 18 of the 26 psychological control items for their mother and their father separately. Planned missing data are controlled by the researcher and thus missing completely at random (MCAR). Survey versions were equally distributed across demographics characteristics (all chi-square tests were not significant; Table 3). Sample items included "My parent will avoid looking at me when I have disappointed him/her" and "My parent tells me that I should be ashamed when I misbehave.” Mean scores were computed for each measure of maternal and paternal psychological control (i.e., Barber, 1996; Hart \& Robinson, 1995; Olsen et al., 2002) and used as indicators for maternal psychological control and paternal psychological control latent variables. For Barber's (1996) PCS-YSR, mean scores for the eleven items retained in previous measurement work (Romm et al., 2019) were computed. 
Beliefs about parental motivations. Following each of the parental psychological control items that participants endorsed, they were asked to rank their beliefs about their parents' motivations for engaging in the psychologically controlling behavior. Specifically, participants were asked to rank their beliefs about their parents' motivations for using psychological control from 1 (the belief with which the adolescent believes most strongly drives their parent's use of psychological control) to 6 (the belief with which the adolescent believes least strongly drives their parent's use of psychological control) for mothers and fathers separately. For each of the psychological control items endorsed, participants received a list of six options to rank why their parent engages in the specific psychologically controlling behavior (i.e., my parent wants to control my thoughts feelings, and behaviors, because my parent does not respect me, because I do not matter to my parent, because my parent does not view me as competent, to keep me safe or out of concern for me, and because my parent believes that most parents do this). Ranked responses were reverse coded and summed to create motivation scores that could range from 0 to 108, whereby higher scores indicated that a belief about parental motivation was chosen more frequently across psychological control items. Directions provided to participants and an example item can be found in Appendix C.

Disapproval of parental psychological control. In addition to ranking their beliefs about parental motivations for using psychological control, participants were asked to rate their level of disapproval of each psychologically controlling behavior. Each psychological control item that participants indicated that their parent engages in was followed by the statement, "Please rate whether you approve or disapprove of this behavior." Response options ranged from 1 (Strongly disapprove) to 5 (Strongly approve). Items were reverse coded so that higher scores 
indicated greater disapproval of psychological control. An example item can be found in Appendix D.

Parental behavioral control. Parental behavioral control was measured with ten items from the Children's Reports of Parental Behavior: An Inventory (CRPBI) assessing the extent to which each parent engages in firm control. Sample items included "My mother/father is a person who believes in having a lot of rules and sticking with them" and "My mother/father insists that I must do exactly as I'm told.” Response options ranged from 1 (Not like my parent) to 3 (A lot like my parent). Mean scores were computed by averaging responses to each of the ten items for adolescents' report of mothers $(\alpha=.81)$ and fathers $(\alpha=.81)$, separately (Appendix E).

Parental warmth. To assess parental warmth, participants rated the extent to which each of the seven items was descriptive of their mother and father, separately (Brody et al., 2004). Sample items included "How often does your mom/dad understand the way you feel about things?" Participants rated each item on a 4-point Likert-type scale from 1 (Never) to 4 (Always). Mean scores were computed by averaging responses to each of the seven items for mothers $(\alpha=$ $.93)$ and fathers $(\alpha=.94)$, separately (Appendix F).

Substance use. Adolescents' substance use was measured using a 17-item self-report scale. Participants were asked to rate how often in the last three months they have engaged in alcohol behaviors (8 items) on a Likert-type scale from 1 (Never) to 4 (Often). Sample items included "In the last three months, how often have you drank alcohol?" and "In the last three months, how often have you drank so much you got sick?" Additionally, participants were asked to report the number of occasions in the last three months they have used the following ten substances: cigarettes, smokeless tobacco, electronic cigarettes, marijuana, hallucinogens, cocaine, sedatives, stimulants, prescription pain killers, and inhalants $(0=$ never used, $1=$ one 
time, 2 = 2-3 times, $3=4-9$ times, $4=10-19$ times, $5=20-39$ times, $6=40$ or more times $)$. Mean scores for adolescents' substance use were computed by averaging responses to each of the 18 items $(\alpha=.89$; Appendix G).

Risky cyber behaviors. In order to assess risky Internet and cell-phone behaviors, adolescents responded to 11 items asking how often in the last 30 days participants engaged in risky Internet and cell-phone behaviors, as well as cyber-bullying offending behaviors from 1 (Never) to 7 (Very Often; Hinduja \& Patchin, 2009). Sample items include "How often in the last 30 days have you added friends on Facebook whom you have never met offline?" and "In the last 30 days, I have posted something online about another person to make others laugh." Mean scores were calculated for each adolescent with higher scores indicating greater engagement in risky cyber behaviors $(\alpha=.91 ;$ Appendix $H)$.

Problematic eating behaviors. The Dutch Eating Behavior Scale was used to measure restrained, external, and emotional eating behaviors (van Strien, Fritjers, Bergers, \& Defares, 1986). Participant responses were measured on a 5-point Likert-type scale from 1 (Never) to 5 (Very Often). Higher scores on each subscale (restrained, external, and emotional eating) were associated with higher levels of problematic eating behaviors. Participants' scores on the external and emotional eating subscales were combined in an over-eating behavior scale. Participants' scores on the restrained eating scale were used to measure under-eating behavior. Sample items included "When you have put on weight, do you eat less than you usually do?" (i.e., under-eating behavior) and "Do you have a desire to eat when you have nothing to do?" (i.e., over-eating behavior). Mean scores were calculated for the over-eating behavior scale $(\alpha=.95)$ and the under-eating behavior scale $(\alpha=.93)$ with higher scores indicating higher levels of problematic eating behaviors (Appendix I). 


\section{Center for Epidemiological Studies - Depression Inventory (CES-D). Depressive} symptoms were assessed using the 20-item CES-D (Radloff, 1977). Participants were asked to rate the frequency of depressive symptoms experienced within the past week on a Likert-type scale from 0 (Rarely or none of the time) to 3 (Most or all of the time). Sample items included "During the past week, I was bothered by things that usually don't bother me" and "During the past week, I thought my life had been a failure." Sum scores were calculated for each adolescent by adding responses to each of the 20 items $(\alpha=.93$; Appendix $\mathrm{J})$.

\section{Data Analysis Strategy}

All analyses were performed using SPSS version 25 and Mplus version 8. Models were estimated utilizing full-information maximum likelihood (FIML). First, bivariate correlations among demographic characteristics and variables of interest were examined. Demographic characteristics that were significantly associated with key study variables were included as controls in subsequent analyses. For all analyses using structural equation modeling (SEM), significant parameters were only examined upon achieving adequate model fit. Standard model fit criteria were used, including chi-square tests, root mean square error of approximation (RMSEA), and the Comparative Fit Index (CFI). Model fit was considered good if the $\chi^{2} / d f$ was less than 3.0, CFI > .95, and RMSEA <.05 and model fit was deemed adequate the chi-square ratio was less than 5.0, CFI > .90, and RMSEA <.08 (Kline, 2015; Little, 2013).

Hypotheses regarding variability in adolescents' beliefs about parental motivations for using psychological control based on age and gender were investigated using mixed-model ANOVAs with adolescent age and gender added as covariates. A measurement model for maternal and paternal psychological control was then assessed within a confirmatory factor analysis (CFA) framework. Next, measurement invariance was tested using multiple group 
analysis. First, for each construct, an unconstrained multi-group model was fit across adolescents with low versus high levels of disapproval of psychological control to serve as a baseline model against which successively more restrictive models (i.e., configural model) were compared. Second, to test for metric invariance, the factor loadings were constrained to be equal across groups. If constraining the factor loadings to be equal across groups did not lead to a significantly worse model fit, the factor loadings were considered invariant across groups. Third, in addition to the constraints imposed on the factor loadings, the intercepts of the observed variables were constrained to be equal across groups. Scalar (intercept) invariance across groups was established if these additional constraints did not yield a significantly worse model fit. Change in CFI was used to evaluate invariance, as chi-square difference tests have been found to be too sensitive to large sample sizes in invariance testing (Cheung \& Rensvold, 2002; Little, Bovaird, \& Card, 2012). Consistent with current recommendations, a change in CFI less than .01 was used as the criteria for establishing measurement invariance (Little, 2013).

Next, a structural equation model tested maternal and paternal psychological control as predictors of adolescents' problematic outcomes (substance use, risky cyber behaviors, overeating behaviors, under-eating behaviors, depressive symptoms). Next, latent variable interactions were tested in order to determine whether adolescents' positive beliefs and negative beliefs about psychological control interacted with parents' use of psychological control to predict adolescents' problematic outcomes. Significant interaction effects were further probed and simple slopes were graphed and examined for significance. Latent variable interactions were also tested to determine whether adolescents' disapproval of psychological control interacted with parental psychological control to predict problematic outcomes. Finally, multi-group analyses were performed to test whether the interactions between psychological control and 
adolescents' beliefs about parental motivations for using psychological control varied by adolescents' disapproval of psychological control. To test these three-way interactions, the fit of an unconstrained model that freely estimated structural paths between groups was compared to the fit of a model that constrained the paths to be equal. When the unconstrained model provided a significantly better fit than the constrained model, a series of likelihood ratio tests were used to determine which model parameters should be constrained across groups and which should be left to freely vary.

\section{Results}

\section{Data Cleaning and Preliminary Analyses}

Analyses were performed to assess missing data, outliers, and normality. Of the original 410 participants, four participants completed $25 \%$ or less of the survey and were removed from all analyses due to extreme amounts of missing data on the majority of key study variables. For the remaining 406 participants, mahalanobis distance scores obtained from the psychological control, substance use, risky cyber behaviors, over-eating behaviors, under-eating behaviors, and depressive symptoms scales were used to test for multivariate outliers. Nine percent of participants $(\mathrm{n}=36)$ violated mahalanobis distance. Two validity questions were built into the survey to also help identify potentially problematic cases. Thirteen participants failed both validity questions. Upon examination of both multivariate outliers and failed validity checks, only four participants showed inattentive reporting throughout the entire survey. To ensure findings were not due to the inclusion of these potentially problematic cases, all analyses were conducted with and without these cases and the pattern of findings did not change. Although SEM is robust against assumptions of normality (Kline, 2015), for variables that were not normally distributed, analyses were conducted with and without properly transformed variables. 
The patterns of significant findings did not vary when using transformed variables, and thus, only results for the models using the untransformed variables are reported.

Descriptive statistics for key study variables are reported in table 4. Additional analyses were performed to examine differences in variability based on participants' state and school. Results are described in Appendix K. Generally, participants residing in Maryland had lower levels of positive beliefs about maternal and paternal psychological control, as well as higher levels of substance use and risky cyber behaviors compared to participants residing in West Virginia. Furthermore, students in high school reported greater substance use, over-eating, and under-eating behaviors compared to students in middle school.

Tables 5-8 display correlations and mean differences among demographic variables and key study variables. Adolescent age was associated positively with substance use with females reporting greater levels of over-eating behavior, under-eating behavior, and depressive symptoms. Adolescents who identified as white reported higher levels of negative beliefs about their mothers' use of psychological control than adolescents who identified as another race. Higher SES based on lower levels of financial strain was associated with lower levels of perceived maternal and paternal psychological control, as well as fewer negative beliefs about their mothers' and fathers' use of psychological control. Adolescents from higher SES families also reported less disapproval of their mothers' and fathers' use of psychological control, as well as lower levels of over-eating behaviors, under-eating behaviors, and depressive symptoms. Adolescents' GPA was associated negatively with perceived maternal and paternal psychological control, as well as adolescents' negative beliefs about parents' use of psychological control. GPA was also associated negatively with disapproval of their mothers' and fathers' use of psychological control, as well as adolescents' substance use, risky cyber behaviors, and 
depressive symptoms. Paternal education and parent relationship status were associated with substance use, such that adolescents with fathers who completed graduate school reported less substance use than adolescents with fathers who had a high school education. Adolescents with parents who were married reported less substance use than adolescents with parents who were together, but not married. Additionally, there were significant differences in adolescents' depressive symptoms by parent education and relationship status, such that adolescents with parents with a graduate education reported fewer depressive symptoms than adolescents with parents who completed high school. Adolescents with parents who were married also reported fewer depressive symptoms than those with parents who were either together and not married or divorced. Parent relationship status was also associated with adolescents' report of maternal psychological control and risky cyber behaviors. Specifically, adolescents with parents who were married reported less maternal psychological control than adolescents with parents who were not together. These adolescents also reported lower levels of risky cyber behaviors than adolescents with parents who were together but not married. Finally, adolescents in middle school reported lower levels of engagement in substance use, over-eating, and under-eating behaviors compared to adolescents in high school.

\section{Research Question 1}

(1) Are differences in adolescents' beliefs about parental motivations for using psychological control associated with adolescent age and gender?

\section{Differences in Adolescents' Beliefs about Parental Motivations for Using Psychological}

\section{Control}

Repeated measures ANOVAs examined differences in adolescents' report of their beliefs about their mother and fathers' motivations for using psychological control. Participants' ranked 
responses were summed separately for mothers and fathers and for each of the six beliefs with higher scores indicating greater endorsement of the belief about the parental motivation for using psychological control. Analyses indicated significant differences in beliefs about parents' motivations for using psychological control for both mothers and fathers. Main effects, means, and standard deviations are presented in Table 9. Pairwise comparisons using Bonferroni corrections indicated adolescents reported that their mothers most often used psychological control to keep the adolescent safe, followed by controlling the adolescent's personal world or because adolescents view psychological control as a normative parenting behavior, followed by compensating for the adolescent's lack of competence, disrespecting the adolescent, and because the adolescent does not matter to the parent. All means for adolescents' beliefs about their mothers' use of psychological control were significantly different from one another. With regards to fathers, pairwise comparisons indicated that adolescents reported that their fathers most often used psychological control to keep the adolescent safe, followed by controlling the adolescent's personal world, because they view it as a normative parenting behavior, compensating for the adolescent's lack of competence, disrespecting the adolescent, and because the adolescent does not matter to the parent. All differences were statistically significant with the exception of beliefs about using psychological control to control the adolescent's personal world and beliefs about using psychological control because it is a normative parenting behavior.

Next, separate mixed-model ANOVAs including adolescent age and gender as betweensubjects factors and adolescents' beliefs about parental motivations for using psychological control as the within-subjects factor were performed for adolescents' report of their mothers' and fathers' motivations for using psychological control. Results indicated that there were no age $(F(5,389)=1.62, n s)$ or gender differences $(F(5,389)=.95, n s)$ in adolescents' beliefs about 
their mothers' motivations for using psychological control. Similarly, there were no age $(F(5$, $347)=1.12, n s)$ or gender differences $(F(5,347)=1.67, n s)$ in adolescents' beliefs about their fathers' motivations for using psychological control. Additionally, adolescent age and gender did not interact to predict adolescents' beliefs about maternal $(F(5,389)=.99, n s)$ or paternal psychological control $(F(5,347)=.85, n s)$.

\section{Research Question 2}

(2) Do adolescents' beliefs about parental motivations for using psychological control moderate the association between parents' use of psychological control and adolescents' problematic outcomes?

Measurement Model. Prior to examining the role of adolescents' beliefs about parental motivations for using psychological control on the association between psychological control and problematic outcomes, a measurement model assessing the structure of maternal and paternal psychological control assessed as latent variables was examined. Means were created for each separate measure of maternal and paternal psychological control (i.e., Barber, 1996; Hart \& Robinson, 1995; Olsen et al., 2002) and used as indicators of psychological control latent variables. The measurement model included two separate but correlated first-order latent variables representing maternal and paternal psychological control, with three indicators each (Figure 4). Significant correlations were observed among indicators of the same psychological control measure $(r=.26-.43)$. Additionally, maternal psychological control was significantly associated with paternal psychological control $(\mathrm{r}=.59)$. Therefore, measurement error terms for indicators for the same measure (e.g., maternal psychological control measured by Barber with paternal psychological control measured by Barber) were allowed to covary across the mother and father latent variables to improve model fit. Prior to covarying error terms, the measurement 
model provided a poor fit to the data $\left(\chi^{2} / d f=14.51, \mathrm{CFI}=.91, \mathrm{RMSEA}=.18[.154, .213]\right)$. After covarying error terms, fit indices indicated that the measurement model provided a good fit to the data $\left(\chi^{2} / d f=2.71, \mathrm{CFI}=.99, \mathrm{RMSEA}=.07[.024, .108]\right)$. Standardized factor loadings ranged from .72 to .88 and were all statistically significant at the .001 level (Table 10).

Measurement Invariance by Adolescent Disapproval of Psychological Control. The factor structures of maternal and paternal psychological control were tested for invariance across adolescents with low versus high levels of disapproval of maternal and paternal psychological control. A median split was used to create a group of adolescents with low $(M=24.44, \mathrm{SD}=$ 9.85) versus high $(M=59.83, \mathrm{SD}=13.76)$ levels of disapproval of maternal psychological control and low $(M=14.32, \mathrm{SD}=6.98)$ versus high $(M=50.30, \mathrm{SD}=17.17)$ levels of disapproval of paternal psychological control. A series of multi-group analyses tested for metric (factor loadings) and scalar (intercepts) invariance across groups. Results from all measurement invariance tests are described in Table 11. The factor loadings and intercepts for maternal psychological control were invariant for adolescents with lower compared to higher levels of disapproval of maternal psychological control. Similarly, the factor loadings and intercepts for paternal psychological control were invariant for adolescents with lower compared to higher levels of disapproval of paternal psychological control. Therefore, the psychological control latent variables were invariant across low and high levels of disapproval.

Associations between Psychological Control and Problematic Outcomes. To test associations between maternal psychological control, paternal psychological control, and adolescent problematic outcomes, a structural equation model was performed. Five observed problem behavior variables (i.e., substance use, risky cyber behaviors, over-eating behaviors, under-eating behaviors, depressive symptoms) were included as endogenous outcomes. The 
residual error terms for the five problematic outcome variables were allowed to covary. Maternal psychological control and paternal psychological control were measured as latent variables and were specified as exogenous predictors of problematic outcomes. Adolescent age, gender, and financial strain, as well as maternal and paternal warmth and behavioral control were included as covariates. Predictor variables with significant bivariate correlations were allowed to covary resulting in covariances among all dependent variables. Additionally, maternal and paternal warmth were allowed to covary, as well as maternal and paternal behavioral control. The model provided a good fit to the data $\left(\chi^{2} / d f=2.02, \mathrm{CFI}=.97, \mathrm{RMSEA}=.05[.038, .062]\right)$. Table 12 displays the unstandardized estimates and standard errors of the structural parameters. With regards to the covariates, adolescent age was associated positively with substance use, whereas gender was associated positively with over-eating behaviors, under-eating behaviors, and depressive symptoms with female adolescents reporting greater levels of each problematic outcome. Financial strain was associated with both substance use and depressive symptoms, such that adolescents with greater financial strain (i.e., lower SES) reported lower levels of substance use, but greater levels of depressive symptoms. Maternal behavioral control was associated with greater under-eating behaviors among adolescents, whereas greater paternal warmth was associated with lower levels of both substance use and depressive symptoms. Over and above demographic characteristics and positive forms of parenting, maternal psychological control was associated positively with over-eating behaviors, under-eating behaviors, and depressive symptoms, whereas paternal psychological control was not associated significantly with any of the five problematic outcomes.

Psychological Control X Adolescent Belief Interactions. To test whether the associations between parental psychological control and adolescent problematic outcomes varied 
as a function of adolescents' beliefs about their parents' motivations for using psychological control, a series of models tested the effects of latent variable interactions. Building on the full model which included covariates, maternal psychological control, and paternal psychological control, adolescents' positive beliefs about mothers'/fathers' use of psychological control and adolescents' negative beliefs about mothers'/fathers' use of psychological control were included as predictors of adolescent problematic outcomes. Additionally, four latent variable interaction terms representing psychological control X beliefs about parental motivations (e.g., maternal psychological control X negative beliefs) were included as predictors (Figure 1). Follow-up analyses were conducted to probe significant interactions to aid in interpretation including the examination of simple slopes.

Main effects for adolescents' beliefs about parents' motivations for using psychological control, as well as interactions between psychological control and adolescents' beliefs are reported in Table 13. Both adolescents' positive and negative beliefs about mothers' motivations for using psychological control were directly associated with adolescents' depressive symptoms, such that adolescents with lower levels of positive beliefs and higher levels of negative beliefs about their mothers' motivations for using psychological control reported higher levels of depressive symptoms. Additionally, the interaction between maternal psychological control and positive beliefs was significantly associated with adolescents' substance use, such that psychological control was associated with greater substance use for adolescents with fewer positive beliefs about their mothers' use of psychological control $(B=.15, S E=.08, p<.05)$, but not for those with higher levels of positive beliefs $(B=.03, S E=.08, n s)$. In contrast, the interaction between maternal psychological control and negative beliefs was significantly associated with adolescents' over-eating behaviors. Specifically, only adolescents with greater 
negative beliefs were at risk for engaging in over-eating behaviors in response to maternal psychological control $(B=.78, S E=.14, p<.001)$. The association between maternal psychological control and over-eating behaviors was not significant for adolescents with fewer negative beliefs $(B=.14, S E=.07, n s)$. Simple slopes for both interactions are graphed in figure 5.

With regards to paternal psychological control, the interaction between paternal psychological control and positive beliefs was significantly associated with both substance use $(B=.18, S E=.11, p<.05)$ and under-eating behaviors $(B=.30, S E=.15, p<.05)$, such that these associations were significant only for adolescents with low levels of positive beliefs about their fathers' use of psychological control. The associations between paternal psychological control and substance use $(B=-.03, S E=.09, n s)$ and under-eating behaviors $(B=.23, S E=.14$, $n s$ ) were not significant for adolescents with higher levels of positive beliefs. The interaction between paternal psychological control and negative beliefs was significantly associated with both over-eating behaviors and depressive symptoms. Specifically, paternal psychological control was associated with greater over-eating behaviors $(B=.49, S E=.13, p<.001)$ and depressive symptoms $(B=.58, S E=.20, p<.05)$ for adolescents with higher negative beliefs. However, paternal psychological control was not associated with either over-eating behaviors $(B$ $=.22, S E=.13, n s)$ or depressive symptoms $(B=.04, S E=.11, n s)$ for adolescents with low levels of negative beliefs about their fathers' use of psychological control. Simple slopes for paternal interactions are graphed in figures 6 and 7.

\section{Research Question 3}

(3) Does adolescents' level of disapproval of parental psychological control moderate the association between psychological control and adolescents' problematic outcomes? 
Psychological Control X Adolescent Disapproval Interactions. To test whether the associations between parental psychological control and adolescent problematic outcomes varied as a function of adolescents' disapproval of their parents' use of psychological control, a series of models included latent variable interactions. Similar to the previous model, adolescents' disapproval of maternal and paternal psychological control were included as predictors. Additionally, two latent variable interaction terms representing psychological control X disapproval (e.g., maternal psychological control X disapproval) were included as predictors of problematic outcomes (Figure 2). Follow-up analyses were conducted to probe significant interactions to aid in interpretation and simple slopes were examined.

Main effects for adolescents' disapproval of parents' use of psychological control, as well as interactions between psychological control and adolescents' disapproval are reported in Table 14. The interaction between maternal psychological control and youth disapproval was significantly associated with adolescents' depressive symptoms, such that psychological control was associated with greater depressive symptoms for adolescents with greater levels of disapproval about their mothers' use of psychological control $(B=.76, S E=.06, p<.05)$, but not for those with lower levels of disapproval $(B=.07, S E=.05, n s)$. Simple slopes are graphed in figure 8. Additionally, adolescents' disapproval about their fathers' use of psychological control was directly associated with greater over-eating behaviors, under-eating behaviors, and depressive symptoms.

\section{Research Question 4}

(3) Do parental psychological control, adolescents' beliefs about parental motivations for using psychological control, and adolescents' level of disapproval interact to predict adolescents' problematic outcomes? 
Three-way Interactions. Finally, three-way interactions were examined to investigate whether the influence of adolescents' beliefs about psychological control on the associations between psychological control and problematic outcomes varied by adolescents' disapproval of psychological control. A series of multigroup analyses with the sample divided into youth who reported either high or low levels disapproval for psychological control based on a median split were conducted. Models were run separately for adolescents' disapproval of maternal and paternal psychological control. Models contained latent variable interactions between both parental psychological control and youths' positive and negative beliefs about psychological control. Latent variable interaction models were estimated in Mplus using an MLR estimator. The MLR estimator requires that chi-square difference testing to determine fit of constrained and freed models need to be based on loglikelihood values and scaling correction (Satorra, 2000). Model comparison tests are reported in Table 15.

Constraining all structural paths to be equal across adolescents with low and high levels of disapproval of maternal psychological control yielded a significantly worse model fit ( $\Delta \chi^{2}$ $(45)=126.98, \mathrm{p}<.001)$, indicating that the structural paths significantly varied for adolescents with lower versus higher levels of disapproval. Examination of the modification indices indicated that the structural path between the interaction between maternal psychological control and negative beliefs on adolescents' under-eating behaviors should be freed in order to improve model fit. Freeing this path led to a significant improvement in model fit. The interaction between maternal psychological control and adolescents' negative beliefs about mothers' use of psychological control was statistically significant for adolescents with high levels of disapproval about maternal psychological control $(B=.15, S E=.01, p<.05)$. An examination of the unconstrained path indicated that for adolescents with high levels of disapproval of maternal 
psychological control, higher maternal psychological control was associated with greater undereating behaviors at high $(B=.23, S E=.14, p<.001)$, but not low levels of negative beliefs about maternal psychological control $(B=.14, S E=.14, n s$; Figure 9). Among youth with low levels of disapproval, maternal psychological control did not significantly interact with adolescents' negative beliefs about their mother's use of psychological control $(B=.01, S E=.04, n s)$. Thus, results indicate that a combination of high negative beliefs about mothers' motivations for using psychological control and high levels of disapproval of such control are especially problematic for adolescents' under-eating behaviors.

With regards to adolescents' disapproval of their fathers' use of psychological control, constraining all paths to be equal across adolescents with low and high levels of disapproval also yielded a significantly worse model fit, $\Delta \chi^{2}(45)=117.89, p<.05$. An examination of the modification indices indicated that two parameters should be freed. Specifically, there were differences between adolescents with low and high levels disapproval with regards to the interaction between paternal psychological control and positive beliefs on two different outcomes: adolescents' engagement in substance use (low disapproval: $B=-.01, S E=.02, n s$; high disapproval: $B=.25, S E=.01, p<.05$ ) and under-eating behaviors (low disapproval: $B=$ $.11, S E=.03, n s ;$ high disapproval: $B=.25, S E=.07, p<.05)$. Freeing these two paths led to a significant improvement in model fit. Among adolescents with high levels of disapproval, higher paternal psychological control was associated with greater substance use $(B=.89, S E=.10, p<$ $.05)$ and under-eating behaviors $(B=.79, S E=.16, p<.05)$ for adolescents with lower levels of positive beliefs about fathers' motivations for using psychological control. However, among adolescents with high levels of disapproval, psychological control was not associated with substance use $(B=.12, S E=.10, n s)$ or under-eating behaviors $(B=.07, S E=.16, n s$; Figure 10) 
for adolescents with greater positive beliefs. In contrast, among adolescents with low levels of disapproval, paternal psychological control did not interact with adolescents' positive beliefs about their father's use of psychological control in predicting either substance use or undereating behaviors. This suggests that adolescents with lower levels of positive beliefs about their fathers' motivations for using psychological control are at greater risk for engaging in both substance use and under-eating behaviors compared to adolescents with higher levels of positive beliefs only when they also have high levels of disapproval of paternal psychological control. For adolescents with lower levels of disapproval of such control, positive beliefs did not moderate the association between paternal psychological control and either substance use or under-eating behaviors.

\section{Summary of Main Findings from Predictive Models}

Results indicated that maternal psychological control was associated with greater substance use for adolescents with lower levels of positive beliefs about their mothers' motivations for using psychological control and greater over-eating behaviors for adolescents with greater negative beliefs about their mothers' motivations for using psychological control. Furthermore, maternal psychological control was associated with greater depressive symptoms for adolescents with greater disapproval over their mothers' use of psychological control. With regards to under-eating behaviors, maternal psychological control was associated with greater under-eating for adolescents with high levels of negative beliefs about their mothers' motivations for using psychological control and high levels of disapproval of psychological control only. With regards to paternal psychological control, such control was associated with greater overeating behaviors and depressive symptoms for adolescents with greater levels of negative beliefs about their fathers' motivations for using psychological control. Additionally, paternal 
psychological control was associated with greater substance use and under-eating behaviors for adolescents with low levels of positive beliefs about their fathers' motivations for using psychological control and high levels of disapproval of psychological control only.

\section{Discussion}

Recent research has focused on identifying individual differences in the association between parental psychological control and adolescents' problematic outcomes. For instance, adolescents' personality traits and internalizing symptoms have been found to place them at more or less risk for engaging in problem behaviors in response to psychological control (Mabbe et al., 2016; Romm \& Metzger, 2018). However, much of this research has taken a unidirectional, top-down approach to understanding the associations among psychological control and adolescent outcomes. The current study considered adolescents as an active participant in this process by investigating how youth reason about and appraise parental psychological control. Findings highlight the utility in assessing adolescents' beliefs about their parents' motivations for using psychological control, as well as adolescents' disapproval of psychological control, as these sociocognitive factors were found to influence adolescents' likelihood for experiencing problematic outcomes when faced with psychologically controlling parenting.

\section{Differences Among Adolescents' Beliefs about Parental Motivations for Using}

\section{Psychological Control}

Examining mean differences in adolescents' rankings of their beliefs about their mothers' and fathers' motivations for using psychological control provides important insights into whether adolescents believe their parents are using such control for negative compared to positive reasons. Interestingly, findings suggested that adolescents most commonly believed that their 
mothers and fathers were motivated to use psychological control to keep the adolescent safe, followed by wanting to control the adolescent's personal world and viewing psychological control as a normative parenting behavior. Adolescents indicated that they were less likely to believe that their parents used psychological control for other negative reasons such as to compensate for the adolescent's lack of competence, to disrespect the adolescent, or because the adolescent does not matter to the parents. Psychological control is typically conceptualized as a negative, emotionally manipulative parenting behavior that interferes with the autonomy of and disrespects the adolescent (Barber, 1996). However, the current findings suggest that many adolescents actually believe that their parents use this control for positive compared to negative reasons. Although somewhat surprising, these findings are consistent with previous research examining adolescents' beliefs about why their parents use other negative parenting behaviors, such as authoritarian parenting. Adolescents most commonly believed that their parents used authoritarian parenting behaviors to keep the adolescent safe and out of trouble, rather than using it for the parent's own benefit (Camras et al., 2012). This particular finding provides insight into how adolescents think about a parenting behavior that is considered solely negative and extremely problematic for youth. Rather than reasoning about psychological control negatively, adolescents also believe that their parents use this negative parenting behavior for positive reasons. This suggests that psychological control may not be perceived by adolescents as negatively as it is conceptualized in the literature. Thus, adolescents may commonly believe that their parents have the adolescent's best interest in mind, even if they recognize psychological control as a negative parenting behavior. That is, adolescents may believe that their parents are well intentioned, but misguided in their use of psychological control. It is also noteworthy that many adolescents reported that parents use psychological control because it is viewed as a 
normal parenting behavior, suggesting that adolescents tend to view psychological control as more typical than researchers have assumed. It is possible that psychological control is used more than was once thought and that it is only problematic at extreme, as opposed to moderate levels. Alternatively, adolescents may perceive psychological control as a normative parenting behavior, but it may not be used as often as adolescents believe. For instance, adolescents may assume that psychological control is a parenting behavior that their peers also experience, but this assumption may not be accurate. Adolescents' likelihood for indicating that their parents use psychological control for positive reasons runs counter to the common assumption that psychological control is perceived as a negative parenting behavior by adolescents, leading to their engagement in problem behaviors as a reaction to this negative interpretation. Instead, adolescents actively interpret their parents' behaviors through both a positive and a negative lens, which may provide insight into why some adolescents do not experience problematic outcomes as a result of psychological control. Findings highlight the idea that adolescents' interpretations of parenting may not completely align with whether the parenting behavior is conceptualized as positive or negative for youth development.

However, the current findings suggest that adolescents also commonly reported that their parents engaged in psychological control for negative reasons, especially to control the adolescent's thoughts, feelings, or behaviors. The endorsement of this particular belief aligns closely with theoretical definitions of psychological control. For instance, Barber (1996) initially described psychological control as involving excessive personal control that intrudes into the adolescent's personal world. This negative parental motivation was likely most commonly endorsed, as youth strive for greater autonomy and independence from their parents during adolescence. Interestingly, adolescents were less likely to report that their parents use 
psychological control for reasons related to relatedness (i.e., the adolescent does not matter to the parent), competence (i.e., the adolescent is not competent enough to make their own decisions), and disrespect (i.e., the parent wants to disrespect the adolescent). Because autonomy and questions of personal jurisdiction are key to this developmental period, adolescents may be more sensitive or attuned to parenting behaviors that violate this sense of autonomy. This may lead to youth assuming that psychological control is used as a means of interfering with this desired increase in autonomy.

Contrary to hypotheses, prioritization of beliefs about parental motivations for using psychological control did not vary by adolescents' age or gender. It was hypothesized that older adolescents and adolescent boys would be more likely to endorse the belief that their parents use psychological control to control their thoughts, feelings, or behaviors and to compensate for the adolescent's lack of competence, whereas younger adolescents and adolescent girls would be more likely to believe that their parents use psychological control for positive reasons (i.e., to keep the adolescent safe, because it is a normative parenting behavior). However, the current findings suggest that all adolescents prioritize the belief that their parents use psychological control to keep the adolescent safe and to control the adolescent's thoughts, feelings, and behaviors. Thus, adolescents seem to balance both positive and negative beliefs when thinking about their parents' use of psychological control, regardless of their age and gender. It is often assumed that parents have greater safety concerns about their younger adolescents and their adolescent daughters compared to their older adolescents or their adolescent sons. However, it is likely that parents have these concerns for both sons and daughters of all ages, but that the form that this concern takes may differ (Keijsers \& Poulin, 2013; Koepke \& Denissen, 2012). That is, parents may display greater rules and monitoring over younger adolescents or adolescent 
daughters compared to older adolescents or adolescent sons to ensure safety, but parents' use of psychological control may be used in part to ensure adolescents adhere to parental rules to ensure safety for both adolescent sons and daughters of all ages. Similarly, although it is expected that parents will begin to use less behavioral control as adolescents get older, their use of psychological control may be viewed as intrusive and interfering with adolescents' autonomy even earlier in adolescence, as all adolescents strive for greater autonomy and independence from their parents during this developmental period (Zimmer-Gembeck \& Collins, 2003). These findings are consistent with previous research which found that all adolescents similarly viewed high levels of parental psychological control as intrusive regardless of age or gender (Kakihara \& Tilton-Weaver, 2019).

\section{Implications of Beliefs about Psychological Control}

The current study is an important first step toward understanding how adolescents prioritize their beliefs about parental motivations for using psychological control. Moreover, findings indicate that adolescents' beliefs about why their parents use psychological control have important implications for their likelihood of experiencing problematic outcomes in response to psychological control. Although psychological control was directly associated with adolescents' problematic outcomes, adolescents with greater negative beliefs and fewer positive beliefs about maternal and paternal psychological control were at greater risk for experiencing a host of problematic outcomes as a result of psychologically controlling parenting. In contrast, the associations among psychological control and problematic outcomes were weaker for adolescents with fewer negative beliefs and greater positive beliefs about parents' motivations for using psychological control. That is, having greater negative beliefs and fewer positive beliefs appears to be a risk factor for engaging in problematic outcomes in response to 
psychological control, whereas having fewer negative beliefs and greater positive beliefs buffers adolescents' likelihood for engaging in problematic outcomes when faced with psychological control. Adolescents' beliefs about maternal psychological control were also directly associated with adolescents' depressive symptoms over and above mothers' use of psychological control. Adolescents who felt that their mothers were using psychological control for negative reasons were at greater risk for experiencing depressive symptoms, whereas adolescents who believed that their mothers were using this control for positive reasons were at decreased likelihood for experiencing depressive symptoms. Because adolescents' beliefs about maternal psychological control were associated with depressive symptoms over and above psychological control, as well as positive aspects of parenting (i.e., behavioral control, warmth), these beliefs do not appear to be a function of the overall parent-child relationship. Instead, adolescents seem to have varied beliefs about their parents' use of psychological control that directly influence their problematic outcomes, as well as influence their likelihood for experiencing problematic outcomes in response to psychological control.

Taken together, these findings suggest that parental psychological control does not have the same negative influences on all adolescents. Instead, adolescents appear to be more active agents in the parenting process. Adolescents have distinct beliefs about their parents' motivations for using psychological control and these beliefs may amplify their risk for engaging in problem behaviors or experiencing depressive symptoms in response to their parents' use of psychological control. When adolescents feel a lack of control, a restriction of their free will, or feel as though they are not competent to direct their own lives, they are at greater risk for experiencing depressive symptoms or turning inward to assert their autonomy through engagement in over-eating behaviors (Brown \& Siegel, 1988; Soenens et al., 2008). Consistent 
with this idea, adolescents who were more likely to believe that their parents used psychological control to control their personal world, compensate for their lack of competence, and disrespect the adolescent were at greater risk for engaging in over-eating behaviors and experiencing depressive symptoms compared to adolescents with lower levels of these negative beliefs. Thus, negative beliefs about parents' motivations for using psychological control appear to place adolescents at greater risk for experiencing internalizing problems (i.e., over-eating behaviors, depressive symptoms) compared to outcomes that are typically considered more externalizing (e.g., substance use, risky cyber behavior). The belief that parents are engaging in psychological control for negative reasons may lead to feelings of anger or hostility in the adolescent, resulting in an opposition or unwillingness to behave in ways that adhere to the parent's wishes. This finding is relatively consistent with previous research, suggesting that the emotionally manipulative nature of psychological control promotes adolescent dependence upon parents and greater isolation from peers (Davis, 2001; Fontaine, 2006). This dependence and isolation has been found to contribute to greater depressive symptoms among adolescents, as well as greater over-eating behaviors, as adolescents often engage in over-eating behaviors to cope with feelings of isolation (Hunter et al., 2015; Snoek et al., 2007). Interestingly, adolescents' positive beliefs also moderated the association between maternal psychological control and substance use, such that psychological control was associated with greater substance use for adolescents with fewer positive beliefs, but not for those with greater positive beliefs about their mothers' motivations for using psychological control. Parents and adolescents generally agree that it is acceptable for parents to have greater rules over behaviors that are harmful to the adolescent's health or safety, such as substance use (Jackson, 2002). Thus, adolescents may have felt that their parents should be using psychological control to keep them safe and out of trouble. Adolescents who believed 
that their parents were not using psychological control for this reason may have felt that their parents did not disapprove of their engagement in substance use behaviors.

Interestingly, the results also suggest that greater positive beliefs and fewer negative beliefs about parents' motivations for using psychological control may serve as a buffer of the association between psychological control and problematic outcomes. Specifically, maternal psychological control was not associated with over-eating behaviors and paternal psychological control was not associated with either over-eating behaviors or depressive symptoms for adolescents with lower levels of negative beliefs about parents' use of psychological control. When adolescents do not feel as though their parents are using psychological control for negative reasons, such as trying to control the adolescent's thoughts, feelings, or behaviors or compensating for the adolescent's lack of competence, youth may not feel the need to turn inward to assert their autonomy leading to engagement in over-eating behaviors. They may also be less likely to experience depressive symptoms as a result of feeling like they cannot exert control over their own lives (Brown \& Siegel, 1988; Soenens et al., 2008). Additionally, maternal psychological control was not associated with adolescents' substance use behaviors when adolescents believed that their mothers were engaging in psychological control for positive reasons. Parents and adolescents generally agree that it is acceptable for parents to have greater rules over behaviors that are harmful to the adolescent's health or safety, such as substance use (Jackson, 2002). Thus, adolescents who felt that their mothers used psychological control to keep them safe and out of trouble likely accepted their use of this control and in turn, engaged in fewer substance use behaviors to ensure their own safety. Findings speak to the importance of considering the combination of parenting behaviors with adolescents' views of parenting behavior, as psychological control was differentially associated with adolescents' outcomes 
based on their beliefs about their parents' motivations for using this control. Taken together, lower levels of negative beliefs and greater positive beliefs about parents' motivations for using psychological control appear to serve a protective function for adolescents, as they mitigate the negative effects of psychological control.

These findings are somewhat consistent with previous research which has examined whether adolescents' positive and negative beliefs moderate the association between other types of negative parenting (i.e., authoritarian parenting) and adolescents' problematic outcomes. Although authoritarian parenting was associated with greater depressive symptoms and less school effort for all adolescents, these associations were stronger for adolescents who felt that their parents were using this behavior for the parents' own benefit and were not using the behavior for the child's benefit or because they viewed it as a normative parenting behavior (Camras et al., 2012). Although authoritarian parenting involves low levels of parental warmth, it also involves the use of positive forms of control (i.e., behavioral control; Baumrind, 1971). The current findings extend this work by suggesting that adolescents also vary in their beliefs about why their parents use behaviors that are considered solely negative (i.e., psychological control). These beliefs also buffer the associations among this negative parenting behavior and adolescents' problematic outcomes. The current findings also build on previous research on psychological control specifically, which has found that adolescents reason more negatively about parents' use of psychological control when parents use high compared to moderate levels of psychological control and exert psychological control over personal, rather than prudential concerns (Kakihara \& Tilton-Weaver, 2009). The current findings suggest that these beliefs about parents' motivations for using psychological control have important implications for 
adolescents' likelihood of experiencing problematic outcomes in response to psychological control.

\section{Disapproval of Psychological Control as a Moderator}

Building on previous work, which has found that both adolescents' beliefs about parental motivations and disapproval of negative parenting behaviors independently moderate the associations between negative parenting and problematic outcomes, the current study also examined the role of adolescents' disapproval of psychological control on the association between such control and problematic outcomes. Interestingly, adolescents' disapproval of maternal psychological control only moderated the association between maternal psychological control and depressive symptoms. Specifically, maternal psychological control was associated positively with depressive symptoms for adolescents who were more disapproving of their mother's use of psychological control, but not for adolescents who were less disapproving of this control. This finding aligns with those of Camras et al. (2012), which found that adolescents' disapproval of coercive authority association moderated the association between this negative aspect of parenting and depressive symptoms, but not the associations with either antisocial behavior or school engagement. Adolescents are thought to have a greater emotional reaction to negative parenting when they are disapproving of it, which may explain why adolescents who are disapproving of psychological control react with greater depressive symptoms. Adolescents who do not agree with parents use of psychological control may be more unlikely to put in the effort to listen to the parents' message and behave in ways consistent with the parent's wishes.

However, the current study built upon previous work on other aspects of negative parenting by considering how adolescents' disapproval of psychological control interacts with adolescents' beliefs about parental motivations for using psychological control to influence the 
association between this control and adolescents' problematic outcomes. Findings indicated that maternal psychological control was associated with greater under-eating behaviors for adolescents with greater negative beliefs about their mothers' use of psychological control and high levels of disapproval over this control. This finding suggests that adolescents who believed that their parents were using psychological control for negative reasons (e.g., to control them, compensate for their lack of competence, disrespect them, or because they do not matter to the parent) were not at risk for engaging in under-eating behaviors if they had lower levels of disapproval. Thus, some adolescents appear to believe that their parents use psychological control for negative reasons, but are not as disapproving of this control. For instance, adolescents with less desired autonomy may not be as disapproving of their parents using psychological control to control their thoughts, feelings, or behaviors, and psychological control is not predictive of problematic outcomes that adolescents often engage in to gain control over their lives, such as under-eating behaviors. It is also possible that adolescents who have positive relationships with peers or other adults may be less bothered by their parents' use of psychological control, even when they believe they are using it for negative reasons. For instance, adolescents who feel they receive love, support, and emotional closeness from other individuals may be less bothered by the emotional manipulation they receive from their parents. Additionally, adolescents' positive beliefs about their fathers' motivations for using psychological control interacted with disapproval to predict both substance use and under-eating behaviors. More specifically, psychological control was associated positively with each of these problematic outcomes for adolescents with low levels of positive beliefs and greater disapproval only. Therefore, some adolescents believe that their fathers are less likely to use psychological control for positive reasons, such as keeping them safe or because it is a normative parenting 
behavior, but they are not disapproving of this. This combination of fewer positive beliefs with low levels of disapproval places adolescents at no greater risk for engaging in either substance use or under-eating behaviors. It has been suggested that mothers and fathers are often viewed as having different roles in the family, with mothers being perceived as involved in all domains of adolescents' lives and fathers being perceived as involved in protecting and teaching adolescents' discipline (Finley, Mira, \& Schwartz, 2006). Thus, some adolescents may expect that their fathers should use psychological control for these reasons. They may be disapproving of this control if they do not believe that their fathers are using psychological control to keep them safe and out of trouble, as expected. This may lead to greater risk for rebelling against this control and engaging in problematic outcomes, such as substance use and under-eating behaviors. Taken together, findings suggest that adolescents' beliefs about their parents' motivations for using psychological control are not redundant with their disapproval of this control. In fact, disapproval interacts with adolescents' negative beliefs about their mothers' use of psychological and adolescents' positive beliefs about their fathers' use of psychological control in predicting substance use and under-eating behaviors. That is, greater negative beliefs and fewer positive beliefs only place adolescents at greater risk for engaging in these problematic outcomes in response to psychological control when they also disapprove of this parenting behavior. These findings place emphasis upon the importance of examining both beliefs and disapproval simultaneously as they interact to influence the association between psychological control and problematic outcomes, rather than examining them in separate models, which has been done in previous research (Camras et al., 2012). 


\section{Limitations and Future Directions}

The current study provides several novel contributions to research on how adolescents experience parental psychological control and is the first to examine how sociocognitive factors influence the association between psychological control and problematic outcomes. However, findings should be considered in light of certain limitations. The measures utilized in the current study were collected via adolescent self-report, which enhances the influence of socialdesirability bias and shared-method variance. For instance, adolescents may have under-reported their engagement in problem behaviors and their internalizing symptoms. Although previous research has suggested that youth self-report of perceived parenting is more closely related to youth adjustment than is parents' self-report of parenting (Gecas \& Schwalbe, 1986), future studies would benefit from a multi-informant approach. The current study utilized crosssectional, correlational data so causal inferences about the associations found in the current study cannot be made. Longitudinal data is needed to determine the temporal order and potential bidirectionality of these associations to further elucidate the developmental processes underlying the role of adolescents' sociocognitive factors on the association between parental psychological control and adolescents' developmental outcomes. Although the current study examined parental psychological control as a predictor of adolescent problematic outcomes, it is possible that adolescents' problematic outcomes influences parents' use of psychological control. Furthermore, the sample was limited in terms of diversity, as most of the participants identified as white, resided in one of two mid-Atlantic states, and reported receiving mostly A's and B's in school. Therefore, the current study should be replicated in more diverse samples with regards to race/ethnicity, geographic location, as well as academic success, to increase the generalizability of the findings. 
The current study recruited participants through middle schools and high schools. However, the majority of adolescents who completed the survey were in high school. This restricted age range may have reduced the ability of the present study to detect age differences. Future research should seek to recruit younger adolescents in order to investigate variability in adolescents' beliefs about parental motivations for using psychological control associated with developmental changes that occur during adolescence. Because this study recruited adolescents through students in classrooms, the data may have been subject to selection bias. Students were required to have their parent sign their permission form and return the permission form to their teacher in order to participate, which may be one reason the majority of the sample consisted of students who received mostly As and Bs in school. This may also explain why the mean level of substance use and risky cyber behaviors was relatively low. Future research should seek to recruit adolescents who engage in higher levels of problem behaviors to better detect associations among psychological control, adolescents' beliefs about and disapproval of psychological control, and problematic outcomes. It is possible that adolescents who engage in greater problematic outcomes may be more likely to interpret their parents' psychological control through a negative light. Further, parents of more delinquent adolescents may be more likely to use psychological control for reasons related to controlling the adolescents' behavior or making decisions for the adolescent. Although the current study assessed a wider range of potential beliefs about parental motivations for using psychological control than has been assessed in previous research (Camras et al., 2012; Kakihara \& Tilton-Weaver, 2009), these beliefs are not an exhaustive list. Future research would benefit from utilizing a qualitative approach through the form of open-ended questionnaires or interviews to determine whether adolescents believe that their parents have additional motivations for using psychological control. 
Findings from the current study yield many additional questions for future research to pursue. Assessing the role of adolescents' beliefs about and disapproval of parental psychological control on the association between psychological control and problematic outcomes is an important first step in viewing the adolescent as an active participant in influencing whether they experience problematic outcomes in the face of psychologically controlling parenting. The current findings urge researchers to continue to account for adolescents' beliefs and reasoning about parenting behaviors when examining the role of parenting on adolescent development. Because adolescents' sociocognitive factors appear to have important implications for adolescents' likelihood of experiencing problematic outcomes as a result of psychological control, it remains important for future research to examine the predictors of these sociocognitive factors. For instance, previous research has found that adolescents' negative beliefs about parental psychological control were predicted by higher levels of psychological control and psychological control used over personal issues, whereas positive beliefs about psychological control were predicted by moderate levels of psychological control and psychological control used over prudential issues (Kakihara \& Tilton-Weaver, 2009). However, because psychological control occurs in combination with other negative parenting behaviors, as well as positive forms of parenting (Romm \& Metzger, under review), future research should examine how overall profiles of parenting predict adolescents' beliefs about parents' use of psychologically controlling parenting. This is especially important to consider, as beliefs were not redundant with positive aspects of the parent-child relationship in the current study, as adolescents' perception of behavioral control and warmth were used as control variables. This will provide greater insight into how to promote or reduce the sociocognitive 
factors that place adolescents at more or less risk for experiencing problematic outcomes when faced with psychological control.

In addition to understanding the predictors of adolescents' beliefs and disapproval of parents' use of psychological control, another fruitful direction for researchers to pursue would be to examine demographic differences in the role of adolescents' sociocognitive factors on the association between psychological control and problematic outcomes. Although the current study did not find any differences in the prioritization of adolescents' beliefs about parental motivations for using psychological control based on age and gender, it is possible that age and gender may interact with certain beliefs about parental motivations for using psychological control. For instance, the association between psychological control and problematic outcomes may be stronger for older adolescents and male adolescents with negative beliefs about parental motivations for using psychological control, as these adolescents are thought to desire greater autonomy and independence from their parents (Fuligni, 1998; McElhaney et al., 2009). Thus, if these adolescents perceive their parents as using psychological control to control their personal world or to compensate for their lack of competence, they may be especially likely to engage in problem behaviors to assert their autonomy and independence. Future research would also benefit from examining the role of specific beliefs about parental motivations on the association between psychological control and problematic outcomes in order to understand whether certain types of beliefs are stronger moderators or whether certain beliefs are more problematic for certain outcomes. Adolescents who believe that their parents use psychological control to control them or make up for their lack of competence may engage in behaviors, such as substance use, risky cyber behaviors, or under-eating behaviors to reassert their autonomy and gain control over their lives (Kerr et al., 2003). Alternatively, adolescents who believe that their parents use 
psychological control because they do not matter to the parent may experience greater depressive symptoms as a result of feeling as though they do not receive love and acceptance from their parents. Furthermore, adolescents may engage in greater over-eating behaviors when they believe their parents use psychological control to disrespect them, as adolescents have been found to engage in such behaviors to cope with feelings of shame and criticism that often stem from psychological control (Snoek et al., 2007).

Current findings also have important implications for intervention. Findings suggest that prevention and intervention strategies for adolescents engaging in problem behaviors or experiencing depressive symptoms as a result of psychological control should take adolescents' interpretations of such negative parenting into account. More specifically, interventions may benefit from including an assessment of adolescents' beliefs about the motivations driving their parents' behavior, as well as their disapproval of these behaviors to institute appropriate changes in adolescents' interpretations and the parenting behaviors themselves. Findings also provide practitioners with insight into which types of beliefs matter most for influencing adolescents' likelihood of experiencing specific types of problematic outcomes in response to maternal and paternal psychological control, separately. For instance, if a practitioner is working with an adolescent struggling with substance use as a result of experiencing psychological control from their mother, it may be most beneficial for practitioners to target their beliefs related to mothers' use of psychological control to promote their safety or normalizing the use of this parenting behavior. That is, practitioners may benefit from discussing adolescents' interpretations of their mothers' use of psychological control and providing the adolescent with insight into how their mother could be using this particular behavior for positive reasons. However, for adolescents engaging in over-eating behaviors in response to maternal psychological control, it appears to be 
more beneficial for practitioners to target adolescents' negative beliefs about their mothers' motivations for using psychological control. Adolescents' likelihood for engaging in over-eating behaviors in response to psychological control varied based on their negative beliefs but not their positive beliefs. Therefore, it may be most effective for practitioners to target adolescents' beliefs about control, competence, relatedness, and disrespect with regards to parents' use of psychological control to work towards reducing their engagement in over-eating behaviors.

\section{Conclusions}

Overall, present findings suggest that adolescents endorse different motivations to explain why their mothers and fathers use psychological control. These beliefs about parental motivations have important implications for adolescents' likelihood of experiencing problematic outcomes in response to psychological control. Furthermore, these findings were found to further vary by adolescents' disapproval of their parents' use of psychological control, which suggests that adolescents with similar beliefs about parental motivations vary in their disapproval of parents' use of psychological control. This disapproval in turn appears to interact with adolescents' beliefs about parental motivations for using psychological control to influence the association between psychological control and adolescents' problematic outcomes. The present study was the first to consider how adolescents' beliefs about and disapproval of parental psychological control place adolescents at more or less risk for experiencing problematic outcomes in response to psychological control. Findings urge researchers to begin to treat the adolescent as an active participant in the parenting process, rather than taking a top-down approach to examining the role of parenting on youth outcomes. Specifically, researchers should begin to assess adolescents' interpretations of their parents' behaviors when examining the associations among parenting behaviors and adolescent outcomes. The current study suggests 
that rather than being uniformly influenced by psychological control, adolescents' interpretations of this parenting behavior play an important role in determining whether they experience problematic outcomes in response to this controlling parenting behavior. 


\section{References}

Abar, C., Jackson, K., Colby, B., \& Barnett, N. (2014). Parent-child discrepancies in reports of parental monitoring and their relationship to adolescent alcohol-related behaviors. Journal of Youth and Adolescence, 44(9), 1688-1701. http://dx.doi.org/10.1007/s10964 $-014-0143-6$

Barber, B. K. (1996). Parental psychological control: Revisiting a neglected construct. Child Development, 67, 3296-3319. http://dx.doi.org/10.2307/1131780

Barber, B. K., \& Harmon, E. L. (2002). Violating the self: Parental psychological control of children and adolescents. In B. K. Barber (Ed.), Intrusive parenting: How psychological control affects children and adolescents (pp. 15-52). Washington, DC: American Psychological Association.

Barber, B. K., Maughan, S. L., \& Olsen, J. A. (2005). Patterns of parenting across adolescence. New Directions for Child and Adolescent Development, 108, 5-16. http://dx.doi.org/10.1002/cd.124

Barber, B. K., Olsen, J. E., \& Shagle, S. C. (1994). Associations between parental psychological and behavioral control and youth internalized and externalized behaviors. Child Development, 65, 1120-1136. http://dx.doi.org/10.2307/1131309

Barber, B. K., \& Xia, M. (2013). The centrality of control to parenting and its effects. In A. S. Morris, R. E. Larzelere, \& A. W. Harrist (Eds.), New Directions for Authoritative Parenting (pp. 61-87). Washington, DC: American Psychological Association.

Barber, B. K., Xia, M., Olsen, J. A., McNeely, C. A., \& Bose, K. (2012). Feeling disrespected by parents: Refining the measurement and understanding of psychological control. Journal of Adolescence, 35, 273-287. http://dx.doi.org/10.1016/j.adolescence.2011.10.010 
Baumrind, D. (1971). Current patterns of parental authority. Developmental Psychology, 4, 1103. http://dx.doi.org/10.1037/h0030372

Bell, R. Q. (1979). Parent, child, and reciprocal influences. American Psychologist, 34, 821-826. http://dx.doi.org/10.1037/0003-066X.34.10.821

Bentler, P. M., \& Chou, C. (1987). Practical issues in structural modeling. Sociological Methods \& Research, 16(1), 78-117.

Brody, GH, Murry, VM, et al. (2004). The strong African-American families program:

Translating research into prevention programming. Child Development, 75(3), 900- 917. http://dx.doi.org/10.1111/j.1467-8624.2004.00723.x

Buri, J. R. (1991). Parental Authority Questionnaire. Journal of Personality Assessment, 57(1), 110-119. http://dx.doi.org/10.1207/s15327752jpa5701_13

Camras, L. A., Sun, K., Li, Y., \& Wright, M. F. (2012). Do Chinese and American children’s interpretations of parenting moderate links between perceived parenting and child adjustment? Parenting: Science and Practice, 12, 306-327. http://dx.doi.org/10.1080 $/ 15295192.2012 .709154$

Chao, R. K. (1994). Beyond parental control and authoritarian parenting style: Understanding Chinese parenting through the cultural notion of training. Child Development, 65, 11111119. http://dx.doi.org/10.2307.1131308

Cheah, C. S., Yu, J.,, Hart, C. H., Sun, S., \& Olsen, J. A. (2015). Confirming the multidimensionality of psychologically controlling parenting among Chinese-American mothers: Love withdrawal, guilt induction, and shaming. International Journal of Behavioral Development, 39(3), 285-292. http://dx.doi.org/10.1177/0165025414562238 
Cheung, G. W., \& Rensvold, R. B. (2002). Evaluating goodness-of-fit indexes for testing measurement invariance. Structural equation modeling, 9(2), 233-255. http://dx.doi .org/10.1207/S15328007SEM0902_5

Collins, W. A., \& Steinberg, L. (2006). Adolescent development in interpersonal context. In N. Eisenberg, W. Damon \& R M. Lerner (Eds.), Handbook of Child Psychology: Vol. 3, Social, Emotional, and Personality Development (pp. 1003-1067). Hoboken, NJ: John Wiley \& Sons.

Cui, L., Morris, A. S., Criss, M. M., Houltberg, B. J., \& Silk, J. S. (2014). Parental psychological control and adolescent adjustment: The role of adolescent emotion regulation. Parenting: Science and Practice, 14, 47-67. http://dx.doi.org/10.1080/15295192.2014.880018

Etkin, R. G., Koss, K. J., Cummings, E. M., \& Davies, P. T. (2014). The differential impact of parental warmth on externalizing problems among triangulated adolescents. Journal of Genetic Psychology, 175, 118-133. http://dx.doi.org/10.1080/00221325.2013.813437

Finkenauer, C., Engels, R. C. M. E., \& Baumeister, R. F. (2005). Parenting behavior and adolescent behavioural and emotional problems: The role of self-control. International Journal of Behavioral Development, 29, 58-69. http://dx.doi.org/10.1080 $/ 01650250444000333$

Fuligni, A. J. (1998). Authority, autonomy, and parent-adolescent conflict and cohesion: A study of adolescents from Mexican, Chinese, Filipino, and European backgrounds. Developmental Psychology, 34, 782-792. http://dx.doi.org/10.1037/0012-1649.34.4.782

Galambos, N. L., Barker, E. T., \& Almeida, D. M. (2003). Parents do matter: Trajectories of change in externalizing and internalizing problems in early adolescence. Child Development, 74(2), 578-594. doi: 10.1111/1467-8624.7402017 
Gecas, V., \& Schwalbe, M. L. (1986). Parental behavior and adolescent self-esteem. Journal of Marriage and the Family, 48, 37-46. http://dx.doi.org/10.2307/352226

Giles, G., \& Price, I. R. (2008). Adolescent computer use: Approach, avoidance, and parental control. Australian Journal of Psychology, 60, 63-71. http://dx.doi.org/10.1080/ 00049530701829896

Graham, J. W. (2012). Missing data: Analysis and design. New York, NY: Springer Science \& Business Media.

Grolnick, W. S., \& Pomerantz, E. M. (2009). Issues and challenges in studying parental control: Toward a new conceptualization. Child Development Perspectives, 3, 165-170. http://dx.doi.org/10.1111/j.1750-8606.2009.00099.x

Grusec, J. E., \& Goodnow, J. J. (1994). Impact of parental discipline methods on the child's internalization of values: A reconceptualization of current points of view. Developmental Psychology, 30(1), 4-19. http://dx.doi.org/10.1037/0012-1649.30.1.4

Harris, J. H. (1995). Where is the child's environment? A group socialization theory of development. Psychological Review, 102, 458-489. http://dx.doi.org/10.1037/0033 $-295 X .102 .3 .458$

Hart, C. H., \& Robinson, C. C. (1995). Parental psychological control: An instrument for early childhood. Unpublished manuscript.

Hawk, S. T., Hale, I. I. I. W. W., Raaijmakers, Q. A. W., and Meeus, W. (2008). Adolescents' perceptions of privacy invasion in reaction to parental solicitation and control. Journal of Early Adolescence, 28, 583-608. http://dx.doi/org/10.1177/0272431608317611

Hinduja, S., \& Patchin, J. W. (2010). Bullying, cyberbullying, and suicide. Archives of Suicide Research, 14(3), 206-221. http://dx.doi.org/10.1080/13811118.2010.494133 
Hunter, S. B., Barber, B. K., \& Stolz, H. E. (2015). Extending knowledge of parents' role in adolescent development: The mediating effect of self-esteem. Journal of Child and Family Studies, 24, 2474-2484. http://dx.doi.org/10.1007/s10826-014-0050-1

Jaccard, J., Dodge, T., \& Dittus, P. (2002). Parent-adolescent communication about sex and birth control: A conceptual framework. New Directions for Child and Adolescent Development, 97, 9-41. http://dx.doi.org/10.1002/cd.48

Jackson, C. (2002). Perceived legitimacy of parental authority and tobacco and alcohol use during early adolescence. Journal of Adolescent Health, 31, 425-432. http://dx.doi.org /10.1016/S1054-139X(02)00398-1

Kakihara, F., \& Tilton-Weaver, L. (2009). Adolescents' interpretations of parental control: Differentiated by domain and types of control. Child Development, 80(6), 1722-1738. http://dx.doi.org/10.1111/j.1467-8624.2009.01364.x

Kakihara, F., Tilton-Weaver, L., Kerr, M., \& Stattin, H. (2010). The relationship of parental control to youth adjustment: Do youths' feelings about their parents play a role? Journal of Youth and Adolescence, 12, 1442-1456. http://dx.doi.org/10.1007/s10964-009-9479-8

Keijsers, L., \& Poulin, F. (2013). Developmental changes in parent-child communication throughout adolescence. Developmental Psychology, 49(12), 2301-2308. http://dx.doi.org/10.1037/a0032217

Kerr, M., Stattin, H., Biesecker, G., \& Ferrer-Wreder, L. (2003). Relationships with parents and peers in adolescence. In R. M. Lerner, M. A. Eastbrooks, \& J. Mistry (Eds.), Handbook of psychology: Developmental psychology (pp. 395-419). Hoboken, NJ: Wiley.

Kline, R. B. (2015). Principles and practice of structural equation modeling. Guilford Publications. 
Koepke, S., \& Denissen, J. J. A. (2012). Dynamics of identity development and separation individuation in parent-child relationships during adolescence and emerging adulthood: A conceptual integration. Developmental Review, 32(1), 67-88. http://dx.doi.org/10.1016 /j.dr.2012.01.001

Kuczynski, L. (2003). Beyond bidirectionality: Bilateral conceptual frameworks for understanding dynamics in parent-child relations. In L. Kuczynski (Ed.), Handbook of dynamics in parent-child relations (pp. 3-24). Thousand Oaks, CA: Sage.

Lansford, J., Chang, L., Dodge, K., Malone, P., Oburu, P., Palmerus, K., . . \& \& Quinn, N. (2005). Physical discipline and children's adjustment: Cultural normativeness as a moderator. Child Development, 76, 1234-1246. http://dx.doi.org/10.1111/j.1467-8624.2005.00847.s

Little, T.D. (2013). Longitudinal structural equation modeling. New York, NY: The Guilford.

Little, T. D., Bovaird, J. A., \& Card, N. A. (Eds.). (2012). Modeling contextual effects in longitudinal studies. New York and London: Psychology Press.

Li, X., Li, D., \& Newman, J. (2013). Parental behavioral and psychological control and problematic internet use among Chinese adolescents: The mediating role of self-control. Cyberpsychology, Behavior, and Social Networking, 16, 442-447. http://dx.doi.org/ /10.1089/cyber.2012.0293

Luyckx, K., Soenens, B., Vansteenkiste, M., Goossens, L., \& Berzonsky, M. D. (2007). Parental psychological control and identity formation in emerging adulthood. Journal of Family Psychology, 21(3), 546-550. http://dx.doi.org/10.1037/0893-3200.21.3.546

Mabbe, E., Soenens, B., Vansteenkiste, M., \& Van Leeuwe, K. (2016). Do personality traits moderate relations between psychologically controlling parenting and problem behavior in adolescents? Journal of Personality, 84, 381-392. http://dx.doi.org/10.1111/jopy.12166 
McElhaney, K. B., Allen, J. P., Stephenson, J. C., \& Hare, A. L. (2009). Attachment and autonomy during adolescence. In R. M. Lerner, \& L. Steinberg (Eds.), Handbook of adolescent psychology: Individual bases of adolescent development (pp. 358-403). Hoboken, NJ: John Wiley \& Sons.

McEwen, C., \& Flouri, E. (2009). Fathers' parenting, adverse life events, and adolescents' emotional and eating disorder symptoms: The role of emotion regulation. European Child and Adolescent Psychiatry, 18(4), 206-216. http://dx.doi.org/10.1007/s00787-008-0719-3

Muthén, L.K. and Muthén, B.O. (1998-2012). Mplus User's Guide. Seventh Edition. Los Angeles, CA: Muthén \& Muthén

Nelson, D. A., Yang, C., Coyne, S. M., Olsen, J. A., \& Hart, C. H. (2013). Parental psychological control dimensions: Connections with Russian preschoolers' physical and relational aggression. Journal of Applied Developmental Psychology, 34(1), 1-8. http://dx.doi.org/10.1016/j.appdev.2012.07.003

Nucci, L. (1996). Morality and personal freedom. In E. S. Reed, E. Turiel, \& T. Brown (Eds.), Values and knowledge (pp. 41-60). Mahwah, NJ: Erlbaum.

Nucci, L., Hasbe, Y., \& Lins-Dyer, M. T. (2005). Adolescent psychological well-being and parental control of the personal. In W. Doman, \& J. Smetana (Eds.), New directions for child and adolescent development (pp. 17-30). New York: Wiley.

Nunnally, J. C. (1967). Psychometric theory. New York, NY: McGraw-Hill. 
Olsen, S. F., Yang, C., Hart, C. H., Robinson, C. C., Wu, P., Nelson, D. A.,. . .\& Wo, J. (2002). Maternal psychological control and preschool children's behavioral outcomes in China, Russia, and the United States. In B. K. Barber (Ed.), Intrusive parenting: How psychological control affects children and adolescents (pp. 235-262). Washington, DC: American Psychological Association.

Padilla-Walker, L. M., \& Nelson, L. J. (2012). Black hawk down? Establishing helicopter parenting as a distinct construct from other forms of parental control during emerging adulthood. Journal of Adolescence, 35, 1177-1190. http://dx.doi.org/10.1016/j .adolescence.2012.03.007

Pettit, G. S., Laird, R. D., Dodge, K. A., Bates, J. E., \& Criss, M. M. (2001). Antecedents and behavior-problem outcomes of parental monitoring and psychological control in early adolescence. Child Development, 72, 583-598. http://dx.doi.org/10.1111/1467 $-8624.00298$

Pesola, F., Shelton, K. H., Heron, J., Munafo, M., Hickman, M., \& van den Bree, M. B. M. (2015). The developmental relationship between depressive symptoms in adolescence and harmful drinking in emerging adulthood: The role of peers and parents. Journal of Youth and Adolescence, 44, 1752-1766. http://dx.doi.org/10.1007/s10964-015-0295-

Pomerantz, E. M., \& Eaton, M. M. (2000). Developmental differences in children's conceptions of parental control: "They love me, but they make me feel incompetent." Merrill-Palmer Quarterly, 46, 140-167. Retrieved from https://www.jstor.org/stable/23093346

Radloff, L.S. (1977). The CES-D scale: A self-report depression scale for research in the general Population. Applied Psychological Measurement, 1, 385-401. http://dx.doi.org/10.1177 /014662167700100306 
Rodenburg, G., Kremers, S. P., Oenema, A., \& van de Mheen, D. (2014). Associations of parental feeding styles with child snacking behavior and weight in the context of general parenting. Public Health Nutrition, 17(5), 960-969. http://dx.doi.org/10.1017 /S1368980013000712

Romm, K. F., \& Metzger, A. (2018). Parental psychological control and adolescent problem behaviors: The role of depressive symptoms. Journal of Child and Family Studies, 27(7), 2206-2216. http://dx.doi.org/10.1007/s10826-018-1064-x

Romm, K. F., Metzger, A., \& Alvis, L. M. (2019). Parental psychological control and adolescent problematic outcomes: A multidimensional approach. Journal of Child and Family Studies. http://dx.doi.org/10.1007/s10826-019-01545-y

Rosen, L. H., Principe, C. P., \& Langlois, J. H. (2013). Feedback seeking in early adolescence: Self-enhancement or self-verification? Journal of Early Adolescence, 33(3), 363-377. http://dx.doi.org/10.1177/0272431612441070

Rubin, K. H., Bukowski, W. M., \& Parker, J. G. (2006). Peer interactions, relationships, and groups. In W. Damon, R. Lerner, \& N. Eisenberg (Eds.), Handbook of child psychology: Social, emotional, and personality development (pp. 571-645). New York: Wiley.

Ruble, D., \& Martin, C. L. (1998). Gender development. In W. Damon \& N. Eisenberg (Eds.), Handbook of Child Psychology: Vol. 3, Social, Emotional, and Personality Development (pp. 993-1016). New York: Wiley.

Ryan, R. M., \& Deci, E. L. (2000). Self-determination theory and the facilitation of intrinsic motivation, social development, and well-being. The American Psychologist, 55(1), 6878. http://dx.doi.org/10.1037/0003-066X.55.1.68 
Ryan, R. M., Deci, E. L., Grolnick, W. S., \& La Guardia, J. G. (2006). The significance of autonomy and autonomy support in psychological development and psychopathology. In D. Cicchetti, \& D, Cohen (Eds.), Theory and methods: Developmental psychopathology (pp. 795-849). New York: Wiley.

Satorra, A. (2000). Scaled and adjusted restricted tests in multi-sample analysis of moment structures. In Innovations in multivariate statistical analysis (pp. 233-247). Springer, Boston, MA.

Schaefer, E. S. (1965). A configurational analysis of children's reports of parent behavior. Journal of Consulting Psychology, 29, 552-557. http://dx.doi.org/10.1037/h0022702

Silk, J. S., Morris, A. S., Kanaya, T., \& Steinberg, L. (2003). Psychological control and autonomy granting: Opposite ends of a continuum or distinct constructs? Journal of Research on Adolescence, 13(1), 113-128. http://dx.doi.org/10.1111/1532-7795.1301004

Skinner, H. H., Haines, J., Austin, S. B., \& Field, A. E. (2012). A prospective study of overeating, binge eating, and depressive symptoms among adolescent and young adult women. Journal of Adolescent Health, 50(5), 478-483. http://dx.doi.org/10.1016 /j.adohealth.2011.10.002

Smetana, J. G. (2000). Middle-class African American adolescents' and parents' conceptions of parental authority and parenting practices: A longitudinal investigation. Child Development, 71, 1672-1686. http://dx.doi.org/10.1111/1467-8624.00257

Smetana, J. G. (2002). Culture, autonomy, and personal jurisdiction in adolescent-parent relationships. Advances in Child Development and Behavior, 29, 51-87. http://dx.doi.org/10.1016/S0065-2407(02)80051-9 
Smetana, J. G., Campione-Barr, N., \& Daddis, C. (2004). Longitudinal development of family decision making: Defining heathy behavioral autonomy for middle-class African American adolescents. Child Development, 75(5), 1418-1434. http://dx.doi.org /10.1111/j.1467-8624.2004.00749.x

Smetana, J. G., Crean, H. F., \& Campione-Barr, N. (2005). Adolescents' and parents' changing conceptions of parental authority. In W. Damon, \& J. Smetana (Eds.), New directions for child and adolescent development (pp. 31-46). New York: Wiley.

Smetana, J. G., \& Daddis, C. (2002). Domain-specific antecedents of parental psychological control and monitoring: The role of parenting beliefs and practices. Child Development, 73, 563-580. http://dx.doi.org/10.1111/1467-8624.00424

Snoek, H. M., Engels, R. C. M. E., Janssens, J. M. A. M., \& van Strien, T. (2007). Parental behavior and adolescents' emotional eating. Appetite, 49, 223-230. http://dx.doi.org /10.1016/j.appet.2007.02.004

Soenens, B., Vansteenkiste, M., Duriez, B., \& Goossens, L. (2006). In search of the sources of psychologically controlling parenting: The role of parental separation anxiety and parental maladaptive perfectionism. Journal of Research on Adolescence, 16(4), 539-559. http://dx.doi.org/ 10.1111/j.1532-7795.2006.00507.x

Soenens, B., Vansteenkiste, M., \& Luyten, P. (2010). Toward a domain-specific approach to the study of parental psychological control: Distinguishing between dependency-oriented and achievement-oriented psychological control. Journal of Personality, 78, 217-256. http://dx.doi.org/10.1111/j.1467-6494.2009.00614.x 
Soenens, B., Vansteenkiste, M., Vandereycken, W., Luyten, P., Sierens, E., \& Goossens, L. (2008). Perceived parental psychological control and eating-disordered symptoms: Maladaptive perfectionism as a possible intervening variable. The Journal of Nervous and Mental Disease, 196, 144-152. http://dx.doi.org/10.1097/NMD.0b013e318162aabf

Steinberg, L. (2001). We know some things: Parent-adolescent relationships in retrospect and prospect. Journal of Research in Adolescence, 11, 1-19. http://dx.doi.org/10.1111/15327795.00001

Stone, L. L., Otten, R., Janssens, J. M. A. M., Soenens, B., Kuntsche, E., \& Engels, R. C. M. E. (2013). Does parental psychological control relate to internalizing problems in early childhood? An examination using the Berkeley puppet interview. International Journal of Behavioral Development, 37, 309-318. http://dx.doi.org/10.1177/0165025413490865

Swann, W. B. (1983). Self-verification: Bringing social reality into harmony with the self. In J. Suls \& A. G. Greenwald (Eds.), Social psychological perspectives on the self (pp. 3366). Hillsdale, NJ: Lawrence Erlbaum.

Swann, W. B. (1987). Identity negotiation: Where two roads meet. Journal of Personality and Social Psychology, 53, 1038-1051. http://dx.doi.org/10.1037/0022-3514.53.6.1038

Tabachnick, B. G., \& Fidell, L. S. (2013). Using multivariate statistics. New Jersey: Pearson.

Tokunaga, R. S., \& Rains, S. A. (2010). An evaluation of two characteristics of the relationships Between problematic internet use, time spent using the internet, and psychosocial problems. Human Communication Research, 36, 512-545. http://dx.doi.org/10.1111 /j.1468-2958.2010.01386.x 
Topham, G. L., Hubbs-Tait, L., Rutledge, J. M., Page, M. C., Kennedy, T. S., Shriver, L. H., \& Harrist, A. W. (2011). Parenting styles, parental response to child emotion, and family emotional responsiveness are related to child emotional eating. Appetite, 56, 261-264. http://dx.doi.org/10.1016/j.appet.2011.01.007

van der Ende, J., \& Verhulst, F. C. (2005). Informant, gender, and age differences in ratings of adolescent problem behavious. European Child and Adolescent Psychiatry, 14, 117-126. http://dx.doi.org/10.1007/s00787-005-0438-y

van der Vorst, H., Engels, R. C., Meeus, W., \& Dekovic, M. (2006). Parental attachment, parental control, and early development of alcohol use: A longitudinal study. Psychology of Addictive Behaviors, 20(2), 107-116. http://dx.doi.org/10.1037/0893-164X.20.2.107

van Strien, T., Frijters, J.E., Bergers, G.P., \& Defares, P.B. (1986). The Dutch Eating Behavior Questionnaire (DEBQ) for assessment of restrained, emotional, and external eating behavior. International Journal of Eating Disorders, 5, 295-315. http://dx.doi.org /10.1002/1098-108X(198602)5:2<295::AID-EAT2260050209>3.0.CO;2-T

Walton, A., \& Flouri, E. (2010). Contextual risk, maternal parenting, and adolescent externalizing behavior problems: The role of emotion regulation. Child Care, Health, and Development, 36(2), 275-284. http://dx.doi.org/10.1111/j.1365-2214.2009.01065.x

Zimmer-Gembeck, M. J., \& Collins, W. A. (2003). Autonomy development during adolescence. In G. R. Adama, \& M. D. Berzonsky (Eds.), Blackwell handbook of adolescence. Oxford, UK: Blackwell. 


\section{Table 1}

Categories of Adolescents' Beliefs about Parental Motivations for Using Psychological Control

Adolescents' Beliefs about Parental Motivations for Using Psychological Control

To keep the adolescent safe

Positive Beliefs

Because the parent views psychological control as normative

To control the adolescent's personal world

Negative Beliefs

To disrespect the adolescent

To compensate for the adolescent's lack of competence

Because the adolescent does not matter to the parent 
Table 2

Sample Demographics

\begin{tabular}{|c|c|}
\hline & $\mathrm{N}(\%) / M(S D)$ \\
\hline Age & $15.00(1.64)$ \\
\hline \multicolumn{2}{|l|}{ Gender Identity } \\
\hline Male & $171(42.1)$ \\
\hline Female & $234(57.6)$ \\
\hline Other & $1(<1)$ \\
\hline \multicolumn{2}{|l|}{ Ethnicity } \\
\hline African American/Black & $21(5.2)$ \\
\hline Hispanic/Latino & $6(1.5)$ \\
\hline Asian American/Pacific Islander & $8(2.0)$ \\
\hline Native American & $6(1.5)$ \\
\hline Caucasian/White & $348(85.7)$ \\
\hline Other & $17(4.2)$ \\
\hline \multicolumn{2}{|l|}{ Relation to Mother Figure } \\
\hline Biological Mother & $387(95.3)$ \\
\hline Adoptive Mother & $6(1.5)$ \\
\hline Grandmother & $5(1.2)$ \\
\hline Stepmother & $5(1.2)$ \\
\hline Another Female Mother Figure & $2(<1)$ \\
\hline No Mother Figure & $1(<1)$ \\
\hline \multicolumn{2}{|l|}{ Relation to Father Figure } \\
\hline Biological Father & $351(86.5)$ \\
\hline Adoptive Father & $9(2.2)$ \\
\hline Grandfather & $6(1.5)$ \\
\hline Stepfather & $20(4.9)$ \\
\hline Another Male Father Figure & $4(1.0)$ \\
\hline No Father Figure & $16(3.9)$ \\
\hline \multicolumn{2}{|l|}{ Mother Education Level } \\
\hline Did Not Attend School & $1(<1)$ \\
\hline Completed 8th Grade & $15(3.7)$ \\
\hline High School Graduate or Equivalent & $62(15.3)$ \\
\hline Some College & $53(13.1)$ \\
\hline 2-Year College Degree & $22(5.4)$ \\
\hline 4-Year College Degree & $129(31.8)$ \\
\hline Some Graduate School & $23(5.7)$ \\
\hline Graduate Degree & $53(13.1)$ \\
\hline Don’t Know or Unsure & $47(11.6)$ \\
\hline \multicolumn{2}{|l|}{ Father Education Level } \\
\hline Did Not Attend School & 0 \\
\hline Completed 8th Grade & $12(3.0)$ \\
\hline High School Graduate or Equivalent & $96(23.6)$ \\
\hline Some College & $34(8.4)$ \\
\hline
\end{tabular}


2-Year College Degree

4-Year College Degree

Some Graduate School

Graduate Degree

Don't Know or Unsure

Difficulty Paying Bills

None/Not at All

A Little

Some

A great deal

Parents' Relationship Status

Married

Together, but Not Married

Separated

Not Together, Never Married

Divorced

Grades in School

Mostly As

Some As and Some Bs

Mostly Bs

Some Bs and Some Cs

Mostly Cs

Some Cs and Some Ds

Mostly Ds or Lower
19 (4.7)

95 (23.4)

$21(5.2)$

$58(14.3)$

55 (13.5)

$228(56.2)$

$119(29.3)$

$46(11.3)$

$13(3.2)$

$264(65)$

$23(5.7)$

18 (4.4)

$33(8.1)$

$68(16.7)$

$177(43.6)$

165 (40.6)

12 (3.0)

38 (9.4)

6 (1.5)

7 (1.7)

$1(<1)$ 
Table 3

Tests of Independence with Survey Version and Demographic Characteristics

\begin{tabular}{lccc}
\hline & $\chi^{2}$ & $d f$ & $p$ value \\
\hline Survey version X Gender & 3.28 & 4 & .51 \\
Survey version X Ethnicity & 8.96 & 10 & .54 \\
Survey version X Mother education & 15.35 & 16 & .50 \\
Survey version X Father education & 8.45 & 14 & .87 \\
Survey version X Financial strain & 2.27 & 6 & .89 \\
Survey version X Parent relationship & 7.39 & 8 & .50 \\
Survey version X Grades & 9.51 & 12 & .66 \\
\hline & $F$ & $d f$ & $p$ value \\
\hline Age & .17 & $(2,403)$ & .85 \\
\hline
\end{tabular}


Table 4

Descriptive Statistics for Key Study Variables

\begin{tabular}{lcc}
\hline & Mean $(S D) / N(\%)$ & Range \\
\hline Age & $15.00(1.64)$ & $11-18$ \\
Female & $234(57.60)$ & -- \\
White & $348(85.70)$ & -- \\
Maternal BC & $2.13(.40)$ & $1-3$ \\
Paternal BC & $2.17(.43)$ & $1-3$ \\
Maternal Warmth & $3.32(.76)$ & $1-4$ \\
Paternal Warmth & $3.15(.85)$ & $1-4$ \\
Maternal PC & $2.12(.68)$ & $1-4.47$ \\
Paternal PC & $1.78(.69)$ & $1-4.78$ \\
Maternal Neg. Bel. & $41.05(18.54)$ & $2-95.5$ \\
Maternal Pos. Bel. & $30.44(15.00)$ & $2.5-74$ \\
Paternal Neg. Bel. & $30.80(19.66)$ & $1.5-93$ \\
Paternal Pos. Bel. & $23.64(16.77)$ & $2.5-70.75$ \\
Maternal Disapproval & $42.04(21.37)$ & $2-96$ \\
Paternal Disapproval & $32.31(22.27)$ & $2-101$ \\
Substance Use & $1.34(.58)$ & $1-5.76$ \\
Risky Cyber Behaviors & $1.26(.65)$ & $1-6$ \\
Over-eating & $2.29(.92)$ & $1-5$ \\
Under-eating & $1.98(1.01)$ & $1-5$ \\
Depressive Symptoms & $18.54(14.20)$ & $0-60$ \\
\hline Note. Some variable names &
\end{tabular}

Note. Some variable names have been shortened; $\mathrm{BC}=$ Behavioral Control; $\mathrm{PC}=$ Psychological Control; Neg. $=$ Negative; Pos. $=$ Positive; Bel. $=$ Beliefs 
Table 5

Correlations among Key Study Variables

\begin{tabular}{|c|c|c|c|c|c|c|c|c|c|c|c|c|c|c|c|c|c|c|c|c|c|c|}
\hline & 1 & 2 & 3 & 4 & 5 & 6 & 7 & 8 & 9 & 10 & 11 & 12 & 13 & 14 & 15 & 16 & 17 & 18 & 19 & 20 & 21 & 22 \\
\hline 1. Age & -- & & & & & & & & & & & & & & & & & & & & & \\
\hline 2. Gender & .01 & -- & & & & & & & & & & & & & & & & & & & & \\
\hline 3. Racial Minority & -.04 & .01 & -- & & & & & & & & & & & & & & & & & & & \\
\hline 4. Fin. Strain & $.15^{*}$ & .10 & -.05 & -- & & & & & & & & & & & & & & & & & & \\
\hline 5. Grades & $-.17^{* *}$ & $.12^{*}$ & .02 & $-.21^{* * *}$ & -- & & & & & & & & & & & & & & & & & \\
\hline 6. Mat. BC & -.10 & .01 & .08 & -.05 & .03 & -- & & & & & & & & & & & & & & & & \\
\hline 7. Pat. BC & $-.14^{* *}$ & .05 & .08 & -.03 & .03 & $.46^{* * *}$ & -- & & & & & & & & & & & & & & & \\
\hline 8. Mat. Warmth & $-.10^{*}$ & -.06 & .03 & $-.29 * * *$ & $.16^{* *}$ & $-.14 * *$ & .05 & -- & & & & & & & & & & & & & & \\
\hline 9. Pat. Warmth & $-.15^{* *}$ & $-.10^{*}$ & -.01 & $-.23 * * *$ & $.17^{* *}$ & .01 & $-.13^{*}$ & $.55^{* * *}$ & -- & & & & & & & & & & & & & \\
\hline 10. Mat. PC & .06 & .09 & -.07 & $.25 * * *$ & $-.15^{* *}$ & $.24 * * *$ & .06 & $-.57^{* * *}$ & $-.30 * * *$ & -- & & & & & & & & & & & & \\
\hline 11. Pat. PC & .03 & .03 & -.01 & $.17^{* *}$ & $-.18^{* * *}$ & $.10^{*}$ & $-.32^{* * *}$ & $-.20^{* * *}$ & $-.33^{* * *}$ & $.58^{* * *}$ & -- & & & & & & & & & & & \\
\hline 12. Mat. Neg. Bel. & .01 & .03 & $-.12^{*}$ & $.18^{* * *}$ & $-.20^{* * *}$ & $.21 * * *$ & .10 & $-.50^{* * *}$ & $-.29 * * *$ & $.89 * * *$ & $.58^{* * *}$ & -- & & & & & & & & & & \\
\hline 13. Mat. Pos. Bel. & .01 & .02 & -.01 & .03 & -.05 & $.14^{* *}$ & $.16^{* *}$ & $-.21^{* * *}$ & $-.15^{* *}$ & $.67^{* * *}$ & $.52^{* * *}$ & $.65^{* * *}$ & -- & & & & & & & & & \\
\hline 14. Pat. Neg. Bel. & .04 & -.01 & -.05 & $.14^{* *}$ & $-.22^{* * *}$ & .10 & $.26 * * *$ & $-.20^{* * *}$ & $-.32^{* * *}$ & $.52^{* * *}$ & $.91^{* * *}$ & $.64^{* * *}$ & $.46^{* * *}$ & -- & & & & & & & & \\
\hline 15. Pat. Pos. Bel. & -.01 & -.05 & -.02 & .02 & -.08 & .10 & $.22 * * *$ & -.05 & -.04 & $.41^{* * *}$ & $.70^{* * *}$ & $.44^{* * *}$ & $.67^{* * *}$ & $.75^{* * *}$ & -- & & & & & & & \\
\hline 16. Mat. Disap. & .04 & .06 & -.06 & $.18^{* * *}$ & $-.16^{* *}$ & $.23 * * *$ & $.11^{*}$ & $-.51^{* * *}$ & $-.31 * * *$ & $.89 * * *$ & $.55^{* * *}$ & $.93 * * *$ & $.77^{* * *}$ & $.57^{* * *}$ & $.47^{* * *}$ & -- & & & & & & \\
\hline 17. Pat. Disap. & .05 & .01 & -.02 & $.15^{* *}$ & $-.19 * * *$ & .06 & $.30^{* * *}$ & $-.19 * *$ & $-.34^{* * *}$ & $.50 * * *$ & $.89 * * *$ & $.60^{* * *}$ & $.54^{* * *}$ & $.96 * * *$ & $.82^{* * *}$ & $.61^{* * *}$ & -- & & & & & \\
\hline 18. Substance Use & $.26 * * *$ & .01 & .01 & .03 & $-.33^{* * *}$ & -.09 & $-.15^{* *}$ & $-.27^{* * *}$ & $-.29 * * *$ & $.21 * * *$ & $.10^{*}$ & $.19 * * *$ & .08 & $.17^{* *}$ & .08 & $.18^{* * *}$ & $.14^{* *}$ & -- & & & & \\
\hline 19. Risky Cyber & .07 & -.03 & -.05 & .01 & $-.19 * * *$ & -.01 & $-.11^{*}$ & $-.18^{* * *}$ & $-.14^{* *}$ & $.17^{* *}$ & .07 & $.15^{* *}$ & .07 & .08 & -.01 & $.14^{* *}$ & .06 & $.51 * * *$ & -- & & & \\
\hline 20. Over-eating & .06 & $.23^{* * *}$ & .01 & $.17^{* *}$ & .03 & -.02 & -.03 & $-.19 * * *$ & $-.20^{* * *}$ & $.25 * * *$ & $.17^{* *}$ & $.18^{* * *}$ & $.11^{*}$ & .08 & -.01 & $.19^{* * *}$ & .07 & .08 & $.16^{* *}$ & -- & & \\
\hline 21. Under-eating & .02 & $.26 * * *$ & -.06 & $.14^{* *}$ & -.05 & $.15^{* *}$ & .02 & $-.20^{* * *}$ & $-.12^{*}$ & $.27 * * *$ & $.14^{* *}$ & $.23 * * *$ & $.14^{* *}$ & .10 & .07 & $.22^{* * *}$ & .08 & $.11^{*}$ & $.11^{*}$ & $.40^{* * *}$ & -- & \\
\hline 22. Dep. Symp. & .09 & $.26 * * *$ & -.06 & $.28^{* * *}$ & $-.24 * * *$ & .07 & .01 & $-.36^{* * *}$ & $-.32^{* * *}$ & $.37^{* * *}$ & $.24 * * *$ & $.34^{* * *}$ & $.11^{*}$ & $.20 * * *$ & .02 & $.33^{* * *}$ & $.19 * *$ & $.23 * * *$ & $.26 * * *$ & $.36 * * *$ & $.34 * * *$ & -- \\
\hline
\end{tabular}

Note. Some variable names have been shortened; Fin. = Financial; Mat. = Maternal; Pat. = Paternal; PC = Psychological Control; Neg. = Negative; Pos. $=$ Positive; Bel. $=$ Beliefs; Disap. = Disapproval; Dep. = Depressive; Symp. $=$ Symptoms

$* p<.05 ; * * p<.01 ; * * * p<.001$ 
Table 6

Differences in Key Study Variables by Maternal Education

\begin{tabular}{|c|c|c|c|c|c|c|c|c|c|c|}
\hline & $\begin{array}{c}\text { No } \\
\text { School }\end{array}$ & 8th Grade & $\begin{array}{c}\text { High School } \\
\text { Grad. }\end{array}$ & $\begin{array}{c}\text { Some } \\
\text { College }\end{array}$ & $\begin{array}{l}\text { 2-Year Coll. } \\
\text { Deg. }\end{array}$ & $\begin{array}{l}\text { 4-Year Coll. } \\
\text { Deg. }\end{array}$ & $\begin{array}{l}\text { Some Grad. } \\
\text { School }\end{array}$ & $\begin{array}{c}\text { Grad. } \\
\text { Degree }\end{array}$ & Unsure & F test \\
\hline Maternal PC & 1.53 & $2.24(.86)$ & $2.15(.67)$ & $2.17(.69)$ & $2.44(.84)$ & $2.13(.70)$ & $1.94(.47)$ & $1.97(.63)$ & $2.06(.61)$ & $F(8,396)=1.41, p=.19$ \\
\hline Paternal PC & -- & $1.82(.69)$ & $1.82(.77)$ & $1.79(.78)$ & $1.85(.82)$ & $1.80(.68)$ & $1.69(.59)$ & $1.65(.59)$ & $1.82(.64)$ & $F(7,382)=.41, p=.90$ \\
\hline Mat. Neg. Bel. & 16.00 & $30.25(15.19)$ & $31.45(14.12)$ & $32.41(17.39)$ & $34.95(15.78)$ & $31.16(14.45)$ & $27.25(13.13)$ & $25.04(12.81)$ & $30.76(16.61)$ & $F(8,389)=1.54, p=.14$ \\
\hline Mat. Pos. Bel. & 31.00 & $36.90(17.49)$ & $40.98(18.24)$ & $38.54(16.49)$ & $45.00(19.55)$ & $43.81(18.89)$ & $42.02(20.78)$ & $37.58(18.37)$ & $39.78(19.09)$ & $F(8,389)=.98, p=.45$ \\
\hline Pat. Neg. Bel. & -- & $22.20(14.94)$ & $24.12(16.66)$ & $23.28(18.72)$ & $27.26(19.49)$ & $24.10(16.99)$ & $26.26(15.90)$ & $18.12(14.13)$ & $27.33(16.16)$ & $F(7,348)=1.27, p=.27$ \\
\hline Pat. Pos. Bel. & -- & $25.36(15.74)$ & $29.46(18.22)$ & $27.18(17.49)$ & $32.97(21.68)$ & $31.73(21.28)$ & $38.47(22.29)$ & $26.55(18.05)$ & $36.51(18.63)$ & $F(7,348)=1.71, p=.11$ \\
\hline Mat. Disap. & 26.00 & $43.60(23.00)$ & $44.41(21.30)$ & $42.25(22.19)$ & $46.72(22.52)$ & $43.50(20.52)$ & $40.78(22.20)$ & $35.40(20.80)$ & $40.51(21.78)$ & $F(8,389)=1.05, p=.40$ \\
\hline Pat. Disap. & -- & $32.29(21.37)$ & & $29.56(23.12)$ & $25.83(24.42)$ & $32.81(23.09)$ & $39.33(24.31)$ & $24.96(20.19)$ & $36.27(19.40)$ & $F(7,348)=1.42, p=.20$ \\
\hline Substance Use & 1.06 & $1.41(.53)$ & $1.43(.76)$ & $1.34(.67)$ & $1.45(.54)$ & $1.31(.52)$ & $1.32(.50)$ & $1.35(.54)$ & $1.18(.37)$ & $F(8,396)=.89, p=.53$ \\
\hline Risky Cyber & 1.45 & $1.48(1.14)$ & $1.42(.87)$ & $1.25(.63)$ & $1.36(.54)$ & $1.20(.57)$ & $1.12(.19)$ & $1.24(.45)$ & $1.21(.74)$ & $F(8,396)=1.08, p=.38$ \\
\hline Over-eating & 1.96 & $2.15(1.05)$ & $2.54(.99)$ & $2.29(.87)$ & $2.39(.90)$ & $2.24(.89)$ & $2.40(.94)$ & $2.42(.95)$ & $1.92(.80)$ & $F(8,396)=1.84, p=.07$ \\
\hline Under-eating & 1.80 & $2.14(1.37)$ & $2.07(1.07)$ & $1.95(.86)$ & $2.39(1.15)$ & $1.87(.99)$ & $1.90(.65)$ & $2.09(1.18)$ & $1.79(.82)$ & $F(8,395)=1.04, p=.40$ \\
\hline Dep. Symp. & 10.00 & $22.53(18.11)$ & $23.65(14.59)$ & $19.94(14.06)$ & $21.14(15.13)$ & $18.24(14.87)$ & $14.43(11.95)$ & $14.17(10.31)$ & $14.57(11.55)$ & $F(8,394)=2.77, p=.01$ \\
\hline
\end{tabular}

Note. Some variable names have been shortened; PC = Psychological Control; Mat. = Maternal; Pat. = Paternal; Neg. = Negative; Pos. = Positive;

Bel. = Beliefs; Disap. = Disapproval; Dep. = Depressive; Symp. = Symptoms; Grad. $=$ Graduate; Coll. $=$ College

$* p<.05 ; * * p<.01 ; * * * p<.001$ 
Table 7

Differences in Key Study Variables by Paternal Education

\begin{tabular}{|c|c|c|c|c|c|c|c|c|c|c|}
\hline & $\begin{array}{c}\text { No } \\
\text { School }\end{array}$ & 8th Grade & $\begin{array}{c}\text { High School } \\
\text { Grad. }\end{array}$ & $\begin{array}{c}\text { Some } \\
\text { College }\end{array}$ & $\begin{array}{c}\text { 2-Year Coll. } \\
\text { Deg. }\end{array}$ & $\begin{array}{c}\text { 4-Year Coll. } \\
\text { Deg. }\end{array}$ & $\begin{array}{l}\text { Some Grad. } \\
\text { School }\end{array}$ & $\begin{array}{c}\text { Grad. } \\
\text { Degree }\end{array}$ & Unsure & F test \\
\hline Maternal PC & -- & $2.34(.88)$ & $2.25(.69)$ & $2.02(.60)$ & $2.23(.66)$ & $2.05(.71)$ & $2.07(.59)$ & $1.99(.65)$ & $2.11(.68)$ & $F(7,382)=1.36, p=.22$ \\
\hline Paternal PC & -- & $2.09(1.01)$ & $1.83(.69)$ & $1.68(.73)$ & $2.06(.84)$ & $1.72(.65)$ & $1.66(.59)$ & $1.74(.64)$ & $1.81(.70)$ & $F(7,382)=1.22, p=.29$ \\
\hline Mat. Neg. Bel. & -- & $29.88(15.04)$ & $33.68(14.88)$ & $28.36(14.42)$ & $34.55(14.30)$ & $28.34(14.90)$ & $28.68(13.41)$ & $27.90(14.69)$ & $31.75(16.21)$ & $F(7,375)=1.54, p=.15$ \\
\hline Mat. Pos. Bel. & -- & $37.33(15.21)$ & $42.94(18.65)$ & $36.57(17.23)$ & $48.61(15.91)$ & $39.57(19.28)$ & $39.07(21.41)$ & $41.88(18.18)$ & $41.85(18.87)$ & $F(7,375)=1.09, p=.37$ \\
\hline Pat. Neg. Bel. & -- & $26.42(19.09)$ & $25.31(17.48)$ & $21.69(17.83)$ & $31.45(20.03)$ & $20.84(14.77)$ & $19.89(14.16)$ & $21.78(15.88)$ & $27.19(17.19)$ & $F(7,348)=1.72, p=.10$ \\
\hline Pat. Pos. Bel. & -- & $28.54(16.22)$ & $32.79(22.06)$ & $25.05(16.93)$ & $39.34(17.91)$ & $28.64(18.74)$ & $28.74(26.02)$ & $31.72(18.52)$ & $31.38(17.30)$ & $F(7,348)=1.23, p=.29$ \\
\hline Mat. Disap. & -- & $43.67(22.63)$ & $46.55(20.80)$ & $36.88(19.26)$ & $47.16(20.87)$ & $39.08(21.78)$ & $38.81(20.41)$ & $40.55(21.75)$ & $43.37(22.31)$ & $F(7,375)=1.46, p=.18$ \\
\hline Pat. Disap. & -- & & & $26.28(17.73)$ & $43.74(26.86)$ & & $27.05(21.58)$ & & $35.90(21.32)$ & $F(7,348)=1.95, p=.06$ \\
\hline Substance Use & -- & $1.33(.47)$ & $1.51(.73)$ & $1.51(.72)$ & $1.21(.41)$ & $1.28(.48)$ & $1.30(.36)$ & $1.15(.30)$ & $1.28(.62)$ & $F(7,382)=3.07, p=.01$ \\
\hline Risky Cyber & -- & $1.20(.26)$ & $1.28(.64)$ & $1.38(.68)$ & $1.14(.27)$ & $1.34(.82)$ & $1.09(.17)$ & $1.13(.25)$ & $1.27(.87)$ & $F(7,382)=1.01, p=.42$ \\
\hline Over-eating & -- & $2.27(1.26)$ & $2.36(.97)$ & $2.48(1.05)$ & $2.13(.85)$ & $2.26(.90)$ & $2.43(.93)$ & $2.24(.85)$ & $2.22(.85)$ & $F(7,381)=.52, p=.82$ \\
\hline Under-eating & -- & $2.53(1.39)$ & $1.99(.93)$ & $2.00(1.02)$ & $1.60(.75)$ & $1.89(1.03)$ & $1.98(1.01)$ & $2.04(1.11)$ & $1.89(.94)$ & $F(7,381)=1.09, p=.37$ \\
\hline Dep. Symp. & -- & $27.33(13.67)$ & $20.32(13.67)$ & $1.47(14.79)$ & $16.74(14.40)$ & $19.01(15.21)$ & $16.52(13.03)$ & $13.05(10.98)$ & $19.20(14.36)$ & $F(7,380)=2.28, p=.03$ \\
\hline
\end{tabular}

Note. Some variable names have been shortened; PC = Psychological Control; Mat. = Maternal; Pat. = Paternal; Neg. = Negative; Pos. = Positive;

Bel. = Beliefs; Disap. = Disapproval; Dep. = Depressive; Symp. = Symptoms; Grad. = Graduate; Coll. $=$ College

$* p<.05 ; * * p<.01 ; * * * p<.001$ 
Table 8

Differences in Key Study Variables by Parent Relationship Status

\begin{tabular}{|c|c|c|c|c|c|c|}
\hline & & Together, but Not & & Not Together, Never & & \\
\hline & Married & Married & Separated & Married & Divorced & F test \\
\hline Maternal PC & $2.05(.65)$ & $2.22(.65)$ & $2.19(.75)$ & $2.41(.85)$ & $2.19(.69)$ & $F(4,400)=2.61, p=.04$ \\
\hline Paternal PC & $1.77(.68)$ & $1.83(.68)$ & $1.63(.53)$ & $1.67(.73)$ & $1.92(.77)$ & $F(4,385)=1.10, p=.36$ \\
\hline Mat. Neg. Bel. & $29.04(14.35)$ & $35.47(17.90)$ & $30.03(14.30)$ & $35.45(15.63)$ & $31.80(15.76)$ & $F(4,393)=2.26, p=.06$ \\
\hline Mat. Pos. Bel. & $41.15(19.37)$ & $37.43(16.20)$ & $38.94(19.10)$ & $44.23(16.45)$ & $40.96(16.97)$ & $F(4,393)=.51, p=.73$ \\
\hline Pat. Neg. Bel. & $23.23(16.52)$ & $28.71(18.16)$ & $19.54(11.41)$ & $19.09(15.58)$ & $27.52(18.50)$ & $F(4,351)=1.92, p=.11$ \\
\hline Pat. Pos. Bel. & $31.89(19.71)$ & $31.83(20.49)$ & $23.29(18.61)$ & $23.94(19.08)$ & $30.98(19.35)$ & $F(4,351)=1.56, p=.19$ \\
\hline Mat. Disap. & $41.41(20.91)$ & $45.39(23.06)$ & $42.11(19.80)$ & $51.22(22.74)$ & $42.78(21.59)$ & $F(4,393)=2.03, p=.09$ \\
\hline Pat. Disap. & $31.62(21.95)$ & 38.67 (22.99) & $27.71(17.99)$ & $25.29(20.83)$ & $37.56(24.18)$ & $F(4,351)=2.02, p=.09$ \\
\hline Substance Use & $1.29(.55)$ & $1.68(.92)$ & $1.25(.51)$ & $1.35(.47)$ & $1.44(.58)$ & $F(4,401)=3.36, p=.01$ \\
\hline Risky Cyber & $1.20(.55)$ & $1.63(1.17)$ & $1.49(1.16)$ & $1.27(.40)$ & $1.31(.66)$ & $F(4,401)=3.15, p=.01$ \\
\hline Over-eating & $2.21(.87)$ & $2.67(1.07)$ & $2.14(1.23)$ & $2.59(.79)$ & $2.37(.98)$ & $F(4,400)=2.72, p=.03$ \\
\hline Under-eating & $1.91(.97)$ & $2.16(.85)$ & $1.83(1.01)$ & $2.18(1.11)$ & $2.14(1.14)$ & $F(4,400)=1.35, p=.25$ \\
\hline Dep. Symp. & $16.14(13.45)$ & $25.00(15.43)$ & $21.72(15.54)$ & $23.30(13.04)$ & $22.57(14.85)$ & $F(4,399)=5.85, p<.001$ \\
\hline
\end{tabular}

Note. Some variable names have been shortened; PC = Psychological Control; Mat. = Maternal; Pat. = Paternal; Neg. = Negative; Pos.

$=$ Positive; Bel. $=$ Beliefs; Disap. $=$ Disapproval; Dep. $=$ Depressive Symp. $=$ Symptoms

$* p<.05 ; * * p<.01 ; * * * p<.001$ 
Table 9

Differences in Adolescents' Beliefs about Parents' Motivations for Using Psychological Control

\begin{tabular}{|c|c|c|c|c|c|c|c|c|}
\hline & Control & Disrespect & Compensate & Matter & Safe & Normal & $\begin{array}{l}\text { Main } \\
\text { Effect }\end{array}$ & $\eta 2$ \\
\hline Maternal PC & $38.60(20.31)^{\mathrm{a}}$ & $27.30(16.23)^{\mathrm{b}}$ & $33.95(17.13)^{\mathrm{c}}$ & $21.89(17.26)^{d}$ & $43.98(21.68)^{\mathrm{e}}$ & $38.12(17.23)^{f}$ & $60.07 * * *$ & .43 \\
\hline Paternal PC & $30.29(21.09)^{\mathrm{a}}$ & $21.23(17.40)^{\mathrm{b}}$ & $26.12(18.34)^{\mathrm{c}}$ & $17.33(17.84)^{\mathrm{d}}$ & $33.13(22.76)^{\mathrm{e}}$ & $28.46(17.99)^{\mathrm{a}}$ & $35.81 * * *$ & .34 \\
\hline
\end{tabular}

Note. Some variable names have been shortened; PC = Psychological Control; Control = To control the adolescent's personal world; Disrespect $=$ To disrespect the adolescent; Compensate $=$ To compensate for the adolescent's lack of competence; Matter $=$ Because the adolescent does not matter to the parent; Safe $=$ To keep the adolescent safe. Means with different superscripts significantly differ at Bonferroni-adjusted $p$ values. $* * * p<.001$ 
Table 10

Latent Means, Standard Deviations, and Standardized Factor Loadings of Indicator Variables of Psychological Control

\begin{tabular}{lcc}
\hline & Maternal PC & \multicolumn{2}{c}{ Paternal PC } \\
\hline Indicators & \multicolumn{2}{c}{ Factor Loadings } \\
\cline { 2 - 3 } Barber & .88 & .88 \\
Olsen et al. & .72 & .75 \\
Hart and Robinson & .81 & .82 \\
\hline
\end{tabular}


Table 11

Measurement Invariance Tests for Maternal and Paternal Psychological Control across Adolescents with Low Versus High Disapproval

\begin{tabular}{lcccc}
\hline \multicolumn{4}{c}{ Psychological Control } \\
\cline { 2 - 4 } & $\chi^{2}$ & $\mathrm{df}$ & $\mathrm{CFI}$ & $\Delta \mathrm{CFI}$ \\
\hline By Maternal Disapproval & & & & \\
Configural & 20.73 & 14 & .991 & \\
Factorial Invariance & 76.09 & 20 & .985 & .006 \\
Intercept Invariance & 93.11 & 23 & .982 & .003 \\
By Paternal Disapproval & & & & \\
Configural & 12.61 & 14 & .990 & \\
Factorial Invariance & 76.73 & 20 & .984 & .001 \\
Intercept Invariance & 91.22 & 23 & .982 & .002 \\
\hline
\end{tabular}


Table 12

Unstandardized Estimates and Standard Errors of Structural Model Testing Associations among Psychological Control and Problematic Outcomes

\begin{tabular}{|c|c|c|c|c|c|c|c|c|c|c|}
\hline & \multicolumn{2}{|c|}{ Substance Use } & \multicolumn{2}{|c|}{ Risky Cyber Beh. } & \multicolumn{2}{|c|}{ Over-eating Beh. } & \multicolumn{2}{|c|}{ Under-eating Beh. } & \multicolumn{2}{|c|}{ Dep. Symp. } \\
\hline & $B$ & $S E$ & $B$ & $S E$ & $B$ & $S E$ & $B$ & $S E$ & $B$ & $S E$ \\
\hline \multicolumn{11}{|l|}{ Covariates } \\
\hline Age & $.08 * * *$ & .02 & .02 & .02 & .01 & .03 & -.01 & .03 & .21 & .38 \\
\hline Gender (female) & -.02 & .05 & -.08 & .06 & $.39 * * *$ & .09 & $.46 * * *$ & .10 & $.58 * * *$ & .24 \\
\hline Financial strain & $-.07 *$ & .04 & -.06 & .04 & .09 & .06 & .07 & .06 & $.25 * *$ & .81 \\
\hline Maternal warmth & -.07 & .06 & -.05 & .07 & .02 & .09 & -.03 & .10 & -.04 & .33 \\
\hline Paternal warmth & $-.13 * *$ & .04 & -.08 & .05 & -.09 & .07 & -.01 & .08 & $-.34 *$ & .98 \\
\hline Maternal BC & -.06 & .06 & -.01 & .06 & -.02 & .06 & $.16^{* * *}$ & .06 & .07 & .06 \\
\hline Paternal BC & $-.14 *$ & .06 & -.07 & .06 & -.07 & .06 & $-.13 *$ & .06 & -.10 & .06 \\
\hline Maternal PC & .08 & .05 & .10 & .06 & $.20 *$ & .08 & $.25 * *$ & .09 & $.30 * *$ & .16 \\
\hline Paternal PC & -.03 & .04 & -.04 & .05 & -.01 & .07 & .10 & .07 & .10 & .97 \\
\hline
\end{tabular}

Note. Some variable names have been shortened $\mathrm{BC}=$ Behavioral Control; $\mathrm{PC}=$ Psychological Control; $* * * \mathrm{p}<.001, * * \mathrm{p}<.01$, $* \mathrm{p}<.05$ 


\section{Table 13}

Unstandardized Estimates and Standard Errors for Psychological Control (PC) X Negative Beliefs and PC X Positive Beliefs Interactions Predicting Problematic Outcomes

\begin{tabular}{|c|c|c|c|c|c|c|c|c|c|c|}
\hline & \multicolumn{2}{|c|}{ Substance Use } & \multicolumn{2}{|c|}{ Risky Cyber } & \multicolumn{2}{|c|}{ Over-eating } & \multicolumn{2}{|c|}{ Under-eating } & \multicolumn{2}{|c|}{ Dep. Symp. } \\
\hline & $B$ & $S E$ & $B$ & $S E$ & $B$ & $S E$ & $B$ & $S E$ & $B$ & $S E$ \\
\hline Maternal Neg. Bel. & .28 & .13 & .10 & .11 & -.13 & .09 & -.02 & .11 & $.29 *$ & .12 \\
\hline Maternal Pos. Bel. & -.10 & .06 & -.07 & .06 & -.09 & .06 & -.02 & .08 & $-.21 * *$ & .07 \\
\hline Paternal Neg. Bel. & -.09 & .09 & -.13 & .10 & $.19 *$ & .08 & -.06 & .10 & $.29 *$ & .10 \\
\hline Paternal Pos. Bel. & $-.29 *$ & .15 & .27 & .15 & -.11 & .11 & -.05 & .14 & .25 & .15 \\
\hline Mat. PC X Neg. Bel. & -.04 & .09 & -.10 & .09 & $-.10 *$ & .05 & -.01 & .06 & -.07 & .07 \\
\hline Mat. PC X Pos. Bel. & $.18 *$ & .08 & .02 & .05 & .01 & .07 & .01 & .07 & .11 & .07 \\
\hline Pat. PC X Neg. Bel. & -.07 & .07 & -.03 & .07 & $-.14 *$ & .07 & -.12 & .09 & $-.15 *$ & .07 \\
\hline Pat. PC X Pos. Bel. & $.15 *$ & .07 & -.01 & .07 & .08 & .08 & $.24 *$ & .10 & .17 & .09 \\
\hline
\end{tabular}

Note. Some variable names have been shortened; Mat. = Maternal; Pat. = Paternal; Neg. = Negative; Pos. = Positive; $* * * p<.001$, $* * \mathrm{p}<.01, * \mathrm{p}<.05$ 
Table 14

Unstandardized Estimates and Standard Errors for Psychological Control (PC) X Disapproval Interactions Predicting Problematic Outcomes

\begin{tabular}{|c|c|c|c|c|c|c|c|c|c|c|}
\hline & \multicolumn{2}{|c|}{ Substance Use } & \multicolumn{2}{|c|}{ Risky Cyber } & \multicolumn{2}{|c|}{ Over-eating } & \multicolumn{2}{|c|}{ Under-eating } & \multicolumn{2}{|c|}{ Dep. Symp. } \\
\hline & $B$ & $S E$ & $B$ & $S E$ & $B$ & $S E$ & $B$ & $S E$ & $B$ & $S E$ \\
\hline Maternal Disapproval & .09 & .10 & .02 & .09 & -.12 & .09 & -.09 & .09 & .10 & .10 \\
\hline Paternal Disapproval & -.15 & .14 & -.20 & .12 & $.45 * * *$ & .05 & $.40 * * *$ & .07 & $.32 * * *$ & .09 \\
\hline Mat. PC X Disapproval & .07 & .05 & -.02 & .03 & -.02 & .04 & .03 & .05 & $.10 *$ & .05 \\
\hline Pat. PC X Disapproval & -.05 & .08 & .04 & .06 & .10 & .08 & .07 & .08 & .07 & .08 \\
\hline
\end{tabular}

Note. Some variable names have been shortened; Mat. = Maternal; Pat. = Paternal; $* * * \mathrm{p}<.001, * * \mathrm{p}<.01, * \mathrm{p}<.0$ 
Table 15

Model Comparisons Testing Three-Way Interactions: Psychological Control X Beliefs X Disapproval

\begin{tabular}{|c|c|c|c|c|}
\hline & $\begin{array}{c}\text { Loglikelihood } \\
\text { Value }\end{array}$ & df & $\begin{array}{l}\text { Scaling } \\
\text { Correction }\end{array}$ & $\Delta \chi^{2}(\mathrm{df})$ \\
\hline \multicolumn{5}{|c|}{ Maternal PC X Beliefs X Maternal Disapproval } \\
\hline Constrained & -7560.306 & 114 & 1.6252 & \\
\hline Unconstrained & -7482.765 & 159 & 1.5109 & $\Delta \chi^{2}(45)=126.98, p<.001$ \\
\hline \multicolumn{5}{|c|}{ Paternal PC X Beliefs X Paternal Disapproval } \\
\hline Constrained & -6833.679 & 114 & 1.5424 & \\
\hline Unconstrained & -6756.403 & 159 & 1.4769 & $\Delta \chi^{2}(45)=117.89, p<.05$ \\
\hline
\end{tabular}

Note. Some variable names have been shortened; PC = Psychological Control 


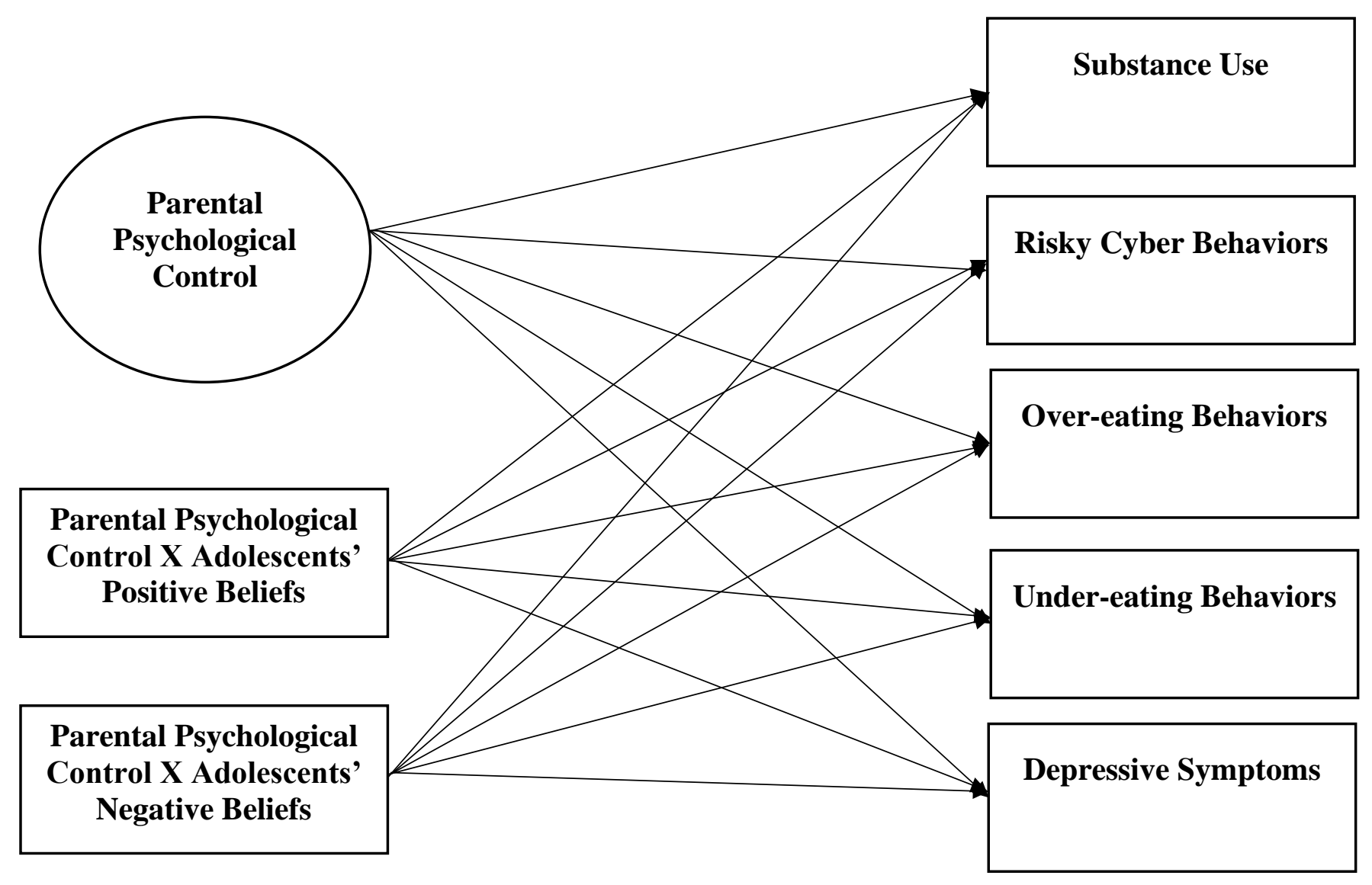

Figure 1. Conceptual model examining interactions between maternal/paternal psychological control and positive/negative beliefs about parental motivations for using psychological control as predictors of problematic outcomes. 


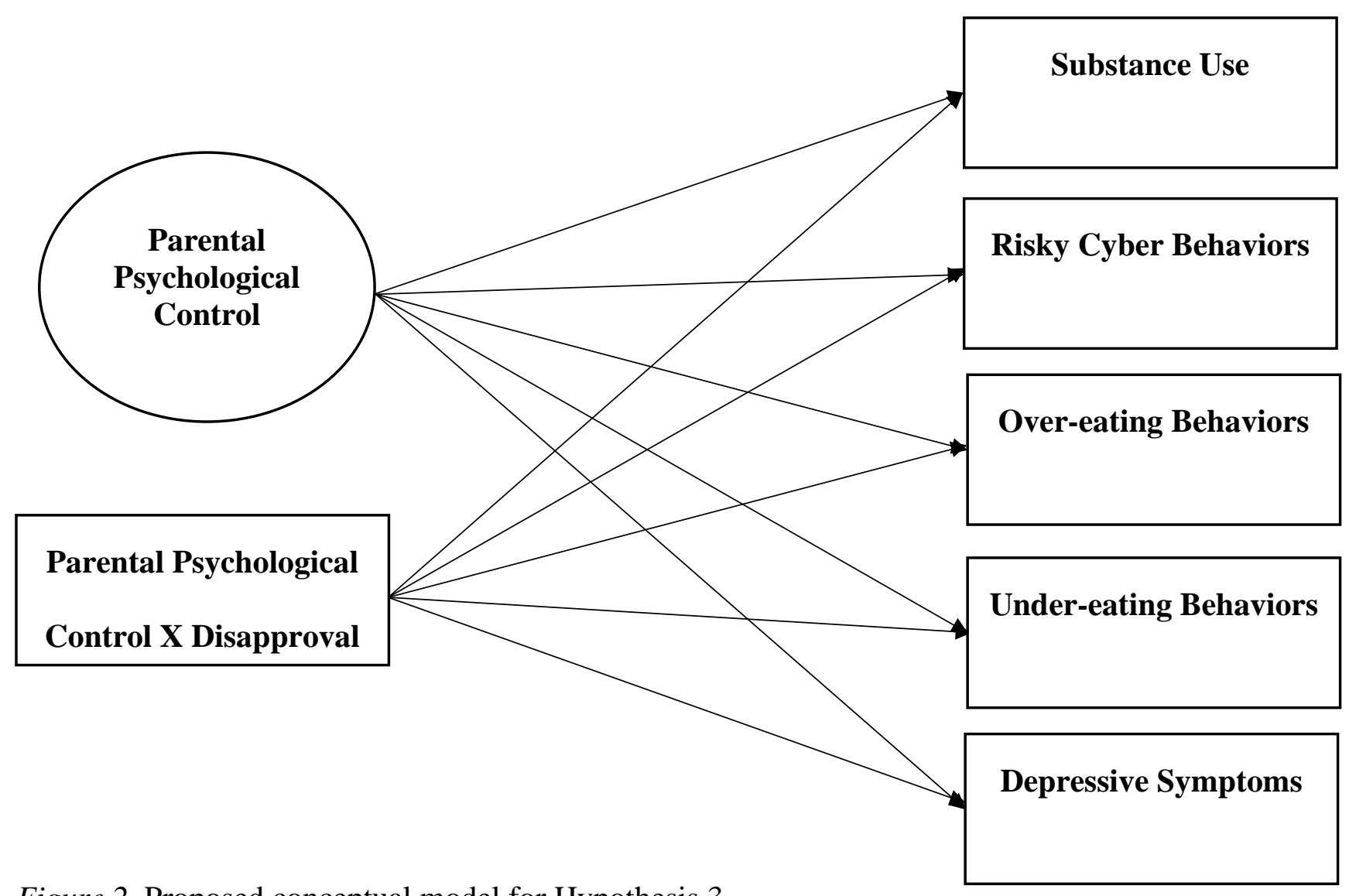

Figure 2. Proposed conceptual model for Hypothesis 3. 


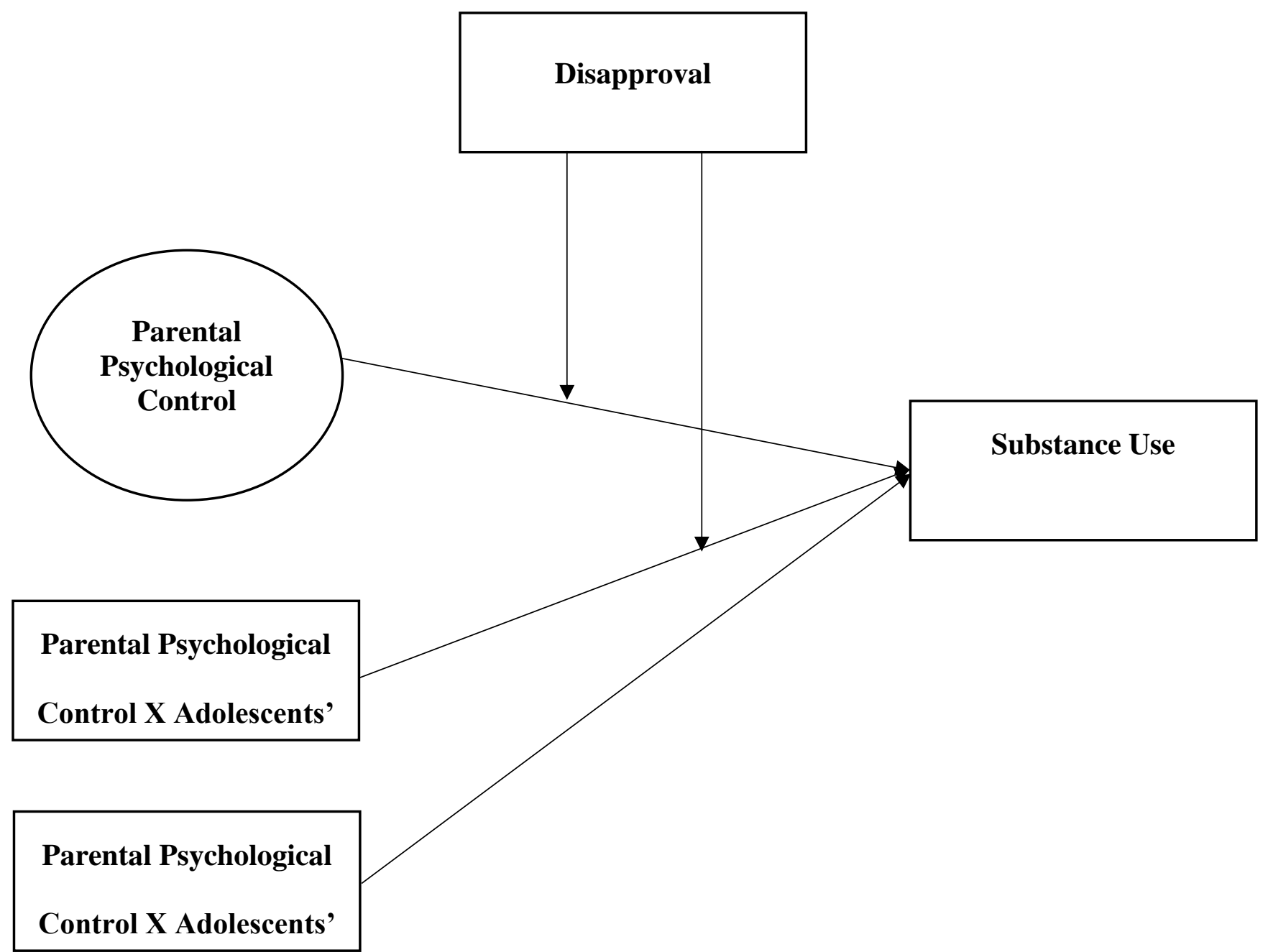

Figure 3. Proposed conceptual model for Hypothesis 4. 

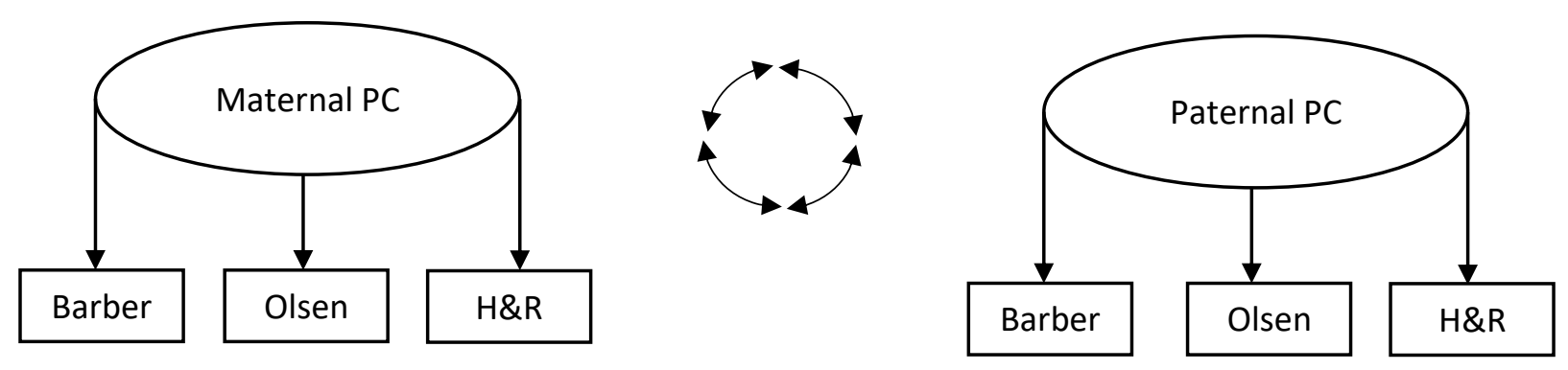

Figure 4. Measurement model for psychological control.

Note. Some variable names have been shortened; PC = Psychological control; Olsen = Olsen et al.; H\&R = Hart and Robinson. 

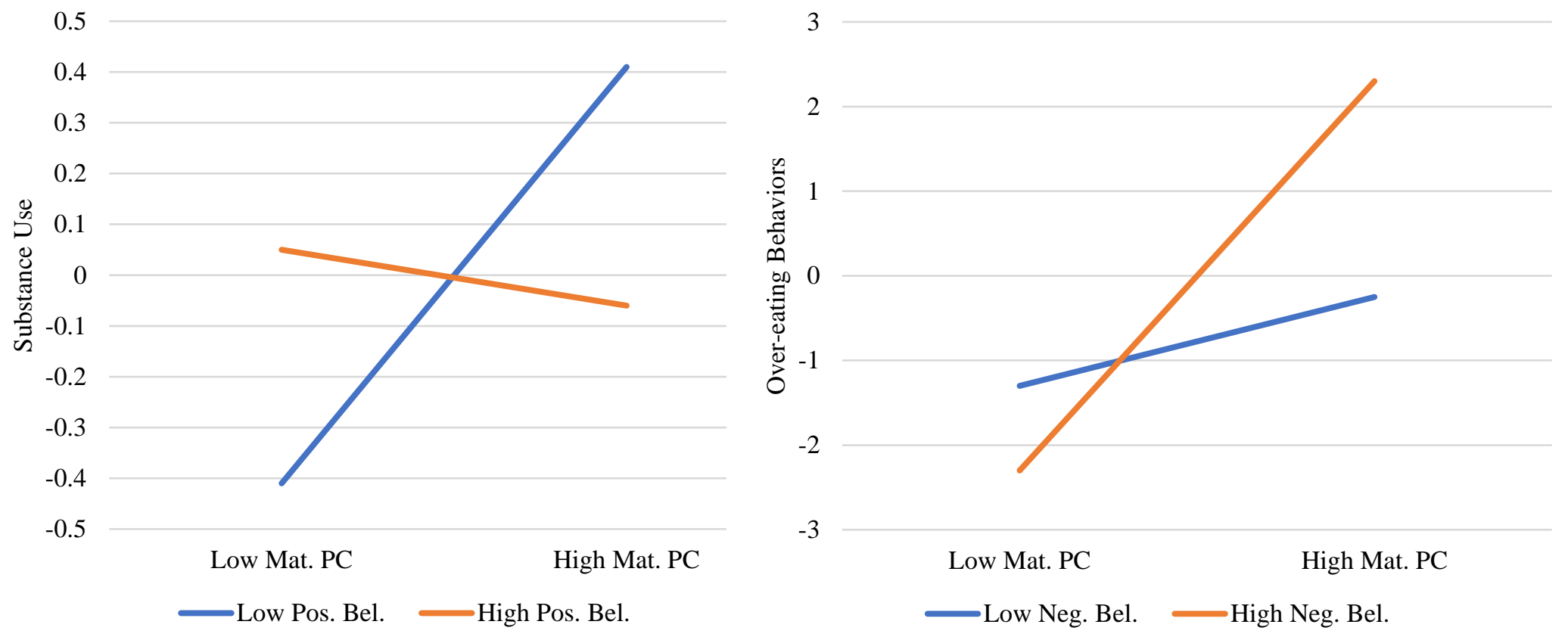

Figure 5. Maternal psychological control by adolescents' positive beliefs about maternal psychological control interaction effects on substance use (left) and maternal psychological control by adolescents' negative beliefs about maternal psychological control interaction effects on over-eating (right). 
0.6

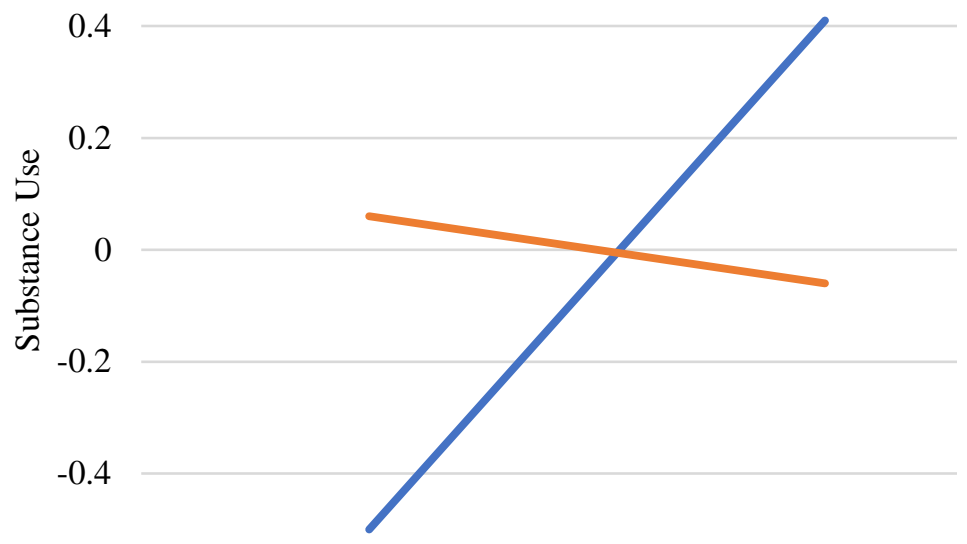

$-0.6$

Low Pat. PC

Pos. Bel.

\section{5}

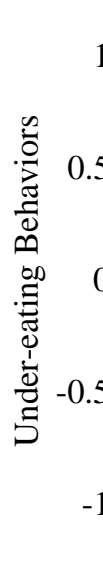

$-1.5$

Low Pat. PC High Pat. PC

Figure 6. Paternal psychological control by adolescents' positive beliefs about paternal psychological control interaction effects on substance use (left) and under-eating (right). 
1.5

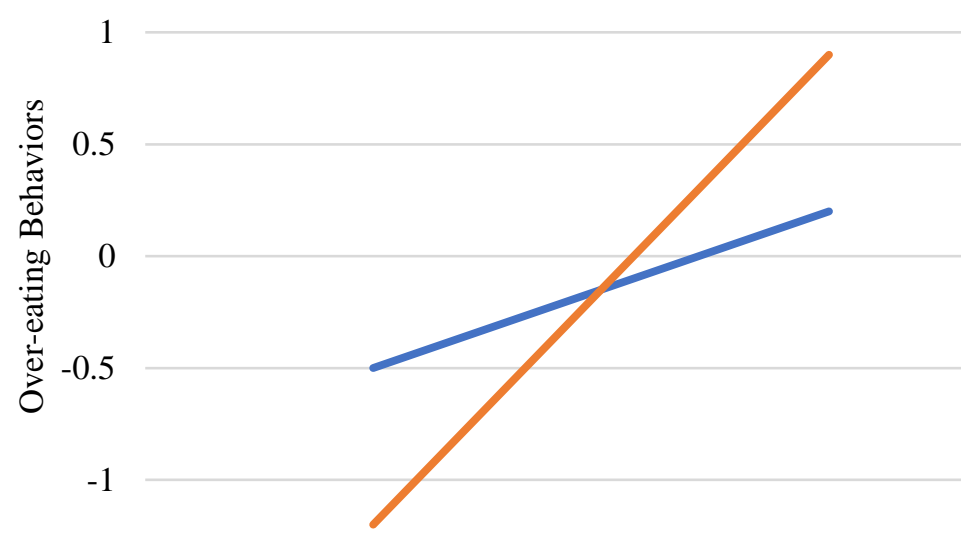

$-1.5$ Low Pat. PC High Pat. PC

Low Neg. Bel. $\quad$ High Neg. Bel.
15

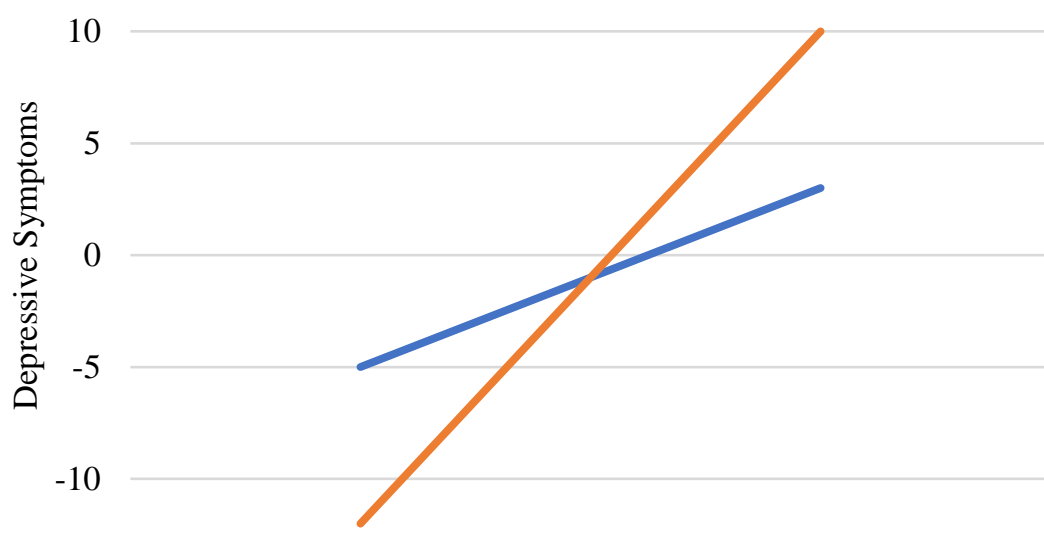

$-15$
High Pat. PC

Low Neg. Bel. $\quad$ High Neg. Bel.

Figure 7. Paternal psychological control by adolescents' negative beliefs about paternal psychological control interaction effects on over-eating (left) and depressive symptoms (right). 


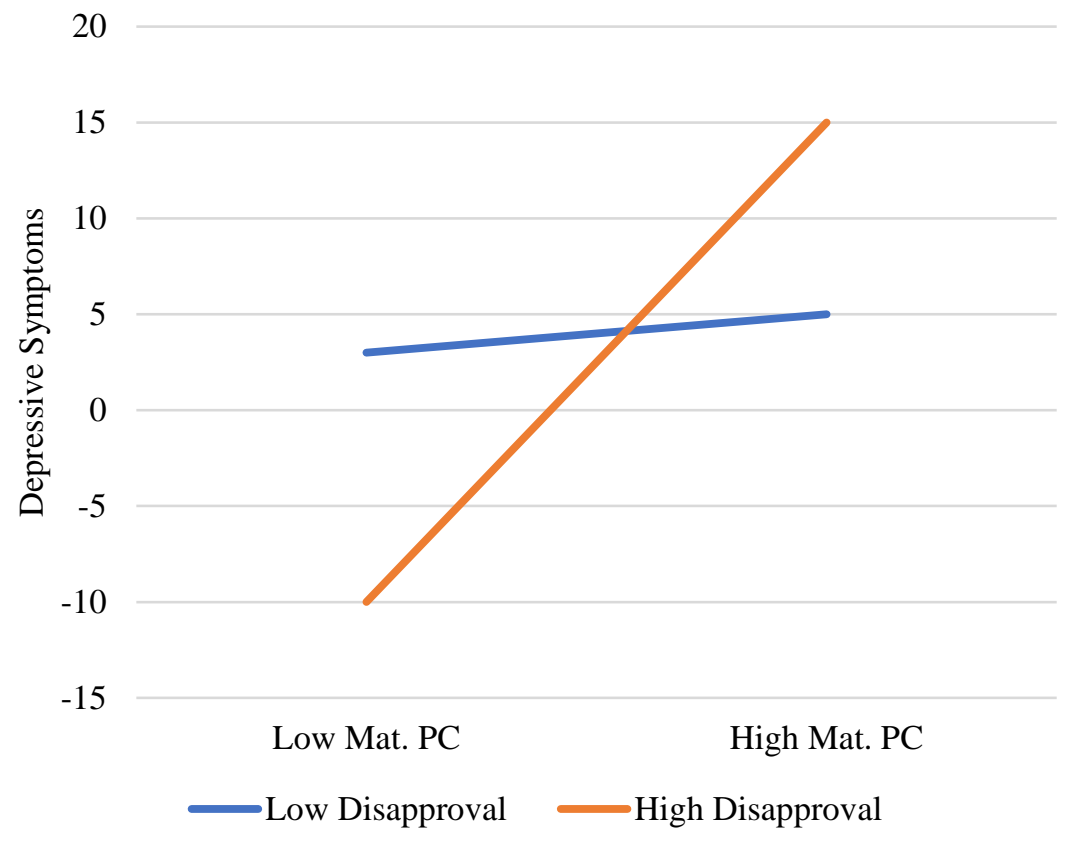

Figure 8. Maternal psychological control by adolescents' disapproval of maternal psychological control interaction effects on depressive symptoms. 


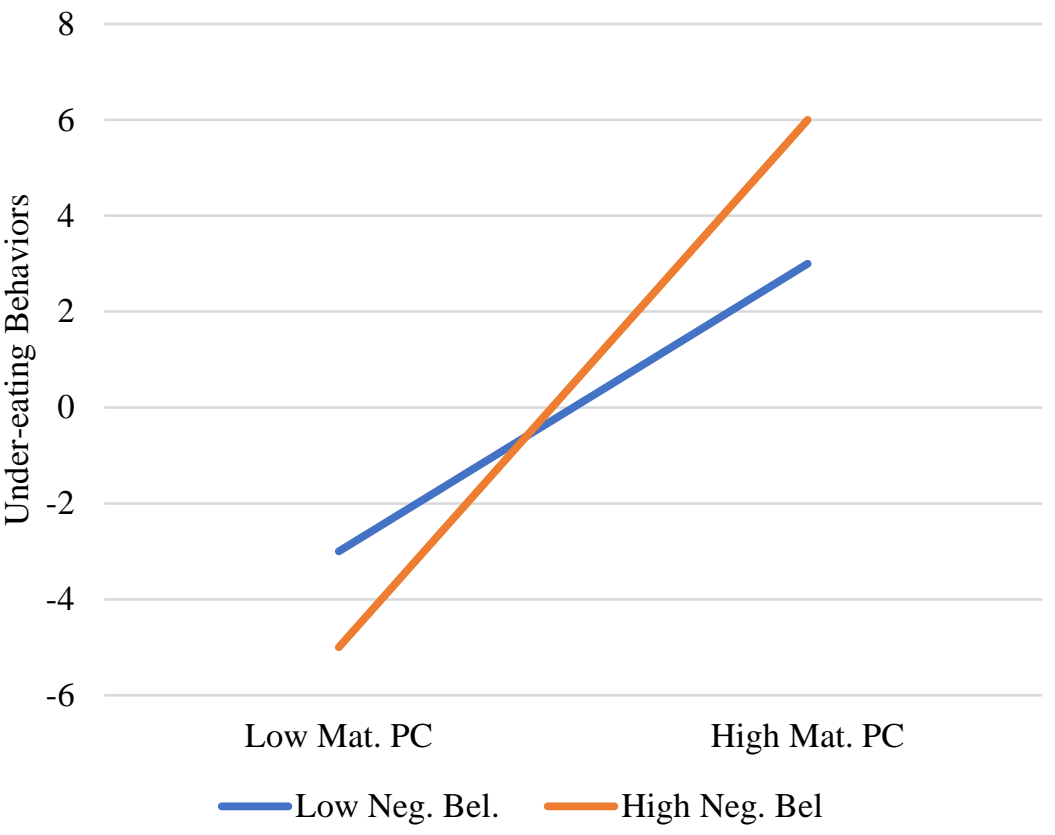

Figure 9. Maternal psychological control by adolescents' negative beliefs about maternal psychological control interaction effects on under-eating behaviors for adolescents with high levels of disapproval. 


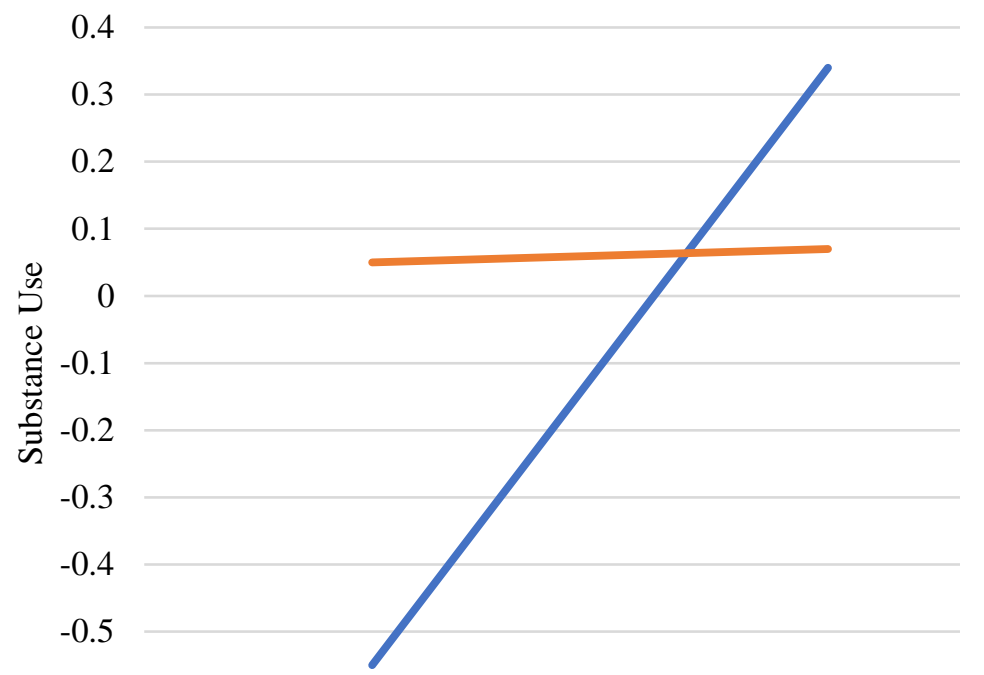

$-0.6$
High Pat. PC

Low Pat. PC High Pos. Bel.

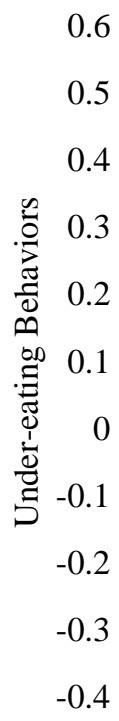

$-0.4$
High Pat. PC

Pos. Bel.

Figure 10. Paternal psychological control by adolescents' positive beliefs about paternal psychological control interaction effects on substance use (left) and under-eating behaviors (right) for adolescents with high levels of disapproval. 
Appendices 


\section{APPENDIX A}

\section{DEMOGRAPHICS}

1. What is your age in years?

$\begin{array}{lll}\square 11 & \square 12 & \square 13 \\ \square 14 & \square 15 & \square 16 \\ \square 17 & \square 18 & \square \text { Other }\end{array}$

2. What is your birthday (Month/Day/Year)?

3. What is your grade in school?

\begin{tabular}{lll}
$\square 6^{\text {th }}$ & $\square 7^{\text {th }}$ & $\square 8^{\text {th }}$ \\
$\square 9^{\text {th }}$ & $\square 10^{\text {th }}$ & $\square 11^{\text {th }}$ \\
$\square 12^{\text {th }}$ & $\square$ Other \\
\hline
\end{tabular}

4. What gender are you?

$\square$ Male $\quad \square$ Female $\quad \square$ Other (describe)

5. What is your ethnicity (Please circle)?

$\square$ African-American/Black $\quad \square$ Hispanic/Latino

$\square$ Asian-American/Pacific Islander $\quad \square$ Native American

$\square$ Caucasian/White

$\square$ Other (describe) 
6. What is the highest level of schooling your mother (or female guardian) completed?

Did not attend school

Completed $8^{\text {th }}$ grade

High school graduate or equivalent

Some college

2-year college degree

4-year college degree

Some graduate school

Graduate degree (doctor, lawyer, $\mathrm{PhD}$ )

Don't know or unsure
7. What is the highest level of schooling your father (or male guardian) completed?

$\square$ Did not attend school

$\square$ Completed $8^{\text {th }}$ grade

High school graduate or equivalent

Some college

$\square$ 2-year college degree

4-year college degree

Some graduate school

Graduate degree (doctor, lawyer, $\mathrm{PhD}$ )

Don't know or unsure

At what type of JOB does your MOTHER work?

At what type of JOB does your FATHER work?

8. How much difficulty do your parents have paying the bills?

None/Not at all

A little

Some

A great deal

9. Who currently lives in your home (Circle all that apply)?

$\square$ mother (birth or adopted)

father (birth or adopted)

stepmother 
$\square$ stepfather

$\square$ brothers/sisters? (ages of siblings)

$\square$ other adults (who?)

10. What is your parents' relationship status?

\section{$\square$ Married}

$\square$ Together, but not married

$\square$ Separated

$\square$ Not together, never married

$\square$ Divorced

11. What grades do you typically earn in school? (Please circle):

$\square$ Mostly A’s

$\square$ Some A's some B's

$\square$ Mostly B's

$\checkmark$ Some B's some C's

$\square$ Mostly C's

$\square$ Some C's some D's

$\square$ Mostly D's or lower 


\section{APPENDIX B}

PSYCHOLOGICAL CONTROL SCALE - YOUTH SELF-REPORT (BARBER, 1996)

Each of the following statements asks about your feelings about your parent(s) or guardian(s).

Please circle the response that best applies.

\begin{tabular}{|c|c|c|c|c|c|}
\hline My parent... & $\begin{array}{c}\text { Never } \\
\text { True }\end{array}$ & & $\begin{array}{c}\text { Sometimes } \\
\text { True }\end{array}$ & & $\begin{array}{c}\text { Always } \\
\text { True }\end{array}$ \\
\hline 1. changes the subject, whenever I have something to say. & 1 & 2 & 3 & 4 & 5 \\
\hline 2. finishes my sentences whenever I talk. & 1 & 2 & 3 & 4 & 5 \\
\hline 3. often interrupts me. & 1 & 2 & 3 & 4 & 5 \\
\hline $\begin{array}{l}\text { 4. acts like they know what I'm thinking or } \\
\text { feeling. }\end{array}$ & 1 & 2 & 3 & 4 & 5 \\
\hline $\begin{array}{l}\text { 5. would like to be able to tell me how to feel } \\
\text { or think about things all the time. }\end{array}$ & 1 & 2 & 3 & 4 & 5 \\
\hline $\begin{array}{l}\text { 6. is always trying to change how I feel or think } \\
\text { about things. }\end{array}$ & 1 & 2 & 3 & 4 & 5 \\
\hline 7. blames me for other family members' problems. & 1 & 2 & 3 & 4 & 5 \\
\hline 8. brings up my past mistakes when they criticize me. & 1 & 2 & 3 & 4 & 5 \\
\hline $\begin{array}{l}\text { 9. tells me that I am not a loyal or good member } \\
\text { of the family. }\end{array}$ & 1 & 2 & 3 & 4 & 5 \\
\hline $\begin{array}{l}\text { 10. tells me of all the things they have done } \\
\text { for me. }\end{array}$ & 1 & 2 & 3 & 4 & 5 \\
\hline $\begin{array}{l}\text { 11. says, if I really cared about them, I would } \\
\text { not do things that cause them to worry. }\end{array}$ & 1 & 2 & 3 & 4 & 5 \\
\hline $\begin{array}{l}\text { 12. is less friendly with me, if I do not see things } \\
\text { their way. }\end{array}$ & 1 & 2 & 3 & 4 & 5 \\
\hline $\begin{array}{l}\text { 13. will avoid looking at me when I have disappointed } \\
\text { them. }\end{array}$ & 1 & 2 & 3 & 4 & 5 \\
\hline
\end{tabular}




\begin{tabular}{|l|c|c|c|c|c|}
\hline $\begin{array}{l}\text { 14. if I have hurt their feelings, stops talking } \\
\text { to me until I please them again. }\end{array}$ & 1 & 2 & 3 & 4 & 5 \\
\hline 15. often changes their moods when with me. & 1 & 2 & 3 & 4 & 5 \\
\hline $\begin{array}{l}\text { 16. goes back and forth between being warm and } \\
\text { critical toward me. }\end{array}$ & 1 & 2 & 3 & 4 & 5 \\
\hline
\end{tabular}

Psychological Control Measure (Hart \& Robinson, 1995)

Each of the following statements asks about your feelings about your parent(s) or guardian(s).

Please circle the response that best applies.

\begin{tabular}{|l|c|c|c|c|c|}
\hline My parent... & Never & & Sometimes & & Always \\
& True & & True & & True \\
\hline 1. ignores me when I try to get their attention. & 1 & 2 & 3 & 4 & 5 \\
\hline 2. tries to change me. & 1 & 2 & 3 & 4 & 5 \\
\hline 3. tells me that my behavior was dumb or stupid. & 1 & 2 & 3 & 4 & 5 \\
\hline 4. acts disappointed when I misbehave. & & & & & \\
\hline 5. wants to control whatever I do. & 1 & 2 & 3 & 4 & 5 \\
\hline
\end{tabular}


Psychological Control Items from Olsen et al., 2002

Each of the following statements asks about your feelings about your parent(s) or guardian(s).

Please circle the response that best applies.

\begin{tabular}{|c|c|c|c|c|c|}
\hline My parent... & $\begin{array}{l}\text { Never } \\
\text { True }\end{array}$ & & $\begin{array}{c}\text { Sometimes } \\
\text { True }\end{array}$ & & $\begin{array}{c}\text { Always } \\
\text { True }\end{array}$ \\
\hline 1. doesn't pay attention when I am talking to them. & 1 & 2 & 3 & 4 & 5 \\
\hline 2. tells me I am not as good as they were growing up. & 1 & 2 & 3 & 4 & 5 \\
\hline 3. lets me know when they are angry with me. & 1 & 2 & 3 & 4 & 5 \\
\hline 4. tells me that I should be ashamed when I misbehave. & 1 & 2 & 3 & 4 & 5 \\
\hline 5. tells me I am not as good as other children. & 1 & 2 & 3 & 4 & 5 \\
\hline
\end{tabular}




\section{APPENDIX C}

ADOLESCENTS' BELIEFS ABOUT PARENTAL MOTIVATIONS FOR USING PSYCHOLOGICAL CONTROL

Directions

\section{Please answer the next set of questions based on your mother/father.}

For each item, please rank the reasons that you believe your parent engages in each behavior.

- Place a 1 next to the reason that is most important

- Place a 2 next to the reason that is second most important

- Place a 3 next to the reason that is third most important

- Place a 4 next to the reason that is fourth most important

- Place a 5 next to the reason that is fifth most important

- Place a 6 next to the reason that is least important

\section{EXAMPLE:}

1. Why does your parent engage in this behavior?

3 to control my thoughts, feelings, and behaviors

1 because my parent does not respect me

4 because my parent does not view me as competent

2 because I do not matter to my parent

6 to keep me safe/out of concern for me

5 because my parent believes that most parents do this 
Sample Item

Each of the following statements asks about your feelings about your parent(s) or guardian(s). Please circle the response that best applies.

\begin{tabular}{|l|c|c|c|c|c|}
\hline My parent... & Never & & Sometimes & & Always \\
& True & & True & & True \\
\hline 1. changes the subject, whenever I have something to say. & 1 & 2 & 3 & 4 & 5 \\
\hline
\end{tabular}

Why does your parent engage in this behavior?

to control my thoughts, feelings, and behaviors

because my parent does not respect me

because my parent does not view me as competent

because I do not matter to my parent

to keep me safe/out of concern for me

because my parent believes that most parents do this 


\section{APPENDIX D}

\section{ADOLESCENTS' DISAPPROVAL OF PARENTAL PSYCHOLOGICAL CONTROL}

Sample Item

Each of the following statements asks about your feelings about your parent(s) or guardian(s).

Please circle the response that best applies.

\begin{tabular}{|l|c|c|c|c|c|}
\hline My parent... & $\begin{array}{c}\text { Never } \\
\text { True }\end{array}$ & & True & & True \\
\hline 1. changes the subject, whenever I have something to say. & 1 & 2 & 3 & 4 & 5 \\
\hline
\end{tabular}

Please rate whether you approve or disapprove of this behavior.

\begin{tabular}{|l|c|c|c|c|c|}
\hline & Strongly & & Neutral & & Strongly \\
Disapprove & & Approve \\
\hline $\begin{array}{l}\text { 1. changes the subject, whenever I have something to } \\
\text { say. }\end{array}$ & 1 & 2 & 3 & 4 & 5 \\
\hline
\end{tabular}




\section{APPENDIX E}

BEHAVIORAL CONTROL - CHILDREN'S REPORTS OF PARENTAL BEHAVIOR:

\section{AN INVENTORY}

Each of the following statements asks about your feelings about your parent(s) or guardian(s).

Please circle the response that best applies.

\begin{tabular}{|l|c|c|c|}
\hline My parent... & Not Like & Somewhat & A Lot Like \\
& & Mike My & Marent \\
\hline 1. believes in having a lot of rules and sticking with them. & 1 & 2 & 3 \\
\hline 2. insists that I must do exactly as I am told. & 1 & 2 & 3 \\
\hline 3. is very strict with me. & 1 & 2 & 3 \\
\hline 4. gives hard punishment. & 1 & 2 & 3 \\
\hline 5. is easy with me. & 1 & 2 & 3 \\
\hline 6. lets me off easy when I do something wrong. & 1 & 2 & 3 \\
\hline 7. gives me as much freedom as I want. & 1 & 2 & 3 \\
\hline 8. lets me go anyplace I please without asking. & & & \\
\hline
\end{tabular}




\section{APPENDIX F}

PARENTAL WARMTH - CHILD REARING PRACTICES QUESTIONNAIRE

Each of the following statements asks about your feelings about your parent(s) or guardian(s).

Please circle the response that best applies.

\begin{tabular}{|l|c|c|c|c|}
\hline & Never & Sometimes & Often & Always \\
\hline $\begin{array}{l}\text { 1. How often does your parent let you know they really } \\
\text { care about you? }\end{array}$ & 1 & 2 & 3 & 4 \\
\hline $\begin{array}{l}\text { 2. How often does your parent act supportive and } \\
\text { understanding towards you? }\end{array}$ & 1 & 2 & 3 & 4 \\
\hline $\begin{array}{l}\text { 3. How often does your parent act loving and affectionate } \\
\text { toward you? }\end{array}$ & 1 & 2 & 3 & 4 \\
\hline $\begin{array}{l}\text { 4. How often does your parent have a good laugh with you } \\
\text { about something that is funny? }\end{array}$ & 1 & 2 & 3 & 4 \\
\hline $\begin{array}{l}\text { 5. How often does your parent let you know that they } \\
\text { appreciate you, your ideas, or the things you do? }\end{array}$ & 1 & 2 & 3 & 4 \\
\hline $\begin{array}{l}\text { 6. How often does your parent understand the way you feel } \\
\text { about things? }\end{array}$ & 1 & 2 & 3 & 4 \\
\hline $\begin{array}{l}\text { 7. How often does your parent help you do something that } \\
\text { is important to you? }\end{array}$ & 1 & 2 & 3 & 4 \\
\hline
\end{tabular}




\section{APPENDIX G}

\section{SUBSTANCE USE}

\begin{tabular}{|l|c|c|c|c|}
\hline In the last 3 months, how often have you... & Never & Rarely & Sometimes & Often \\
\hline 1. Drank alcohol? & 1 & 2 & 3 & 4 \\
\hline 2. Attended a party where alcohol was served? & 1 & 2 & 3 & 4 \\
\hline 3. Been drunk? & 1 & 2 & 3 & 4 \\
\hline 4. Drank so much you got sick? & 1 & 2 & 3 & 4 \\
\hline 5. Been offered alcohol by a friend? & 1 & 2 & 3 & 4 \\
\hline 6. Refused alcohol that was offered by a friend? & 1 & 2 & 3 & 4 \\
\hline 7. Accepted alcohol that was offered by a friend? & 1 & 2 & 3 & 4 \\
\hline 8. Hung around with kids who drink alcohol? & 1 & 2 & 3 & 4 \\
\hline
\end{tabular}

\begin{tabular}{|l|c|c|c|c|c|c|c|}
\hline $\begin{array}{l}\text { In the last 3 months, how } \\
\text { often have you used each of } \\
\text { the following substances? }\end{array}$ & $\begin{array}{l}\text { Never } \\
\text { Used }\end{array}$ & Time & Times & Times & Times & Times & More \\
\hline 1. Cigarettes? & 0 & 1 & 2 & 3 & 4 & 5 & 6 \\
\hline 2. Smokeless tobacco? & 0 & 1 & 2 & 3 & 4 & 5 & 6 \\
\hline 3. Electronic cigarettes? & 0 & 1 & 2 & 3 & 4 & 5 & 6 \\
\hline 4. Marijuana? & 0 & 1 & 2 & 3 & 4 & 5 & 6 \\
\hline
\end{tabular}




\begin{tabular}{|l|c|c|c|c|c|c|c|}
\hline 5. Hallucinogens? & 0 & 1 & 2 & 3 & 4 & 5 & 6 \\
\hline 6. Cocaine? & 0 & 1 & 2 & 3 & 4 & 5 & 6 \\
\hline 7. Sedatives? & 0 & 1 & 2 & 3 & 4 & 5 & 6 \\
\hline 8. Stimulants? & 0 & 1 & 2 & 3 & 4 & 5 & 6 \\
\hline 9. Prescription pain killers? & 0 & 1 & 2 & 3 & 4 & 5 & 6 \\
\hline 10. Inhalants? & 0 & 1 & 2 & 3 & 4 & 5 & 6 \\
\hline
\end{tabular}




\section{APPENDIX H}

\section{RISKY CYBER BEHAVIORS}

\begin{tabular}{|l|c|c|c|c|c|c|}
\hline How often in the last 30 days... & Never & One & $2-3$ & $4-9$ & $10-19$ & $20-39$ \\
Used & Time & Times & Times & Times & Times \\
\hline $\begin{array}{l}\text { 1. Have you posted photos on } \\
\text { Facebook involving alcohol and } \\
\text { drug use? }\end{array}$ & 1 & 2 & 3 & 4 & 5 & 6 \\
\hline $\begin{array}{l}\text { 2. Have you posted sexually } \\
\text { suggestive photos of yourself or } \\
\text { your friends on Facebook? }\end{array}$ & 1 & 2 & 3 & 4 & 5 & 6 \\
\hline $\begin{array}{l}\text { 3. Have you added friends on } \\
\text { Facebook whom you have never met } \\
\text { offline? }\end{array}$ & 1 & 2 & 3 & 4 & 5 & 6 \\
\hline $\begin{array}{l}\text { 4. Have you texted/sexted sexual } \\
\text { photos? }\end{array}$ & 1 & 2 & 3 & 4 & 5 & 6 \\
\hline $\begin{array}{l}\text { 5. Have you texted/sexted sexual } \\
\text { messages? }\end{array}$ & 1 & 2 & 3 & 4 & 5 & 6 \\
\hline $\begin{array}{l}\text { 6. Have you texted mean or hurtful } \\
\text { messages? }\end{array}$ & 1 & 2 & 3 & 4 & 5 & 6 \\
\hline $\begin{array}{l}\text { 7. Have you posted something } \\
\text { online about another person to make } \\
\text { others laugh? }\end{array}$ & 1 & 2 & 3 & 4 & 5 & 6 \\
$\begin{array}{l}\text { 8. Have you sent someone a } \\
\text { computer text message to make } \\
\text { them angry or to make fun of them? }\end{array}$ & 1 & 2 & 3 & 4 & 5 & 6 \\
\hline $\begin{array}{l}\text { 9. Have you took a picture of } \\
\text { someone and posted it online } \\
\text { without their permission? }\end{array}$ & 1 & 2 & 3 & 4 & 5 & 6 \\
\hline $\begin{array}{l}\text { 10. Have you posted something on } \\
\text { social media to make them angry or } \\
\text { to make fun of them? }\end{array}$ & 1 & 2 & 3 & 4 & 5 & 6 \\
\hline $\begin{array}{l}\text { 11. Have you sent someone an email } \\
\text { to make them angry or to make fun } \\
\text { of them? }\end{array}$ & 1 & 2 & 3 & 4 & 5 & 6 \\
\hline
\end{tabular}




\section{APPENDIX I}

\section{DUTCH EATING BEHAVIOR QUESTIONNAIRE - PROBLEMATIC EATING}

\section{BEHAVIORS}

\begin{tabular}{|c|c|c|c|c|c|}
\hline & Never & Seldom & Sometimes & Often & $\begin{array}{l}\text { Very } \\
\text { Often }\end{array}$ \\
\hline $\begin{array}{l}\text { 1. When you have put on weight, do } \\
\text { you eat less than you usually do? }\end{array}$ & 1 & 2 & 3 & 4 & 5 \\
\hline $\begin{array}{l}\text { 2. Do you try to eat less at mealtimes } \\
\text { than you would like to eat? }\end{array}$ & 1 & 2 & 3 & 4 & 5 \\
\hline $\begin{array}{l}\text { 3. How often do you refuse food or } \\
\text { drinks offered because you are } \\
\text { concerned about your weight? }\end{array}$ & 1 & 2 & 3 & 4 & 5 \\
\hline $\begin{array}{l}\text { 4. Do you watch exactly what you } \\
\text { eat? }\end{array}$ & 1 & 2 & 3 & 4 & 5 \\
\hline $\begin{array}{l}5 . \text { Do you deliberately eat foods that } \\
\text { are slimming? }\end{array}$ & 1 & 2 & 3 & 4 & 5 \\
\hline $\begin{array}{l}\text { 6. When you have eaten too much, do } \\
\text { you eat less than usual the following } \\
\text { day? }\end{array}$ & 1 & 2 & 3 & 4 & 5 \\
\hline $\begin{array}{l}\text { 7. Do you deliberately eat less in } \\
\text { order not to become heavier? }\end{array}$ & 1 & 2 & 3 & 4 & 5 \\
\hline $\begin{array}{l}\text { 8. How often do you try not to eat } \\
\text { between meals because you are } \\
\text { watching your weight? }\end{array}$ & 1 & 2 & 3 & 4 & 5 \\
\hline $\begin{array}{l}\text { 9. How often in the evenings do you } \\
\text { try not to eat because you are } \\
\text { watching your weight? }\end{array}$ & 1 & 2 & 3 & 4 & 5 \\
\hline $\begin{array}{l}10 . \text { Do you take into account your } \\
\text { weight with what you eat? }\end{array}$ & 1 & 2 & 3 & 4 & 5 \\
\hline $\begin{array}{l}\text { 11. Do you have the desire to eat } \\
\text { when you are irritated? }\end{array}$ & 1 & 2 & 3 & 4 & 5 \\
\hline $\begin{array}{l}\text { 12. Do you have a desire to eat when } \\
\text { you have nothing to do? }\end{array}$ & 1 & 2 & 3 & 4 & 5 \\
\hline $\begin{array}{l}\text { 13. Do you have a desire to eat when } \\
\text { you are depressed or discouraged? }\end{array}$ & 1 & 2 & 3 & 4 & 5 \\
\hline
\end{tabular}




\begin{tabular}{|c|c|c|c|c|c|}
\hline $\begin{array}{l}\text { 14. Do you have a desire to eat when } \\
\text { you are feeling lonely? }\end{array}$ & 1 & 2 & 3 & 4 & 5 \\
\hline $\begin{array}{l}\text { 15. Do you have a desire to eat when } \\
\text { somebody lets you down? }\end{array}$ & 1 & 2 & 3 & 4 & 5 \\
\hline $\begin{array}{l}\text { 16. Do you have a desire to eat when } \\
\text { you are angry or upset? }\end{array}$ & 1 & 2 & 3 & 4 & 5 \\
\hline $\begin{array}{l}\text { 17. Do you have a desire to eat when } \\
\text { you are expecting something } \\
\text { unpleasant to happen? }\end{array}$ & 1 & 2 & 3 & 4 & 5 \\
\hline $\begin{array}{l}\text { 18. Do you get the desire to eat when } \\
\text { you are anxious, worried or tense? }\end{array}$ & 1 & 2 & 3 & 4 & 5 \\
\hline $\begin{array}{l}\text { 19. Do you have a desire to eat when } \\
\text { things are going against you or when } \\
\text { things have gone wrong? }\end{array}$ & 1 & 2 & 3 & 4 & 5 \\
\hline $\begin{array}{l}\text { 20. Do you have a desire to eat when } \\
\text { you are frightened? }\end{array}$ & 1 & 2 & 3 & 4 & 5 \\
\hline $\begin{array}{l}21 . \text { Do you have a desire to eat when } \\
\text { you are disappointed? }\end{array}$ & 1 & 2 & 3 & 4 & 5 \\
\hline $\begin{array}{l}\text { 22. Do you have a desire to eat when } \\
\text { you are emotionally upset? }\end{array}$ & 1 & 2 & 3 & 4 & 5 \\
\hline $\begin{array}{l}\text { 23. Do you have a desire to eat when } \\
\text { you are bored or restless? }\end{array}$ & 1 & 2 & 3 & 4 & 5 \\
\hline $\begin{array}{l}\text { 24. If food tastes good to you, do you } \\
\text { eat more than usual? }\end{array}$ & 1 & 2 & 3 & 4 & 5 \\
\hline $\begin{array}{l}25 . \text { If food smells and looks good, do } \\
\text { you eat more than usual? }\end{array}$ & 1 & 2 & 3 & 4 & 5 \\
\hline $\begin{array}{l}\text { 26. If you see or smell something } \\
\text { delicious, do you have a desire to eat } \\
\text { it? }\end{array}$ & 1 & 2 & 3 & 4 & 5 \\
\hline $\begin{array}{l}27 . \text { If you have something delicious } \\
\text { to eat, do you eat it right away? }\end{array}$ & 1 & 2 & 3 & 4 & 5 \\
\hline $\begin{array}{l}\text { 28. If you walk past a convenience } \\
\text { store or fast food restaurant do you } \\
\text { have the desire to buy something } \\
\text { delicious? }\end{array}$ & 1 & 2 & 3 & 4 & 5 \\
\hline $\begin{array}{l}\text { 29. If you walk past a snack bar or a } \\
\text { café, do you have the desire to buy } \\
\text { something delicious? }\end{array}$ & 1 & 2 & 3 & 4 & 5 \\
\hline $\begin{array}{l}30 . \text { If you see others eating, do you } \\
\text { have the desire to eat? }\end{array}$ & 1 & 2 & 3 & 4 & 5 \\
\hline
\end{tabular}




\begin{tabular}{|l|c|c|c|c|c|}
\hline $\begin{array}{l}\text { 31. Can you resist eating delicious } \\
\text { foods? }\end{array}$ & 1 & 2 & 3 & 4 & 5 \\
\hline $\begin{array}{l}\text { 32. Do you eat more than usual, } \\
\text { when you see others eating? }\end{array}$ & 1 & 2 & 3 & 4 & 5 \\
\hline $\begin{array}{l}\text { 33. When preparing a meal are you } \\
\text { inclined to eat something? }\end{array}$ & 1 & 2 & 3 & 4 & 5 \\
\hline
\end{tabular}




\section{APPENDIX J}

CENTER FOR EPIDEMIOLOGICAL STUDIES - DEPRESSION INVENTORY

\begin{tabular}{|l|c|c|c|c|}
\hline During the past week... & $\begin{array}{c}\text { Less than 1 } \\
\text { Day }\end{array}$ & 1 -2 Days & $3-4$ Days & $5-7$ Days \\
\hline $\begin{array}{l}\text { 1. I was bothered by things that } \\
\text { usually don't bother me }\end{array}$ & 1 & 2 & 3 & 4 \\
\hline $\begin{array}{l}\text { 2. I did not feel like eating; my } \\
\text { appetite was poor. }\end{array}$ & 1 & 2 & 3 & 4 \\
\hline $\begin{array}{l}\text { 3. I felt that I could not shake off the } \\
\text { blues even with help from my } \\
\text { family or friends }\end{array}$ & 1 & 2 & 3 & 4 \\
\hline $\begin{array}{l}\text { 4. I felt that I was just as good as } \\
\text { other people }\end{array}$ & 1 & 2 & 3 & 4 \\
\hline $\begin{array}{l}\text { 5. I had trouble keeping my mind on } \\
\text { what I was doing }\end{array}$ & 1 & 2 & 3 & 4 \\
\hline 6. I felt depressed & 1 & 2 & 3 & 4 \\
\hline $\begin{array}{l}\text { 7. I felt that everything I did was an } \\
\text { effort }\end{array}$ & 1 & 2 & 3 & 4 \\
\hline 8. I felt hopeful about the future & 1 & 2 & 3 & 4 \\
\hline $\begin{array}{l}\text { 9. I thought my life had been a } \\
\text { failure }\end{array}$ & 1 & 2 & 3 & 4 \\
\hline 10. I felt tearful & 1 & 2 & 3 & 4 \\
\hline $\begin{array}{l}\text { 11. My sleep was restless } \\
\text { 12. I was happy }\end{array}$ & 1 & 2 & 3 & 4 \\
\hline $\begin{array}{l}\text { 13. I talked less than usual } \\
\text { 14. I felt lonely }\end{array}$ & 1 & 2 & 3 & 4 \\
\hline
\end{tabular}




\begin{tabular}{|l|c|c|c|c|}
\hline 16. I enjoyed life & 1 & 2 & 3 & 4 \\
\hline 17. I had crying spells & 1 & 2 & 3 & 4 \\
\hline 18. I felt sad & 1 & 2 & 3 & 4 \\
\hline 19. I felt that people disliked me & 1 & 2 & 3 & 4 \\
\hline 20. I could not get going & 1 & 2 & 3 & 4 \\
\hline
\end{tabular}




\section{APPENDIX K}

\section{STATE, SCHOOL LEVEL, AND SCHOOL DIFFERENCES IN KEY STUDY VARIABLES}

Additional analyses were performed to examine differences in variability based on state, school level, and school (Tables 1-2). Results indicated that multiple key study variables varied by state, school level, and school. Specifically, students residing in West Virginia reported higher levels of positive beliefs about their mothers' and fathers' use of psychological control, whereas students residing in Maryland reported higher levels of substance use and risky cyber behaviors. Additionally, students in high school reported higher levels of substance use, overeating, and under-eating behaviors compared to students attending middle school. With regards to school, students attending Allegany High School reported greater levels of substance use, over-eating behaviors, and under-eating behaviors than students attending St. Mike's Parish School. 
Table 1

State and School Level Differences in Key Study Variables

\begin{tabular}{|c|c|c|c|c|c|c|}
\hline & \multicolumn{2}{|r|}{ State } & \multicolumn{4}{|c|}{ School Level } \\
\hline & MD & WV & T test & Middle & High & T test \\
\hline Maternal PC & $2.06(.69)$ & $2.16(.67)$ & $\mathrm{t}(1,403)=1.48, \mathrm{p}=.140$ & $2.09(.60)$ & $2.12(.70)$ & $\mathrm{t}(1,403)=-.35, p=.72$ \\
\hline Paternal PC & $1.74(.70)$ & $1.82(.69)$ & $\mathrm{t}(1,388)=1.09, \mathrm{p}=.280$ & $1.74(.54)$ & $1.79(.72)$ & $\mathrm{t}(1,288)=-.58, p=.57$ \\
\hline Maternal Neg. Beliefs & $29.68(15.53)$ & $31.07(14.56)$ & $\mathrm{t}(1,396)=.92, \mathrm{p}=.360$ & $30.50(12.99)$ & $30.43(15.39)$ & $\mathrm{t}(1,396)=.04, p=.97$ \\
\hline Maternal Pos. Beliefs & $38.65(18.55)$ & $43.06(18.34)$ & $\mathrm{t}(1,396)=2.38, \mathrm{p}=.018$ & $42.12(17.99)$ & $40.84(18.67)$ & $\mathrm{t}(1,396)=.51, p=.61$ \\
\hline Paternal Neg. Beliefs & $23.24(17.33)$ & $24.12(16.36$ & $t(1,354)=.49, p=.622$ & $22.73(13.97)$ & $23.96(17.32)$ & $\mathrm{t}(1,354)=-.53, p=.60$ \\
\hline Paternal Pos. Beliefs & $28.25(19.30)$ & $32.74(19.76$ & $\mathrm{t}(1,354)=2.14, \mathrm{p}=.033$ & $31.37(16.30)$ & $30.67(20.33)$ & $\mathrm{t}(1,354)=.25, p=.80$ \\
\hline Maternal Disapproval & $40.50(21.43)$ & $43.33(21.28)$ & $\mathrm{t}(1,396)=1.32, \mathrm{p}=.188$ & $41.12(18.67)$ & $42.23(21.88)$ & $\mathrm{t}(1,396)=-.38, p=.70$ \\
\hline Paternal Disapproval & $31.01(22.28)$ & $33.31(22.26)$ & $\mathrm{t}(1,354)=.97, \mathrm{p}=.335$ & $30.65(17.77)$ & $32.67(23.13)$ & $\mathrm{t}(1,354)=-.65, p=.52$ \\
\hline Substance Use & $1.40(.67)$ & $1.28(.48)$ & $\mathrm{t}(1,404)=-2.14, \mathrm{p}=.033$ & $1.14(.41)$ & $1.38(.60)$ & $\mathrm{t}(1,404)=-3.08, p=.01$ \\
\hline Risky Cyber Behaviors & $1.35(.77)$ & $1.19(.52)$ & $\mathrm{t}(1,404)=-2.58, \mathrm{p}=.010$ & $1.14(.64)$ & $1.29(.66)$ & $\mathrm{t}(1,404)=-1.67, p=.10$ \\
\hline Over-eating Behaviors & $2.29(.95)$ & $2.29(.89)$ & $\mathrm{t}(1,403)=-.02, \mathrm{p}=.983$ & $1.98(.80)$ & $2.35(.93)$ & $\mathrm{t}(1,403)=-3.07, p=.01$ \\
\hline Under-eating Behaviors & $1.93(1.00)$ & $2.02(1.02)$ & $\mathrm{t}(1,403)=.87, \mathrm{p}=.388$ & $1.75(.89)$ & $2.02(1.03)$ & $\mathrm{t}(1,403)=-2.00, p=.05$ \\
\hline Depressive Symptoms & $17.35(14.06)$ & $19.94(14.27)$ & $\mathrm{t}(1,402)=-1.83, \mathrm{p}=.068$ & $15.46(12.43)$ & $19.13(14.45)$ & $\mathrm{t}(1,402)=-1.92, p=.06$ \\
\hline
\end{tabular}

Note. Some variable names have been shortened; PC = Psychological Control; Neg. = Negative; Pos. = Positive 
Table 2

School Differences in Key Study Variables

\begin{tabular}{rccccc}
\hline & UHS & AHS & Warwood & St. Mike's & F test \\
\hline Maternal PC & $2.20(.70)$ & $2.06(.69)$ & $1.81(.73)$ & $2.16(.55)$ & $F(3,401)=2.00, p=.11$ \\
Paternal PC & $1.85(.74)$ & $1.74(.70)$ & $1.35(.31)$ & $1.83(.55)$ & $F(3,401)=2.53, p=.06$ \\
Maternal Neg. Beliefs & $31.32(15.23)$ & $29.68(15.53)$ & $23.60(14.37)$ & $32.03(12.29)$ & $F(3,394)=1.36, p=.25$ \\
Maternal Pos. Beliefs & $43.47(18.53)$ & $38.64(18.55)$ & $32.25(25.17)$ & $44.31(15.44)$ & $F(3,394)=3.39, p=.02$ \\
Paternal Neg. Beliefs & $24.75(17.34)$ & $23.24(17.33)$ & $16.40(11.40)$ & $23.92(14.18)$ & $F(3,352)=.86, p=.47$ \\
Paternal Pos. Beliefs & $33.36(21.16)$ & $28.25(19.30)$ & $20.75(16.13)$ & $33.37(15.69)$ & $F(3,352)=2.87, p=.04$ \\
Maternal Disapproval & $44.30(22.31)$ & $40.50(21.43)$ & $31.92(25.64)$ & $43.17(16.36)$ & $F(3,394)=1.84, p=.14$ \\
Paternal Disapproval & $34.51(23.99)$ & $31.01(22.28)$ & $20.80(15.35)$ & $32.51(17.71)$ & $F(3,352)=1.53, p=.21$ \\
Substance Use & $1.34(.50)$ & $1.41(.67)$ & $1.06(.19)$ & $1.16(.45)$ & $F(3,402)=3.57, p=.01$ \\
Risky Cyber Behaviors & $1.21(.47)$ & $1.35(.77)$ & $1.04(.10)$ & $1.16(.71)$ & $F(3,402)=2.48, p=.06$ \\
Over-eating Behaviors & $2.42(.89)$ & $2.29(.95)$ & $1.83(.67)$ & $2.01(.83)$ & $F(3,401)=3.20, p=.01$ \\
Under-eating Behaviors & $2.13(1.05)$ & $1.93(1.00)$ & $1.93(1.05)$ & $1.71(.85)$ & $F(3,401)=2.65, p=.05$ \\
Depressive Symptoms & $18.16(14.66)$ & $19.94(14.27)$ & $12.54(8.33)$ & $16.19(13.22)$ & $F(3,400)=1.90, p=.13$ \\
\hline Note. Some variable & & &
\end{tabular}

Note. Some variable names have been shortened; PC = Psychological Control; Neg. = Negative;

Pos. $=$ Positive 